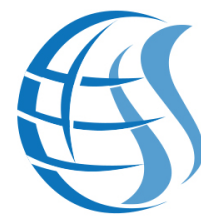

SCALABRINI

MIGRATION

STUDY

CENTERS

\title{
Perspectives on the Content and Implementation of the Global Compact for Safe, Orderly, and Regular Migration
}

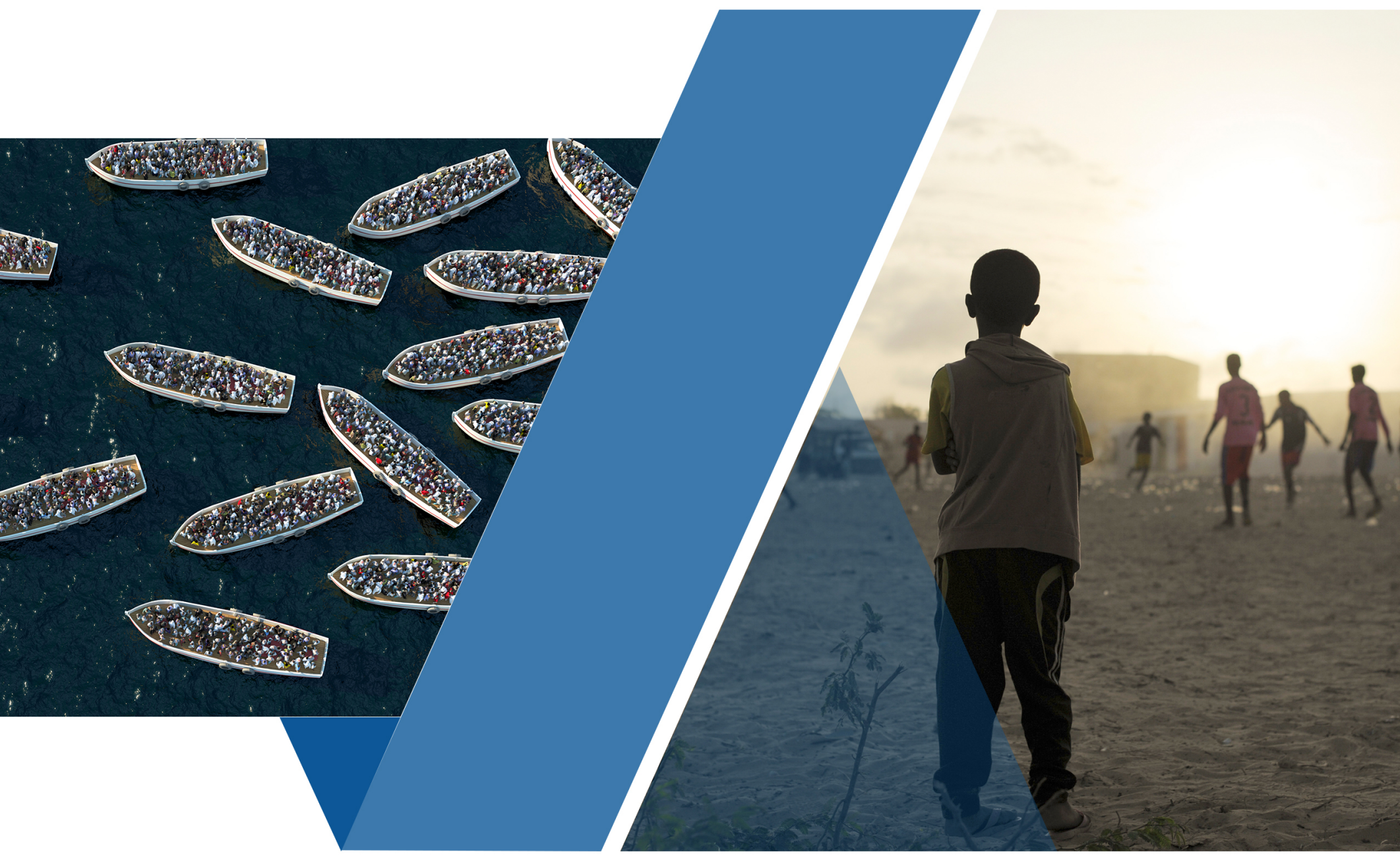

2018 INTERNATIONAL MIGRATION POLICY REPORT

\section{8}



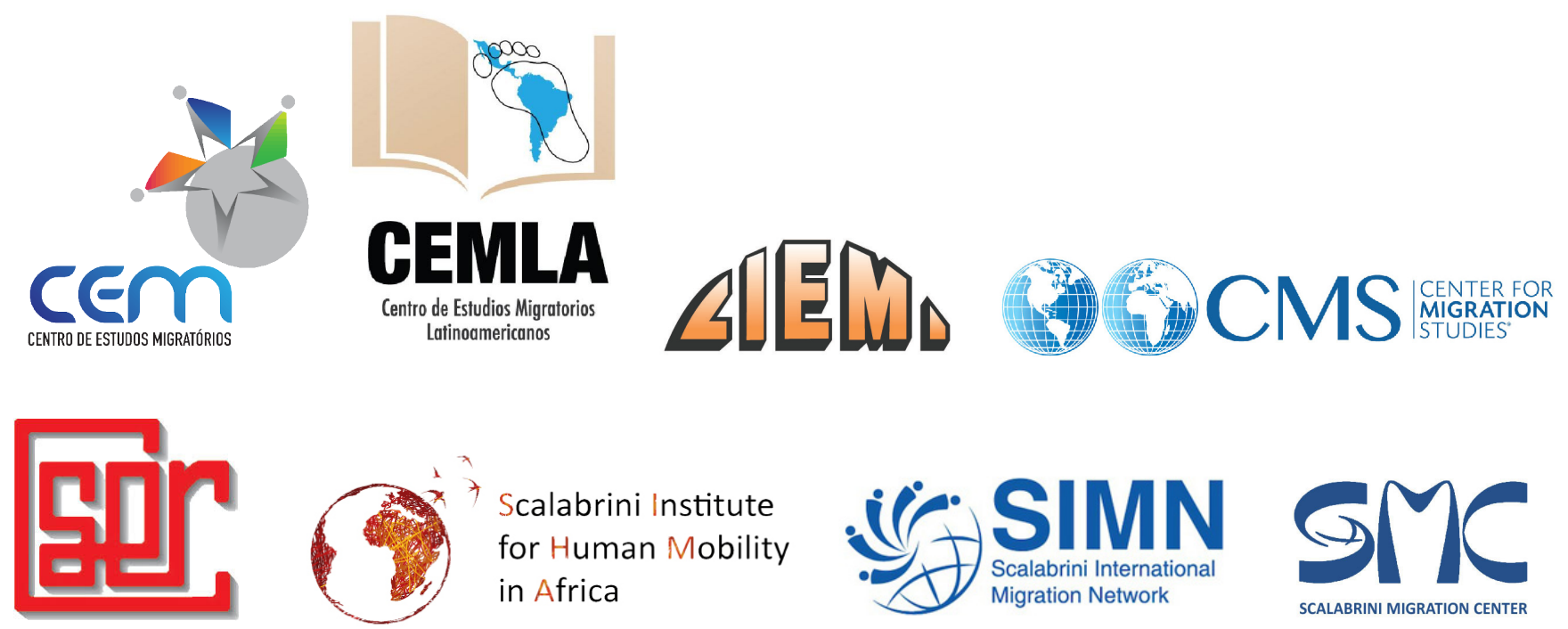

A report of the

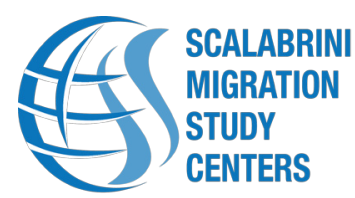

The Scalabrini Migration Study Centers consist of the Centro de Estudios Migratorios (CEM) in Brazil, the Centro de Estudios Migratorios Latinoamericanos (CEMLA) in Argentina, the Centre d'Information et d'Études sur les Migrations Internationales (CIEMI) in France, the Center for Migration Studies of New York (CMS) in the United States, the Centro Studi Emigrazione Roma (CSER) in Italy, the Scalabrini Institute for Human Mobility in Africa (SIHMA) in South Africa, and the Scalabrini Migration Center (SMC) in the Philippines.

This report was edited by J. Kevin Appleby, Senior Director for International Migration Policy for CMS and the Scalabrini International Migration Network (SIMN), and by Donald Kerwin, Executive Director of CMS. The editors would like to thank Fr. Leonir Chiarello, c.s., Executive Director of SIMN, for his strong support during the process.

Cover photo credits:

Left photo: Shutterstock / Alexyz3d

Right photo: UN Photo / Tobin Jones

Suggested citation:

Appleby, J. Kevin, and Donald Kerwin, eds. 2018. 2018 International Migration Policy Report: Perspectives on the Content and Implementation of the Global Compact for Safe, Orderly, and Regular Migration. New York: Scalabrini Migration Study Centers. https://doi.org/10.14240/ internationalmigrationrpt2018. 


\title{
2018 International Migration Policy Report
}

\author{
Perspectives on the Content and \\ Implementation of the Global Compact \\ for Safe, Orderly, and Regular Migration
}

\author{
A report of the \\ Scalabrini Migration Study Centers
}

September 2018 


\title{
International Migration Policy Report
}

\section{Table of Contents}

\author{
Section 1: Introduction
}

12018 International Migration Policy Report: Perspectives on the Content and Implementation of the Global Compact for Safe, Orderly, and Regular Migration

Scalabrini Migration Study Centers

\section{Section 2: Migration Challenges and Recommendations Relating to the Global Compact on Safe, Orderly, and Regular Migration}

3 Return Migration: A Conceptual and Policy Framework

Graziano Battistella (Scalabrini Migration Center)

15 The Regularization of Zimbabwean Migrants: A Case of Permanent Temporariness

Sergio Carciotto (Scalabrini Institute for Human Mobility in Africa)

27 In Search of Protection: Unaccompanied Minors in Italy

Pietro Demurtas (Institute for Research on Population and Social Policies [IRPPS]), Mattia Vitiello (IRPPS), Marco Accorinti (IRPPS), Aldo Skoda (Scalabrini International Migration Institute), Carola Perillo (Fondazione Centro Studi Emigrazione - Roma)

47 The Global Compact for Safe, Orderly, and Regular Migration: Will It Live Up to Its Name? Kevin Appleby (Center for Migration Studies and Scalabrini International Migration Network)

\section{Section 3: The Role of Faith-Based Organizations in Supporting Migrants in Vulnerable Situations}

65 Meeting the Needs of Women and Girl Migrants and Refugees in the Comprehensive Refugee Response Framework: The Unique Role of Faith-Based Organizations Laurie Carafone (Kids in Need of Defense)

76 Protecting Families and Facilitating Their Integration Linda Rabben (University of Maryland)

87 The Role of Faith-Based Organizations in Immigrants' Health and Entrepreneurship Mike Nicholson (Center for Migration Studies)

\section{Section 4: SIMN and CMS Policy Interventions During the Global Compact on Migration Process}

101 Opening Remarks at the Side Event "The Protection and Integration of Migrants in Vulnerable Situations: The Case of Faith-Based Organizations"

Fr. Leonir Chiarello (Scalabrini International Migration Network)

June 4, 2018

103 The Importance of Families and Faith-Based Institutions to Migrants and the Migration Experience Donald Kerwin (Center for Migration Studies)

June 4, 2018

106 The Current Context of Migration and Refuge in Central America: Vulnerability of Women and Girls Carol Giron (Scalabrini Missionaries and Scalabrini International Migration Network)

June 4, 2018 
110 Global Compact on Migration: Issues at Play

Kevin Appleby (Center for Migration Studies and Scalabrini International Migration Network)

May 8, 2018

119 The Global Compact on Migration Should Support Expanded Social Security Coverage and Portability of Benefits, Including for Irregular Migrants and Deportees

Donald Kerwin (Center for Migration Studies)

July 25, 2017

121 SIMN Policy Director Testifies at Interactive Multi-Stakeholder Meeting on UN Global Compact on Migration

Scalabrini International Migration Network

July 26, 2017

122 Statement of Scalabrini International Migration Network (SIMN) and Center for Migration Studies of New York (CMS) on Zero Draft of Global Compact on Migration

Scalabrini International Migration Network and Center for Migration Studies

February 22, 2018

126 Statement of Scalabrini International Migration Network - Second Round of Negotiations of the Global Compact on Migration

Scalabrini International Migration Network

March 15, 2018

128 Statement of Scalabrini International Migration Network - Third Round of Negotiations of the Global Compact on Migration

Scalabrini International Migration Network

April 6, 2018

130 Statement of the Scalabrini International Migration Network Global Compact on Safe, Orderly, and Regular Migration

Scalabrini International Migration Network

May 18, 2018

132 Statement of the Scalabrini International Migration Network - Fifth Round of Negotiations Scalabrini International Migration Network

June 5, 2018

134 Statement of Scalabrini International Migration Network - Sixth Round of Negotiations

Scalabrini International Migration Network

July 10, 2018

136 U.S. Catholic Working Group on Global Compacts on Refugees and Migration Statement on Revision 1 of the Zero Draft Plus of the Global Compact on Safe, Orderly, and Regular Migration U.S. Catholic Working Group on Global Compacts on Refugees and Migration May 7, 2018

140 U.S. Catholic Working Group on Global Compacts on Refugees and Migration Statement on Second Formal Consultations towards a Global Compact on Refugees

U.S. Catholic Working Group on Global Compacts on Refugees and Migration April 5, 2018

143 Statement on the Global Compact on Migration Leading into the Sixth and Final Round By the U.S. Catholic Working Group on Global Compacts on Refugees and Migration

U.S. Catholic Working Group on Global Compacts on Refugees and Migration June 25, 2018

145 Joint Civil Society Statement at the Conclusion of Negotiations on the Global Compact for Safe, Orderly, and Regular Migration

July 13, 2018 
Section 1: Introduction 


\section{International Migration Policy Report}

2018 International Migration Policy Report: Perspectives on the Content and Implementation of the Global Compact for Safe, Orderly, and Regular Migration

\section{Scalabrini Migration Study Centers}

The 2018 International Migration Policy Report: Perspectives on the Content and Implementation of the Global Compact for Safe, Orderly, and Regular Migration features several articles focusing upon issues discussed and negotiated by United Nations (UN) member states in producing the Global Compact for Safe, Orderly, and Regular Migration ("the Compact"). The final draft of the Global Compact was agreed to in New York by 191 member states on July 13, 2018, with final adoption of the document set for December 2018 at an intergovernmental conference in Marrakesh, Morocco.

The articles, written by global Scalabrini Migration Study Centers founded by the Congregation of the Missionaries of St Charles, Scalabrinians, provide best practices and recommendations on important migration policy issues included in the Compact. The study centers contributing to the report include the Center for Migration Studies of New York (CMS), the Scalabrini Migration Center (SMC) in the Philippines, the Scalabrini Institute for Human Mobility in Africa (SIHMA), and the Fondazione Centro Studi Emigrazione - Roma (CSER).

The report also includes shorter essays from special contributors to CMS addressing other important topics addressed by the member states during the negotiations of the Compact. The appendix features a sampling of interventions made by the Scalabrini International Migration Network (SIMN) and CMS during the negotiation process.

In his paper, "Return Migration: A Conceptual and Policy Framework," Graziano Battistella, c.s., executive director of SMC in Quezon City, Philippines, tackles the controversial issue of return migration, ranging from voluntary to forced returns. The author proposes a conceptual framework to accommodate four categories of returns: (1) return of achievement; (2) return of completion; (3) return of setback; and (4) return of crisis (forced return). These models could be adopted by UN member states, but each category would require a different policy framework.

Sergio Carciotto, executive director of SIMHA in Cape Town, South Africa, addresses the issue of labor migration in his paper, "The Regularization of Zimbabwean Migrants: A Case of Permanent Temporariness." The author, using the example of Zimbabwean laborers in South Africa, makes the case that migrant workers should be eligible for permanent residence after a certain length of time working in a host nation, as they have contributed to the host nation's economy and culture. Permanent residence would also ensure that workers can market their skills and fully contribute to their new country, while also being protected from workplace abuse and exploitation.

In the paper, "In Search of Protection: Unaccompanied Minors in Italy," a team of writers examines the pressing topic of unaccompanied migrant children and how nations should treat them. Pietro 
Demurtas, Mattia Vitiello, and Marco Accorinti of the Institute for Research on Population and Social Policies at the National Research Council in Rome, Aldo Skoda of the Scalabrini International Migration Institute in Rome, and Carola Perillo of CSER critique Italy's policy on these children and offer recommendations for reform of the system, concluding with four principles of protection for possible adoption by the compacts.

Finally, Kevin Appleby, senior director of international migration policy at CMS and SIMN, highlights issues that have been controversial in negotiations on the Global Compact on Migration in his piece, "The Global Compact on Safe, Orderly, and Regular Migration: Will It Live Up to Its Name?" The author - who has been centrally involved in the process leading to the compact - offers recommendations to resolve issues related to regularization, border enforcement and return, the rights of irregular migrants, information firewalls, and the protection of migrants in vulnerable situations.

The papers are followed by a series of shorter essays addressing "on the ground" issues confronting migrants in vulnerable situations, with a focus upon how faith-based organizations (FBOs) help fill service and protection gaps.

In "Protecting Families and Facilitating Their Integration," Linda Rabben, associate research professor, Department of Anthropology at the University of Maryland, discusses the global crisis in forcible displacement, focusing on the hardships and challenges encountered by migrant families and children. Rabben describes several successful FBO programs for migrants. Following a series of recommendations, she concludes that FBOs have as much to contribute to the compacts' implementation, as to its content.

Laurie Carafone, co-director of legal services for Kids in Need of Defense (KIND) speaks to the needs of women and girls, and how faith-based groups can and do meet them, in her essay "Meeting the Needs of Women and Girl Migrants and Refugees in the Comprehensive Refugee Response Framework: The Unique Role of Faith-Based Organizations."

Mike Nicholson, researcher at the Center for Migration Studies of New York, explores the role of FBOs in providing health care to migrants and promoting their employment and entrepreneurial activities in his essay, "The Role of Faith-Based Organizations in Immigrants' Health and Entrepreneurship."

In advocacy efforts throughout the negotiation of the Global Compact, SIMN and CMS collaborated with the Delegation of the Holy See to the United Nations, member states, faithbased organizations, and civil society to identify and raise issues impacting the human rights of migrants and refugees. SIMN and CMS hope that these collaborations will continue into the implementation phase of the Global Compact.

Speaking to the Plenary Council of the International Catholic Migration Commission (ICMC) in March 2018, Pope Francis stated that the Church "must encourage countries to coordinate more suitable and effective responses to the challenges posed by issues of migration." He also recognized the important role of the Church in providing leadership and service to the most vulnerable of those among us, including persons on the move: "Today, as in the past, liberating the poor, the oppressed, and the persecuted is an integral part of the mission entrusted by God to the Church." 


\section{Section 2: Migration Challenges and}

Recommendations Relating to the Global Compact on Safe, Orderly, and Regular Migration 


\title{
International Migration Policy Report
}

\section{Return Migration: A Conceptual and Policy Framework}

\author{
Graziano Battistella \\ Scalabrini Migration Center
}

\section{Introduction}

Most migrants, even those who resettle in other countries, leave with the idea that one day they will return. In fact, a good number of the so-called "permanent migrants" who went from Europe to the Americas in the nineteenth and twentieth century eventually returned. ${ }^{1}$ The majority, however, remained abroad and the expression, "the myth of return," was eventually coined to indicate a variety of situations (Carling 2015), but principally the fact that return never took place. As migration systems expanded both in terms of migration corridors and policies, the interest in return acquired more prominence. Researchers have examined the reasons people return, how reintegration takes place, the factors that facilitate reinsertion in society and labor markets, the impact of return migration on local societies, and failures in the reintegration process that orient migrants to go abroad again.

Policymakers also have addressed return migration for a variety of reasons. Countries of origin, particularly in the temporary migration system, deal constantly with returning migrants, as settlement abroad is often not possible, and their reintegration is perceived both as an opportunity and a challenge. Countries of destination have explored a variety of schemes to encourage the return of migrants to the point of revitalizing the idea of temporary migration, disguised under the terminology of circular migration, particularly of highly skilled migrants. Countries affected by irregular flows have pursued readmission agreements with countries of origin to ensure they would readmit migrants subject to expulsion. Finally, countries of temporary resettlement of refugees have pushed for programs of assisted voluntary repatriation (AVR), a concept utilized also to indicate the repatriation of irregular migrants.

The variety of forms of return migration, the implications for migrants, their families and the countries, and the vulnerability of migrants and refugees who are subject to repatriation and expulsion demand that sound principles governing return migration be adopted in the Global Compact for Safe, Orderly and Regular Migration and the Global Compact on Refugees. Before indicating possible areas that should be covered in the Compacts, it is necessary to discuss the conceptual difficulties inherent to return migration and the policy framework that could facilitate the choice of interventions toward returning migrants.

\section{Return Migration: Conceptual Difficulties}

In spite of the fact that return migration has always been there, the research on it did not flourish until the 1980s, coinciding with the end of temporary migration programs to Western Europe and the interest of those European countries in encouraging the repatriation of migrants. Since

1 Between 1860 and 1930, more than a quarter of all migrants returned to Europe (Baines 1991). 
then, many more studies have been dedicated to return migration. A recent bibliography (Carling, Mortensen, and Wu 2011), admittedly not complete, listed more than 1,100 contributions dealing with a variety of aspects, but in particular the decision to return and the reintegration after return. Although many aspects of the return process have been investigated, many others remain in need of understanding.

Definition and numbers. If international migration is still searching for a consensus on definitions, ${ }^{2}$ return migration has even less consensus. Excluding the return of contract workers who spend some time with their family before going abroad again, migrants can return for good, at some points in their career or at retirement age, or they can return for some extended time, but then migrate again. The lack of a clear definition generates confusion on the assessment of needs and possibilities and on estimates of the size of return migration. In addition, the absence of administrative tools to register returning migrants means that in many countries the number of returnees is unknown, ${ }^{3}$ as are the interventions that could be provided for reinsertion in the labor market and for assistance and support.

The reasons for return. The determinants of migration have received much attention by scholars, and some theoretical syntheses have been advanced, differing according to discipline and ideological approaches. ${ }^{4}$ The determinants of return migration (except for the mandatory return at the end of contract) do not approach the formulation of a synthesis, as more personal factors seem to be at play. The different migration theories ignore return completely or consider it as a failure or success of the migration process (Cassarino 2004). If family concerns are often presented as the reasons for migration - some authors, like Stark (1993), actually consider them the main reason for migrating - the decision to return is even more prominently directed by family situations, including issues of adaptation, decisions on where the children should be educated, and requests for the migrant to be present in the family. Such variety of possibilities does not allow the formulation and testing of clear hypothesis on why and when a migrant will return.

The relevance of personal factors does not exclude the role of structural factors, both in the countries of origin and destination, in influencing the decision to return. Such a decision can be taken even while the economic differentials of migration persist, provided that the conditions for economic development and reemployment at home are considered more favorably. In the attempt to systematize the issue, Rogers (1984) proposed a matrix, based on combined events related and unrelated to migration with aggregate and individual events respectively in the home and host country, producing eight situations. The matrix might be an oversimplification of factors, but it was sufficient to cast doubt on the expected correlation between level of assimilation and rate of return. There are integrated and successful migrants who do return, just as there are unsatisfied migrants who remain. In particular, periods of economic recession do not necessarily produce an outflow of migrants toward the home country (Warren and Kerwin 2015, 82-84), as witnessed also in the recent global crisis.

2 The consensus definition of "international migration" speaks to the movement of people from one country to another for more than one year. The time frame is arbitrary, but necessary to distinguish migrants from tourists.

3 Appropriately the Global Migration Group $(2017,85)$ has identified the need to determine the stock of returned migrants, as well as " $k \mathrm{k}]$ nowledge of the skills composition of migration flows of both potential outbound and returning migrants."

4 Perhaps the most successful and most cited is the one provided by Massey et al. (1993), which concluded that no single theory is fully explanatory of the phenomenon and that causal processes operate on multiple levels simultaneously. For an updated overview see Piché (2013). 
The types of return. Because of the different types of migration and the different reasons behind migrants' decisions, there are different types of return. A common misunderstanding in policy debates and policy planning is to think of return migration as a homogeneous phenomenon. The return of different populations - permanent or temporary migrants, refugees or asylees, students, second-generation migrants, short-term returnees for health reasons or for employment, those displaced by political or environmental crisis, and the forcibly repatriated because of irregular migration - must be addressed in different ways. ${ }^{5}$

A common misunderstanding in policy debates and policy planning is to think of return migration as a homogeneous phenomenon.

The reintegration process. Most attention has been dedicated to the reintegration of permanent or long-term migrants. Because of their long experience abroad, they have been considered potential contributors to the development of the country of origin as they have savings to invest and have acquired skills that can bring innovation in the economic system. Returnees normally dream of positioning themselves in a different economic activity than the one they had prior to migration. Often this implies a change of sector (from agriculture to industry or services) and sometimes the initiation of a self-employed activity. Research has ascertained that the positive impact of reintegration is dependent on a variety of factors, both personal and structural.

The renewed interest among policymakers in the early 2000s on the nexus between migration and development, and specifically on the potential impact of migration on the development of countries of origin, has refocused attention on return. Some conclusions reached previously (Rogers 1990; Battistella 2004) were reaffirmed.

Some migrants become self-employed and open a business. ${ }^{6}$ The majority of returnees need to find reinsertion in the labor market. If the economy they return to is not expanding, many return migrants have problems in finding a job or they need to go through retraining before finding employment. The level of savings of returning migrants is not sufficient to undertake big initiatives. Transport and service are the sectors where it is easier to open a business. Migrants can take advantage of positive economic conditions, but they cannot turn a sluggish economy into a vibrant one.

Migrants do not necessarily acquire innovative skills abroad; they are often employed in repetitive occupations or occupations which are below their skill level (Battistella and Liao 2013). In addition, the economy of the country of origin may not be able to utilize the skills that migrants have acquired. From a social perspective, there can be difficulties, particularly for long-term or permanent migrants. Migrants do not find the community they dreamed about with nostalgia when abroad, and the community looks at migrants with circumspection. Thus, migrants have to go through a re-adjustment process, which is similar to the adaptation they experienced in the host country.

A specific aspect in the reintegration process concerns the children of migrants. Children born abroad face return as a migratory experience. This is especially traumatic for children when they

5 Kuschminder (2017) speaks of different return strategies.

6 In a recent study in the Philippines, the percentage of self-employed increased from 13 percent before departure to 27 percent after return. This applied to both men and women, although in the case of women 50 percent also returned to nonpaid employment in the household (OECD and SMC 2017). 
are forced to return with their deported parents, even though they may be citizens of the host country and have adapted to the language and culture of the host society, often attending years of schooling. It is precisely the desire of parents to ensure that children attend school and grow up within the culture of the home country that determines the decision and the timing for return. By this decision, parents often seek to ensure that problems of communication and dialogue within the family do not deteriorate. However, reinsertion of children in the home country (actually, the country of the parents) is not unproblematic. In particular, because of difficulties in language and incompatibilities of educational systems, sometimes children have to be set back at least one year, do not receive counseling, and often need to forget what they have learned abroad to absorb the teaching of the local school.

Similar difficulties in reintegration can apply to refugees who have the opportunity to return because the conditions that motivated their search for refuge have ceased. In the worst case, return is complicated by the lack of infrastructure, facilities, and economic conditions to support the reintegration of a large number of refugees, like the Afghans that returned from Pakistan and Iran. Social services like schools and hospitals are strained, paid wages are insufficient, and land prices tend to increase (Muzhary 2017).

The complexities of return require the adoption of a conceptual framework to accommodate the different situations.

An additional difficulty in the understanding of the reintegration process is to know where the migrants will resettle. Not all migrants depart from the city or province of birth. In many cases, international migration is preceded by internal migration. In some cases, it is only the migrant who has moved from one province to another. In other cases, the whole family has migrated. When return takes place, it is possible that the migrant will return to his place of origin, or to the place where the family has moved or to a different place altogether, based on opportunities and means. The current construction boom in Metro Manila is fueled by remittances from Overseas Filipino Workers (OFWs) who presumably will resettle in the metropolis rather than returning to their place of origin.

The complexities of return require the adoption of a conceptual framework to accommodate the different situations. Ignoring the reasons for return, as they can be many and difficult to operationalize, it is possible to place the main types of return on a continuum utilizing two variables: the time for return (at the end or before the end of the migration project) and the decision to return (voluntary and involuntary). ${ }^{7}$ The four general situations that would result are:

- Return of achievement: the migrant returns voluntarily at the end of the migration project (or contract) having achieved the purpose for which he or she went abroad.

- Return of completion: the migrant returns after completing the contract, but it is not a voluntary return, because the migrant would like to stay abroad for another period or to go abroad again; however, it is not possible.

7 Cassarino $(2014 a, 10)$ has questioned the validity of the "decision to return" variable, because it is determined by a destination country perspective, because it ignores the conditions in countries of origin, and because it is difficult to determine when return is voluntary or involuntary. While there is some validity in the objection, it is undeniable that some migrants return because of reasons beyond their control while others do not have to face similar circumstances. The difference makes an impact on the duration of the migration project and ultimately on the policy needed to address return. 
- Return of setback: the migrant returns voluntarily but before the end of the migration process, for various reasons, including unhappiness at working conditions, family reasons, experience of abuse, or trafficking. It is a setback from the perspective of the original migration project.

- Return of crisis (forced return): caused by situations like political upheaval or environmental disaster. It is an involuntary return: the migrant is forced to leave for reasons of security or political decisions made by the country of origin or destination. This scenario can also include the repatriation of irregular migrants.

The continuum, instead of a matrix, ${ }^{8}$ allows for situations that overlap matrix quadrants. In particular, there are similarities between the return of completion and the return of setback. It serves the purpose of illustrating that there are different types of return migration and that different returns require different intervention.

\section{Policies toward Return Migration}

In many countries of origin, policies toward returning migrants were not developed or were a residual concern among policymakers. Attention was mostly on capturing remittances through the formal channels, encouraging that remittances be spent in productive ways, and fostering entrepreneurship. Slowly the need for return migration policies emerged, both to help migrants break the revolving door cycle (the need to continue to go abroad because of lack of alternatives) and to utilize the potential contribution of returning migrants for the development of the country. Countries of destination have increasingly developed return migration schemes mainly to diminish the number of migrants, particularly irregular migrants, in their territory. Unable to avoid the entry of migrants in irregular ways, countries intend to ensure that the repatriation of migrants is successful and, in this regard, have provided incentives toward return and agreements with the countries of origin. ${ }^{9}$

As it is not possible to provide a comprehensive overview of return migration policies in the various countries of the world, I will illustrate briefly the programs offered in the Philippines, a major country of origin in the world and one that has developed policies that address the various aspects of the migration process.

\section{a. Return Migration Policies in the Philippines}

Traditionally, reintegration programs in the Philippines were assigned to the Overseas Welfare Worker Administration (OWWA), the social fund that provides a variety of assistance programs to migrants and their families. The Migrant Workers and Overseas Filipino Act of 1995 (Republic Act [RA] 8042) mandated the establishment of the Replacement and Monitoring Center, which was intended to facilitate the reintegration of Filipino migrants. The provision was not acted upon and was revitalized by the Department Order 79-07 which established the National Reintegration Center for Overseas Filipino Workers (NRCO) in 2007, later institutionalized by RA 10022, which amended RA 1042 in 2010. NRCO received an initial fund of 2 billion pesos (US \$40 million). The institutional organization was unstable, as NRCO was attached to different agencies, and some of its programs overlap with those provided by OWWA. Its basic programs consist of the following.

8 See IOM and SMC $(2013,135)$.

9 According to Cassarino $(2014 a, 10)$ "at the level of the 28 EU Member States, more than 300 bilateral and multilateral agreements have been concluded to facilitate the swift removal of unauthorized aliens." 
Job referral. It is probably the most needed service that government can provide as most OFWs need employment after return. There are many obstacles in finding employment, including $\mathrm{age}^{10}$ and need for retraining. NRCO can connect returning migrants to potential employers by making available resumes with particular skills and qualifications. This is in addition to a regular service to facilitate employment offered by the Department of Labor throughout the Philippines in the Public Employment Service Offices (PESO) and to job fairs that are regularly organized in different locations. The advantage of the NRCO program is that it is specific to OFWs. An initiative which encountered positive response among returnees was "Sa 'Pinas, Ikaw Ang Mam Sir!" a program to rehire teachers who had left teaching for a job abroad. Through an agreement with the Department of Education, NRCO guarantees 300 slots a year for returning teachers.

Assistance toward entrepreneurship/Micro-enterprise development. This assistance consists in providing start-up capital in the form of loans and technical assistance for OFWs who intend to open a business. The loan can be for a maximum of 2 million pesos (US $\$ 40,000)$ and carries an interest of 7.5 percent and is granted by the Land Bank, a government financial institution. There is no study to assess the performance of this program and the rate of survival of business initiated with the loans. One common criticism of the program among OFWs is that only a few can afford to apply for this loan because of the collateral required by the Land Bank. Financial assistance is needed but for the majority it should be provided without collateral, even if in smaller amounts (US $\$ 2,000-\$ 3,000)$.

Training and capability building. A variety of courses are offered free of charge by the Technical Education and Skills Development Authority (TESDA), the Department of Trade and Industry (DTI), and other institutions, and returnees can avail of them. Financial literacy and money management is utilized by many as everyone needs those basic skills. Popular courses teach welding, catering, cake making, packaging, pharmacy tech, and food safety (Murphy 2016). Other training programs are offered by Local Government Units but are not well publicized for returnees to take advantage of them. Of course, training is effective if it is accompanied by the other forms of assistance that facilitate returnees to initiate self-employment activities.

Counseling. NRCO makes available counseling services not only toward employment but also to address family concerns, value formation, and the need to prepare for return. Similar services are also offered by nongovernmental organizations and faith-based organizations.

Reintegration programs for distressed returnees. Direct assistance by the government is mostly needed for OFWs who return because the migration project was interrupted or who are repatriated because they were working in a country struck by a political or environmental crisis. For them, NRCO - in connection with other government agencies - provides a variety of services, such as rescue and temporary shelter assistance, legal assistance, medical assistance, and repatriation assistance. Balik Pinay! Balik Hanapbuhay! is the program tailored in particular to the reintegration of distressed women migrants. Between 2011 and 2014, 3,720 returning female migrants took advantage of the program (Mantilla 2014).

Return migration in the Philippines is addressed by many government agencies. In addition to the ones already mentioned, programs are run also by the Commission on Filipinos Overseas (CFO). Overall, these programs were mostly conceived to address the welfare and humanitarian needs of displaced OFWs. NRCO is not acknowledged for coordinating an overall approach to provide the knowledge deriving from data and labor market forecasts; engaging multisector, multistakeholder

10 An Anti-Age Discrimination in Employment Act (RA10911) was adopted in 2017. 
cooperation in developing the environment conducive to reintegration; or implementing the appropriate tools and providing the necessary communication and monitoring and evaluation mechanisms to make reintegration smooth for OFWs and beneficial for the country.

\section{b. Return Migration Policies Framework}

The example of return policies designed in the Philippines illustrate what most countries of origin try to implement to facilitate the reintegration of returning migrants and to enhance their contribution toward development. However, such policies often have limited impact because they do not consider the different types of return and the different needs of returning migrants.

Keeping in mind the conceptual continuum developed above, I would like to suggest the corresponding return policies that could be provided. Such policies are distinguished by nature (policy of assistance or policy of development) and the type of intervention (direct intervention to benefit the returning migrants or indirect intervention - policies not elaborated for returning migrants but which returning migrants could utilize).

\section{Figure 1. Return Migration and Return Migration Policies}

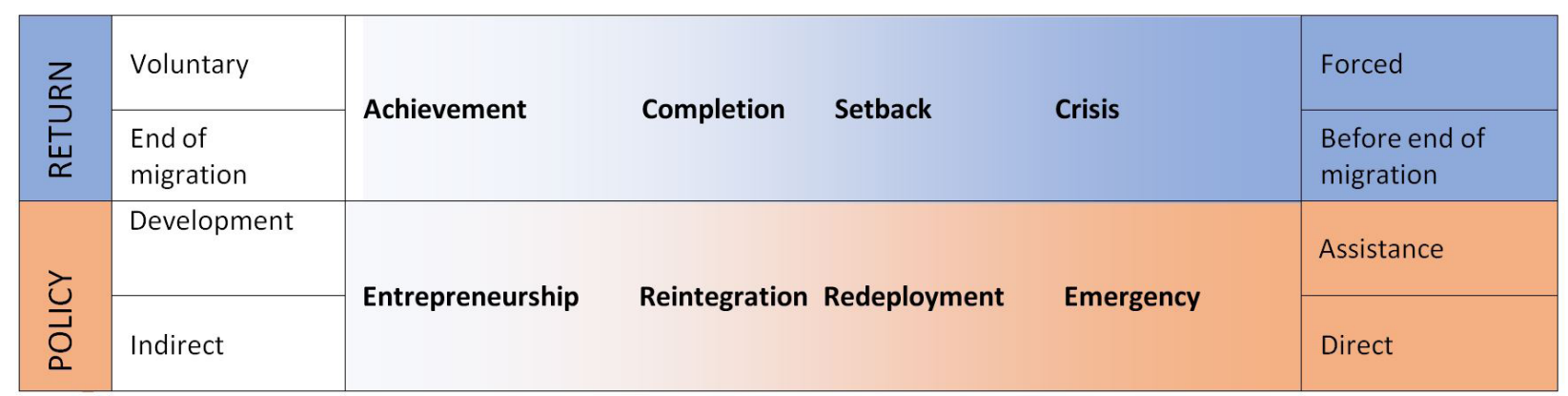

Return of achievement should be addressed by policies of development to encourage entrepreneurship. Such policies would not be designed for return migrants, but for the broader public. Migrants who have achieved their objective through migration might be in a position to take advantage of opportunities that are broadly available. For this reason, such policies indirectly benefit returning migrants. Often, the opportunities that returning migrants can utilize are at the local level. Migrants return to their country, but to a specific province and city of the country. This implies that migration, and specifically return migration, must be factored into local development plans (Asis 2011). It also implies that migrants are provided with the knowledge necessary to take advantage of opportunities. Therefore, these policies should include information on local economic opportunities, financial literacy programs, entrepreneurship development and trainings, access to credit, investment packages, and cooperative undertaking. While not all achievers will be involved in development projects, probably all of them have a clear idea on what to do after migration. There are no specific data to determine what proportion of returning migrants can be considered achievers, but the limited use of government programs for returnees might be explained also by the fact that many returning migrants do not need assistance by the government.

Return of completion should be met by policies of reintegration. These are migrants who are still in need of earning, because what they achieved through migration is not sufficient for what they intended to accomplish upon return. At the same time, they cannot return abroad for a variety 
of reasons, like family situations, the end of the economic activity for which they were hired, a change of employment conditions, or the impossibility of continuing to stay abroad. As they do not possess the sufficient savings for self-employment, they need to find domestic employment. A policy of reintegration should include information on labor market opportunities, retraining programs, and certification of skills acquired abroad. These would be direct reintegration policies and migrants should be informed that such programs are available, but they are also indirect, as some programs would also be available for the local population.

Return of setback should be addressed through policies of reintegration or redeployment. As indicated in the conceptual framework, return of setback has similarities with return of completion and policies also can be to some extent similar. Depending on the setback, migrants might be willing or unwilling to return abroad. Programs for reintegration should be direct programs offered by local governments, while the possibility to return abroad is an indirect policy because it is afforded by employment agencies rather than the government. In case of migrants who return because they have become victims of trafficking, the policy to be offered should be more directly an assistance policy, consisting of legal, social and psychological support.

Return of crisis requires redeployment programs and emergency policies. Redeployment programs should be available because many of these returnees saw their migration project interrupted by external forces and are far from reaching their objectives. Emergency initiatives include financial assistance upon arrival, counseling and psychological support, and information on labor market opportunities.

As some of the policies are useful in all types of return, governments should provide core services that are always available, regardless of the types of return.

As some of the policies are useful in all types of return, governments should provide core services that are always available, regardless of the types of return. Core services should include information on labor market opportunities, retraining programs, provision for skills certification, and protection of acquired rights.

\section{Preparing for Return}

All the stakeholders in the process need to prepare effectively for reintegration to succeed (Cassarino 2014b). Preparedness is needed at the individual and institutional levels. At the individual level, it is presumed that when return is voluntary the returning migrant is prepared for it, but that is not always the case. Often, migrants discover that the situation, both within the family and in the place of return, is different from what they imagined or find out that their human and financial resources are insufficient. This leads often to new migration. On the other hand, forced return typically coincides with insufficient preparedness because the migrant did not expect to conclude suddenly the migration project.

\section{a. Individual Preparedness}

Individual preparedness is not limited to the returning migrant. It also includes family who have taken part in the decision to migrate and to which the migrant returns to utilize the benefits of migration. There are several levels of preparedness to be considered. 
Psychological preparedness. Is the migrant ready and willing to return? In the case of contract labor migration, where return is frequent and periodical, the decision to return usually consists in the decision not to seek reemployment. Psychological preparedness is probably higher than in the case of long-term and permanent migration, where the decision to return consists in a reinsertion in a country where the migrant (and sometimes the family) have not lived for a long time.

Technical preparedness. If return is not for retirement, the returnee needs to find a source of income. It is not sufficient to be aware of one's capabilities and skills; what counts is whether those capabilities can be placed successfully in the local labor market.

Financial preparedness. Remittances are often spent for the very reasons that the migrants undertook the migration project, including for housing, education of children, and payment of debts. Consequently, it is possible that the level of savings accumulated during work abroad will not last for a long time, unless there is a positive reinsertion into an economic activity. On the other hand, reducing the level of expenditures of the family is seldom possible. This is the main reason why return, although meant as final, in many cases lasts only for a while and leads to repeated migration. Financial preparedness requires early planning: it is covered in the predeparture orientation seminars that Filipino migrants must undertake before going abroad. Early preparation sometimes consists in the family initiating economic activities while the migrant is still working abroad.

Social capital. The migrants' social capital plays an important role in the success of their return. It must exist in a local context, although not necessarily the place where the migrant was born. Familiarity with the context - the institutions and opportunities available, the key persons that make things happen, where to get advice and support - are indispensable components in the reintegration process.

\section{b. Institutional/Country Preparedness}

Central institution preparedness. This preparedness is to be done by the institutions at the national level responsible for the governance of migration, or indirectly connected to it. Such institutions should equip the migrants with adequate opportunities and effective services. As more than one agency is often involved, interagency collaboration is crucial also to avoid lengthy bureaucratic procedures. Country preparedness should involve cooperation with countries of destination. This cooperation should not be limited to agreements on readmission of irregular migrants or to dialogues to facilitate the placement of workers. Countries of destination can cooperate through direct investment projects and trade agreements. Bilateral agreements for the protection of migrant workers can be expanded to include the development side of migration.

Local institution preparedness. It is at the local level that return migration becomes productive and should be factored in the local development plans. Local institutions should collect data on their migrant populations and provide information on opportunities and constraints. Cooperation between the local and the national agencies should be smooth and productive.

\section{Recommendations}

Return migration should not be considered the aftermath of the migration process or an act that simply concludes migration. It is an important stage in the migration project and very relevant to 
the well-being of the migrant and the welfare of the state. Already the International Convention on the Protection of the Rights of All Migrant Workers and Members of Their Families (MWC) envisioned its application during return (Article 1) and provided for cooperation among state parties for the "orderly return of migrant workers and members of their families" (Article 67.1). The discussion process in preparation of the Global Compacts has addressed return migration in various circumstances, reflected in the Chair Statement at Puerto Vallarta. Civil society has dedicated Act 9, of its Ten Acts for the Global Compact, to return migration.

Given the need for policies to address different types of return, some policy recommendations on return should be included in the Global Compact for Safe, Orderly and Regular Migration and others in the Global Compact on Refugees. The following are necessary to ensure the protection of migrants during return, to facilitate their reintegration, and to maximize their contribution to the country of origin.

1. Develop instruments to estimate the stock of return migrants and institute, and if necessary for the benefit of migrants, an administrative mechanism for the effective registration of returning migrants.

2. Cooperate among countries to enhance individual return preparedness by providing migrants before return with access to adequate information and training to enhance their reintegration process.

3. Ensure state and local government preparedness for the return of migrants by establishing appropriate agencies and equip them with the capability to offer information, orientation, training, job matching, and financial assistance for the successful reintegration of returning migrants.

4. Foster country-to-country cooperation to ensure that return takes place in an orderly and safe manner, ensure the protection and transfer of migrants' belongings and tools, develop appropriate initiatives for skill recognition and portability of benefits and acquired rights, and seek cooperative development agreements (include trade and direct investment) to enhance the contribution of return migrants to their country.

5. Ensure readmission of migrants to countries of origin and avoid collective and arbitrary expulsion and the transfer of migrants to third countries.

6. Ensure the cooperation of transit countries for the safe return of migrants from situations of crisis or natural disaster.

7. Uphold the principle of non-refoulement and ensure the voluntary participation of migrants in assisted voluntary return.

8. Avoid the detention of children and the repatriation of parents or children when it leads to the breakup of the family and is against the best interest of the child.

\section{Conclusion}

Return migration is often badly understood and even more badly planned. In general, return is considered simply as the concluding moment of the migratory project and as such not in need 
of much attention. Its dimensions and modalities are often poorly understood because returning migrants do not need to report to any particular government agency. In reality, return constitutes a specific moment of the migration process and it is often followed by repeated migration. Neglect or inadequate policies do not allow for the breakup of the migration cycle. Existing policies are often generic, one-size-fits-all interventions, for which migrants have little use.

Specific return policies are absolutely needed to reabsorb migrants who are subject to expulsion or repatriation because of individual or country crisis.

This article has argued that return should be properly understood as a diversified process according to the time it takes place, the completion of the migration project, the level of constraint the migrants experience, and the preparedness of the migrants, their families, and the institutions involved. Specific return policies are absolutely needed to reabsorb migrants who are subject to expulsion or repatriation because of individual or country crisis. They are less needed by the migrants, who might be the majority, who were able to achieve the objectives for which they migrated. They are to be formulated at the national but even more at the local level, knowing that migrants return to specific localities. A core of services, such as labor market information, accessibility to retraining programs, provision for skills certification, and protection of acquired rights should always be present. To ensure that migration plays a value-added role in the development process, and that the rights of migrants are properly protected, return migration should involve cooperation among countries of origin and destination. Finally, the best return migration policies might not be those targeting the returning migrants, but overall policies creating an environment that returning migrants can properly utilize.

\section{References}

Asis, Maruja M.B., ed. 2011. Minding the Gaps: Migration, Development and Governance in the Philippines. Manila: Scalabrini Migration Center.

Baines, Dudley. 1991. Emigration from Europe 1815-1930. London: MacMillan. https://doi. org/10.1007/978-1-349-11404-7.

Battistella, Graziano. 2004. "Return Migration in the Philippines: Issues and Policies." In International Migration: Prospects and Policies in a Global Market, edited by J. Edward Taylor and Douglas S. Massey, 212-29. Oxford: Oxford University Press. https://doi.org/1 0.1093/0199269009.003.0012.

Battistella, Graziano, and Karen Anne Sun Liao. 2013. Youth Migration from the Philippines: Brain Drain and Brain Waste. Makati City: UNICEF (United Nations Children's Fund).

Carling, Jorgen. 2015. "Myth of Return." In The Wiley-Blackwell Encyclopedia of Race, Ethnicity and Nationalism,1-2. Hoboken, NJ:Wiley-Blackwell.https://doi.org/10.1002/9781118663202. wberen228.

Carling, Jorgen, Elin Berstad Mortensen, and Jennifer Wu. 2011. A Systematic Bibliography on Return Migration. Oslo: PRIO (Peace Research Institute Oslo).

Cassarino, Jean-Pierre. 2004. "Theorising Return Migration: The Conceptual Approach to Return Migration Revisited." International Journal on Multicultural Societies 6(2): 253-79. 
2014a. Reintegration and Development. San Domenico di Fiesole, Italy: European University Institute, Robert Schumann Center for Advanced Studies.

_. 2014b. "A Case for Return Preparedness." In Global and Asian Perspectives on International Migration, edited by Graziano Battistella, 153-66. New York: Springer. https://doi. org/10.1007/978-3-319-08317-9_8.

Global Migration Group. 2017. "Handbook for Improving the Production and Use of Migration Data for Development." Washington, DC: KNOMAD (Global Knowledge Partnership for Migration and Development), World Bank.

IOM (International Organization for Migration) and SMC (Scalabrini Migration Center). 2013. Country Migration Report: The Philippines 2013. Makati-Quezon City: IOM.

Kuschminder, Katie. 2017. Reintegration Strategies: Conceptualizing How Return Migrants Reintegrate. New York: Palgrave Macmillan.

Mantilla, Chona M. 2014. "Issues and Challenges in Reintegration Services for Filipina Migrant Workers." Presentation at the ASEAN Regional Conference of Senior Officials on Strengthening the Protection and Empowerment of Women Migrant Workers, November 13-14, Manila.

Massey, Douglas, Joaquin Arango, Graeme Hugo, Ali Kouaouci, Adela Pellegrino, and J. Edward Taylor. 1993. "Theories of International Migration: A Review and Appraisal." Population and Development Review 19(3): 431-66. https://doi.org/10.2307/2938462.

Murphy, Alana. 2016. "Negotiating the Gap: Evaluating Livelihood Services for Returning Overseas Filipino Workers." Unpublished working paper.

Muzhary, Fazal. 2017. "Resettling Nearly Half a Million Afghans in Nangrahar: The consequences of the mass return of refugees." Afghanistan Analyst Network.

OECD (Organisation for Economic Co-operation and Development) and SMC (Scalabrini Migration Center). 2017. Interrelation between Public Policies, Migration and Development in the Philippines. Paris: OECD Publishing.

Piché, Victor. 2013. "Contemporary Migration Theories as Reflected in their Founding Texts." Population 68 (1): 141-64. https://doi.org/10.3917/pope.1301.0141.

Rogers, Rosemarie. 1984. "Return Migration in Comparative Perspectives." In The Politics of Return: International Return Migration in Europe, edited by Daniel Kubat. New York: Center for Migration Studies.

- 1990. "Return Migration, Migrants' Savings and Sending Countries' Economic Development: Lessons from Europe." Washington, DC: Commission for the Study of International Migration and Cooperative Economic Development.

Stark, Oded. 1993. The Migration of Labor. Oxford and Cambridge, MA: Blackwell

Warren, Robert, and Donald Kerwin. 2015. "Beyond DAPA and DACA: Revisiting Legislative Reform in Light of Long-Term Trends in Unauthorized Immigration to the United States." Journal on Migration and Human Security 3(1): 80-108. https://doi.org/10.14240/jmhs.v3i1.45. 


\title{
International Migration Policy Report
}

\section{The Regularization of Zimbabwean Migrants: A Case of Permanent Temporariness}

\author{
Sergio Carciotto \\ Scalabrini Institute for Human Mobility in Africa (SIHMA)
}

\section{Abstract}

Since the early 2000s there has been a proliferation of policy initiatives in high income countries to attract highly skilled migrants who are perceived to be net contributors to host societies. Generally, highly skilled migrants enjoy numerous socioeconomic opportunities and benefit from fast-track procedures to switch from temporary visas to permanent residency.

South Africa has sought to capitalize on this trend through domestic legislation and policy that promotes economic growth by facilitating the admission of highly skilled workers. However, these measures have also prevented low-skilled workers from applying for permanent residency, irrespective of their length of time in the country. These policies beg the question whether it is morally acceptable for a liberal democracy to deny a pathway to permanent residency based on skill level.

The paper draws on Joseph $\mathrm{H}$. Carens' theory of citizenship and the principle that "the longer one stays in a society, the stronger one's claim to remain." It uses the example of the Dispensation for Zimbabwean Project, a large regularization program for temporary workers introduced in South Africa in 2010 to argue that temporary status should not be "permanent," but should lead to permanent residency after a period of time.

\section{Introduction}

In an article titled "Back to the future? Can Europe meet its labor needs through temporary migration?" Stephen Castles inquires whether temporary worker schemes introduced in Europe in the 2000s would resemble past guest worker programs which were abolished in 1974. Such programs provided employers with young unskilled workers who were unmarried or had left their families at home and worked on a "rotation basis" (Rotationsprinzip) in agriculture, construction, mining, and manufacturing (Jurgens 2010, 348). His answer to the question is no. However, he argues that "some current approaches do share important common features with past guest worker programs, especially through discriminatory rules that deny rights to migrant workers" (Castles 2006, 1). Castles further observes that unlike older guest worker programs, immigration policies and temporary migration schemes in Europe target highly skilled migrants, while restricting entry for less qualified workers and limiting their rights.

With regard to working conditions, Castle and Ozkul (2014, 30) write, "lower-skilled workers experience highly restrictive conditions, with limitations on duration of stay and the right to change jobs." They face exploitation and abuses, "have a time-limited right to residence and employment in the host country and time spent in employment as a guest worker usually does not 
count or help them to earn permanent residence rights" (Ruhs and Martin 2008, 250). Temporary migrant workers, particularly low-skilled migrants, are treated as "second-class citizens" at risk of becoming part of a new model of "indentured servitude" (De Genova as cited in Castles and Ozkul 2014, 41).

\section{Temporary forms of migration raise a normative question about the socioeconomic rights of those who are neither citizens nor long-term residents.}

Temporary forms of migration raise a normative question about the socioeconomic rights of those who are neither citizens nor long-term residents. They also pose the question of whether the number of years spent in a country should be considered a legitimate and morally acceptable criteria to access permanent residency. If the answer to this question is no, as some argue, temporary workers should not be able to qualify for permanent residency, irrespective of how long they have been in the host country. The term "temporary migrant" refers here to migrant workers employed in low-skilled jobs and excludes other categories of temporary migrants such as asylum seekers, highly skilled workers, foreign investors, and international students, to whom many countries offer a fast-track from temporary to permanent residency and full socio-economic rights.

\section{Temporary Workers and Rights}

As noted by Ruhs (2012, 1288), "the question about rights involves questions about the rights migrants should receive after admission and whether and how these rights should change over time." He further argues that the legal rights of migrants depend on their immigration status in the host country and that selective immigration policies are used to "tightly regulate migrants" access to citizenship status and to specific citizenship rights (ibid., 1288). Some theorists (Ruhs and Martin 2008) argue that denying temporary low-skilled workers equal rights is justified by economic needs. They maintain that there is, in fact, a "trade-off, i.e. an inverse relationship between the number of migrants employed in low-skilled jobs in high-income countries, and the rights afforded these migrants. The primary reason for this trade-off is that employer demand for labor is negatively sloped with respect to labor costs, and that more rights for migrants typically means higher costs" (ibid., 251). In this kind of situation, both employers and migrant workers have something to gain: the former benefits from a reduction in labor costs or to meet a labor shortage, while the latter has an opportunity to migrate safely and legally. According to the "number-rights/trade-off principle" described above, granting more employment rights to migrant workers would simply reduce employers' demand and, therefore, the number of lowskilled migrants legally employed.

Others (see Bell 2006) have argued that a system of unequal rights, as in the case of East Asia, is tolerable because migrant workers accept terms and conditions of employment before they go abroad. This raises the question whether temporary migrants "are better off because they are more likely to be employed or less well off because they endure poorer working conditions" (Fauvelle-Aymar 2015, 14). This paper argues that temporary workers should enjoy the same employment rights that citizens and permanent residents possess. A contractual approach to temporary migration might, in fact, be convenient from the point of view of practical politics, but it cannot be justified on moral grounds as it tolerates a system of "second-class" residents with fewer rights. But nonetheless, if those migrants who enter into this kind of working agreement do so voluntarily and, therefore, are willing to receive less rights, this should only be temporary and limited to short-term non-renewable visas. An exploitative system where migrant workers' 
rights are restricted ad infinitum would not be acceptable and should not be justified even when migrants are willing to accept fewer rights.

The question about what rights migrants should receive after their admission and how these rights should change over time remains a highly contentious issue. Political theorist Joseph $\mathrm{H}$. Carens (2008a,b,c; 2013) provides an answer to this ethical dilemma. He notes that democratic states can admit migrants for a limited period of time and restrict their access to public assistance programs but other restrictions are morally problematic. His argument is based on the assumption that the claim to be a member of a political community grows as time spent in a country increases, irrespective of the condition of sojourn or immigration status. Moreover, democratic legitimacy "lies upon the inclusion of the entire settled population, including those migrants who have spent numerous years in a society and deserve to be included in the citizenry" (Carens 2008b, 22). Membership acquired over an extended period of time spent in a society explains why prolonged temporary status ought to lead automatically to permanent residency first and to citizenship (naturalization) afterwards:

[I]f people admitted to work on a temporary visa have no other moral claim to residence than their presence in the state, it is normally reasonable to expect people who have only been present for a year or two to leave when their visa expires. On the other hand, if a temporary visa of this sort is renewed, it ought at some point to be converted into a right of permanent residence. That is also the implication of the principle that the longer the stay, the stronger the claim to remain. (Carens 2008a, 422).

The question about what rights migrants should receive after their admission and how these rights should change over time remains a highly contentious issue.

The importance of continuous residency leading to permanent residency is echoed by Mares $(2017,20)$, who notes that "the starting point for a consistent liberal response to temporary migration must be a pathway to permanent residence that is, after a certain period of time, unconditional." It therefore follows that, according to Carens' point of view, temporary workers must not be allowed "to morph into a permanent underclass" (UNGA 2017, 10) and should enjoy the same universal legal rights as native workers. He argues that after a given time (five to 10 years) the moral claim of temporary workers for permanent residency and citizenship can be considered legitimate. Carens' (2008a,b,c) theory of citizenship, labeled social membership, is based on the principle that "the longer a person stays, the stronger is his or her claim to remain."

Still the main question remains. Is it legitimate for temporary migrants to acquire, after a set number of years, the legal rights afforded to citizens and long-term residents? Let me try to answer this question with a concrete example: the Dispensation of Zimbabweans Project approved by the Cabinet in South Africa in 2009.

\section{The Regularization of Zimbabwean Migrants}

From 2008 to 2011, South Africa received the highest number of individual asylum applications globally, with a peak of over 300,000 applications in 2009 (Table 1) making it the world's largest recipient of asylum seekers that year. This fact caused delays in adjudication times and allowed economic migrants without a legitimate asylum claim to reside and work legally in the country. 
The increase in asylum claims led the Department of Home Affairs "to implement restrictive practices and policies, stemming both physical access at the border and at the refugee reception offices (RROs), as well as access to protection in adjudication procedures" (Johnson and Carciotto 2016, 169).

\section{Table 1. Number of Asylum Applications Filed Annually in South Africa, 2008-2011}

\begin{tabular}{lr}
\hline Year & Asylum Seekers \\
\hline 2008 & 207,206 \\
2009 & 341,609 \\
2010 & 124,336 \\
2011 & 106,904 \\
2012 & 85,058 \\
2013 & 70,010 \\
2014 & 71,914 \\
2015 & 62,159 \\
2016 & 35,377 \\
\hline
\end{tabular}

Source: Adapted from Department of Home Affairs, Annual Asylum Statistics.

In response to this crisis, one policy adopted to ease the pressure on the asylum system was the implementation of a large regularization program for Zimbabwean nationals in South Africa. In 2009, the Cabinet approved the Dispensation of Zimbabweans Project - or "DZP" - allowing Zimbabwean holders of this special permit to work, conduct business, and study in South Africa. At the launch of the DZP in 2010, the Department of Home Affairs (DHA) estimated that there were approximately 1.5 million undocumented Zimbabweans in South Africa (Bimha 2017).

The DZP relaxed the normal requirements for work, study, or business permits. Applicants were required to submit a valid Zimbabwean passport, evidence of employment in the case of a work permit, evidence of business in the case of an application for a business permit, and an admission letter from a recognized learning institution in the case of a study permit (Amit 2011). The objectives of the "DZP" then were to: a) regularize Zimbabweans residing in South Africa illegally; b) curb the deportation of Zimbabweans who were in South Africa illegally; c) reduce pressure on the asylum seeker and refugee regime; and d) provide amnesty to Zimbabweans who obtained South African documents fraudulently. Just over 245,000 non-renewable temporary permits were issued with a validity of four years.

In August 2014, four months before the expiration date of the Zimbabwean special permits (December 31, 2014), the Minister of Home Affairs announced the launch of a new Zimbabwean Special Dispensation Permit (ZSP) targeting DZP permit-holders who wished to remain in South Africa after the expiry of their permits. The ZSP allowed permit-holders to live, work, conduct business, and study in South Africa for an additional three years until December 31, 2017. 
Despite having announced in 2016 that the ZSP would be terminated the end of 2017, the DHA later announced the availability of the new Zimbabwean Exemption Permit (ZEP) which allowed ZSP holders to work, study, and conduct business for an additional period of four years until December 31, 2021. The then Minister of Home Affairs, Hlengiwe Mkhize, remarked that the ZEP was in line with the White Paper on International Migration Policy, approved by the Cabinet in 2017, and was part of a larger effort to address the inflows of low-skilled labor migrants from neighboring South African Development Community (SADC) countries. This is not the first time that South African government has attempted to address the issue of irregular migration within the region: between 1995 and 2000 three regularization projects for contract and undocumented migrant workers from SADC countries were implemented. However, unlike the three previous regularizations which "were designed to give target populations permanent residence status in South Africa" (Peberdy 2001, 20), the DZP, ZSP, and ZEP programs did not allow permit-holders to apply for permanent residence despite their long, continuous tenure in the country. This exclusionary practice raises numerous concerns. Given the fact that "the eligibility criterion for accessing most social assistance benefits is South African citizenship or permanent residence" (Deacon, Marius, and Beremauro 2014), the lack of a pathway to permanent residency restricts migrants' access to social benefits.

In South Africa, all temporary workers are excluded from accessing social assistance, are not entitled to claim unemployment funds, and are excluded from accessing unemployment insurance if they are ill or on maternity or adoption leave (ibid., 24). Access to housing and basic education for temporary workers is also restricted by the government (see Table 2). Moreover, low-skilled temporary workers are much more likely to occupy low-wage, precarious jobs than South Africans (ACMS 2017). In addition, temporary workers are tied to a specific kind of work and are not allowed to change employers. Such restrictions can make migrant workers vulnerable, as recounted by a Zimbabwean national who was granted a permit to work as a gardener under the DZP dispensation and later secured a job in the construction industry:

I worked for a month at the construction site because it paid better than working as a gardener. After the first month we were taken to Kimberley to do some work for a few weeks. However, when we got there we encountered people from Home Affairs who were checking for papers [legal documentation]. I was immediately arrested because I was doing a job that was not mentioned in my permit. It was a nightmare. I was told that I would be deported but it took long for me to be deported. I spent one and a half months at a holding centre in Kimberley. They keep you there for some time till they have arrested enough people to fill a truck.

(Deacon, Olivier, and Beremauro 2014, 50)

The Constitution of South Africa guarantees equality before the law and the right to equal protection and does not justify discrimination based purely on residency. Yet temporary low-skilled workers are vulnerable to exploitation and are not afforded equal protection. Regularization programs such as the ZDP, the ZSP, and the ZEP address permanent labor shortages and fill permanent jobs with temporary workers. Such workers should not be denied a path to permanent residency. 


\section{Table 2. Access to Social Services and Benefits in South Africa for Different Categories of Residents}

\begin{tabular}{lcccccc}
\hline & $\begin{array}{c}\text { Social } \\
\text { Assistance }\end{array}$ & Pensions & $\begin{array}{c}\text { Unemployment } \\
\text { Benefits }\end{array}$ & $\begin{array}{c}\text { Health } \\
\text { Care }\end{array}$ & $\begin{array}{c}\text { Public } \\
\text { Housing }\end{array}$ & $\begin{array}{c}\text { Public } \\
\text { School }\end{array}$ \\
\hline Citizen & Yes & Yes & Yes & Yes & Yes & Yes \\
$\begin{array}{l}\text { Permanent } \\
\text { Resident }\end{array}$ & Yes & Yes & Yes & Yes & Yes & Yes \\
$\begin{array}{l}\text { Temporary } \\
\text { Resident }\end{array}$ & No & Yes & No & Yes & No & No \\
\hline
\end{tabular}

Source: adapted and updated from Mpedi (2011).

\section{The 2017 White Paper on International Migration}

The Immigration Act of 2002 provides for various types of temporary visas with worker rights, and makes holders of work visas eligible for permanent residency after a period of five consecutive years. Section 31(2)(b) of the Act allows the Minister of Home Affairs "to grant, under specific terms and conditions, a foreigner or a category of foreigners the rights of permanent residence for a specified or unspecified period when special circumstances exist which should justify such a decision."

Provided certain conditions are met, this system "effectively creates automatic qualification for permanent residency and subsequently for citizenship. Thus one of the main criteria used to qualify for permanent residency is the period of stay in the country, irrespective of the type of temporary residence visa initially issued, or purpose of entry" (DHA 2017, 41). However, the 2017 White Paper on International Migration seeks to modify this approach so that the guiding principle to grant permanent residency and naturalization would be the type of residence visa rather than the number of years spent in the country. This policy framework - which restricts citizenship rights for temporary low-skilled migrants - is morally questionable and contravenes the principle that "the longer the stay, the stronger the claim to full membership in society and to the enjoyment of the same rights as citizens."

The White Paper was approved by the Cabinet in March 2017 with the aim of providing a policy framework to guide the review of immigration and related legislation. According to the South African government, the rationale for an overhaul of migration legislation is the economic, social, and legislative changes that have occurred in South Africa during the past 18 years. The White Paper attempts to respond to the needs of a country that has become a major destination for economic migrants, refugees, students, cross-border traders, and entrepreneurs from Africa and the rest of the world. It recommends strategic interventions in eight policy areas: management of admission and departure; management of residency and naturalization; management of international migrants with skills and capital; management of ties with South African expatriates; management of international migration within the African context; management of asylum seekers and refugees; management of the international process for international migrants; and management of enforcement.

The White Paper argues that the current system fails to address the challenges posed by mixed migration flows from neighboring countries "with regard to semi-skilled and unskilled economic 
migrants, who have been largely unable to obtain visas and permits through the mainstream immigration regime" (DHA 2017, 52). This system has had some negative consequences, including a national asylum system overwhelmed and abused by economic migrants, the exploitation of African workers by some South African employers, corruption by police and immigration officials, and costly and ineffective deportation measures.

In line with the National Development Plan (NDP), the new migration policy seeks to attract, acquire, and retain the necessary skills by recruiting migrants in a more strategic way in order to achieve national priorities and economic growth. It attempts to align South Africa's international migration policy with its African-centered foreign policy to better address economic migration of low-skilled and unskilled migrants from the SADC region. To address the growth of undocumented migration and the existing gaps in legislation, the White Paper suggests three strategic initiatives to improve the management of low-skilled economic migrants by expanding the current visa regime (DHA 2017, 56).

First, a new SADC visa would be tied to a program to regularize existing undocumented SADC migrants residing in South Africa along the same lines as the ZSP and other amnesties that South Africa has conducted over the years.

Second, the White Paper would expand the visa regime to address economic migration from neighboring countries. At least three types of visas are recommended for piloting. The SADC special work visa would allow the holder to work in South Africa in a specific sector for a prescribed period of time. It would be based on a quota-regime implemented through bilateral agreements. The number of visas would be based on labor market dynamics like employment levels and the share of jobs held by foreign nationals. The SADC traders' visa would be a longterm, multiple-entry visa for cross-border traders who frequently enter and exit the Republic. The SADC small and medium enterprise (SME) visa would be available for the self-employed and for small business owners.

Third, the White Paper provides for stronger enforcement of immigration and labor laws. It seeks to strengthen the enforcement of labor and migration laws in order to ensure fair employment practices and that unscrupulous employers do not pay lower wages to migrants.

One of the most significant features of these new temporary schemes for low-skilled migrants is the absence of pathways to permanent legal status.

One of the most significant features of these new temporary schemes for low-skilled migrants is the absence of pathways to permanent legal status. At present, the Immigration Act of 2002 allows holders of certain temporary residence visas under specific conditions to apply for a permanent residence permit and subsequently for citizenship. Thus, access to permanent residency is based on the number of years spent in the country, irrespective of the type of temporary visa initially issued.

In the government's view, this approach "does not allow the granting of residency and naturalization to be used strategically" (DHA 2017, 42) and in the best interest of national priorities. Hence, there should not be any automatic progression from residency to citizenship, in order to "dispel a misconception that immigrants have a constitutional right to progress towards citizenship status on the basis of a number of years spent in the country" (ibid., 42). 
In the future, long-term visas may replace permanent permits and be granted only to those migrants who possess high levels of human and financial capital. This new policy will mean that highly skilled workers, investors, and international students graduating in critical skill occupations will receive preferential admission conditions and easy access to permanent residency, while temporary low-skilled migrants will not.

Thus, the White Paper would negatively impact the rights and social conditions of temporary low-skilled African migrants, who will no longer have the right to settle permanently. The granting of permanent residency based on highly selective criteria is, in fact, a tool to control and restrict access to civic, political, and social rights, including the substantive rights of citizenship.

The planned measures to introduce a new visa regime for low-skilled temporary workers acknowledge the demand for low-skilled workers in specific economic sectors, as well as the existence of prevailing colonial circular movements and migration patterns to South Africa. However, this policy plan falls short in addressing issues of "employee portability rights" for temporary contract workers and gives the impression of replicating circular and temporary schemes "which tie migrant workers to certain sectors and employers for a pre-defined period of time, limiting the duration of stay and the right to change job" (Castles 2014, 41). Furthermore, the idea presented in the White Paper of delinking permanent residency from the duration of stay is problematic and morally questionable.

This policy runs afoul of human rights and the common good, which demand policies that benefit all members of a given community. In this regard, "Iong-term settlement does carry moral weight and eventually even grounds a moral right to stay that ought to be recognized in law" (Carens 2008b, 36).

\section{Conclusion}

In South Africa, temporary and exploitative forms of migration date back to colonial times when migrant workers were considered a source of cheap labor for white-owned farms and mines, thus setting the foundation for separate development and the apartheid regime. Since the inception of democracy in 1994 and particularly over the past two decades, South Africa has undergone a protracted process of developing policy and legislation on migration. One of the key policy documents issued by the South African government is the White Paper on International Migration, which supports the enlargement of the current visa regime through the implementation of regularization programs to accommodate temporary low-skilled workers and reduce the influx of undocumented migrants from neighboring countries. Examples of these interventions are the Dispensation for Zimbabwean Project, the Zimbabwean Special Dispensation, and the Zimbabwean Exemption Permit to regularize migrant workers in South Africa.

Originally meant to last only for a period of four years, these programs, which allow temporary migrants to be employed in different areas such as the hospitality and construction industries, are, at the time of writing, in their eighth year of implementation. Such programs do not intend to address short-term labor shortages in South Africa, as the nature of the work that permit-holders conduct is not temporary. Yet permit holders will be excluded from a pathway to permanent residency.

The fact that after a long period of time Zimbabweans are not allowed to graduate to a permanent legal status under the law indicates how recent policy interventions in South Africa aim to weaken 
the nexus between the continuous period of residence in the country and permanent residency. This contravenes Carens' $(2013,89)$ ethical principle that "the longer people stay in a society, the stronger they are morally entitled to the same civil, economic, and social rights as citizens, whether they acquire formal citizenship status or not." According to Carens' theory of social membership, the claim to membership grows over time and it is the length of residence, not the legal status that is the key moral variable. Moreover, democratic legitimacy rests upon the meaningful participation in civic life of the entire population, including temporary workers who have spent a large part of their lives in the country.

Temporary schemes such as the DZP, the ZSP, and the ZEP do not resemble European guest worker programs aimed at filling the demand for cheap labor which were abolished in the late 1970s. However, they introduce limitations on the right to change jobs and to access some work-related social programs.

Non-access to permanent residency, in fact, makes migrant workers more vulnerable and their "temporary status" creates barriers to a meaningful assertion to work-related and social rights.

The limitation of certain legal rights (e.g., right to vote or to hold high public office) is justifiable when temporary migrants are only permitted to remain for a limited time but not when temporary visas are renewed numerous times for multiple consecutive years. In this case, at some point, temporary visa holders should be converted into permanent residence and temporariness should come to an end. Non-access to permanent residency, in fact, makes migrant workers more vulnerable and their "temporary status" creates barriers to a meaningful assertion to workrelated and social rights.

\section{Recommendations}

Temporary labor schemes represent one of the most controversial topics addressed by the zero draft of the Global Compact for Safe, Orderly and Regular Migration, which was released by the United Nations on 5 February 2018. The following recommendations on these programs are drawn from the Now and How: TEN ACTS for the Global Compact document drafted by civil society and the 20 Action Points for the Global Compacts prepared by the Vatican Dicastery for Promoting Integral Human Development's Section on Migrants and Refugees.

1. Ensure that all migrants are protected by their countries of destination, in order to prevent exploitation, forced labor, and human trafficking. This can be achieved by prohibiting employers from withholding employees' documents; by ensuring access to justice for all migrants, independently of their legal status and without negative repercussions on their right to remain; by ensuring that all immigrants can open a personal bank account; by establishing a minimum wage applicable to all workers; and by ensuring that wages are paid at least once a month.

2. The integrity and well-being of the family should always be protected and promoted, independently of legal status. This can be achieved by embracing broader family reunification (grandparents, grandchildren, and siblings) independent of financial requirements; allowing reunified family members to work; undertaking the search for lost family members; combating the exploitation of minors; and ensuring that, if employed, minors' work does not adversely affect their health or their right to education. 
3. Strengthen the role of the International Labour Organization (ILO), in cooperation with other international agencies, to ensure public availability, transparency, accountability, and human rights norms and standards in bilateral, regional, and international agreements on labor mobility, rights, and decent work; ensure the implementation of these agreements; and ratify, implement and cooperate transnationally on the International Convention on the Protection of the Rights of All Migrant Workers and Members of their Families, as well as other human and labor rights conventions.

4. Ensure that all recruitment-related fees are borne by the employer, not the migrant worker; operationalize international standards and cooperation to regulate and monitor migrant labor recruitment and employment; and eliminate abuses of migrant workers and the use of forced labor in supply chains.

5. Enact national policies that provide foreign residents with access to justice, regardless of their migratory status, allowing them to report human rights abuses and violence without fear of reprisal, including abuses suffered in detention and deportation.

6. Access to welfare should be assured to all migrants, respecting their right to health and basic health care independent of legal status, and ensuring access to national pension schemes and the transferability of benefits in case of moving to another country.

7. Implement the SADC Protocol on the Facilitation of Movement of Persons, the draft Protocol on Employment and Labour, and the SADC Portability of Accrued Social Security Benefits within the Region Policy Framework.

8. Include provisions for low-skilled workers in regional labor mobility protocols and assure that labor migration programs guarantee full labor rights and protections for migrants.

9. Ensure that anyone who is allowed to remain in the country for more than a specific time is allowed to graduate to a permanent legal status. On this topic, the Zero Draft of the Global Compact for Safe, Orderly and Regular Migration falls short as it does not encourage the adoption of a pathway to permanent residency for all migrant workers.

10. As indicated by the Zero Draft of the Global Compact for Safe, Orderly and Regular Migration, temporary migrants should be allowed to change employers.

11. Adopt laws which allow for the regularization of status for long-term residents of the host country.

\section{References}

ACMS (African Centre for Migration \& Society). 2017. "Fact sheet on foreign workers in South Africa." Unpublished Report. Johannesburg: ACMS.

Amit, Roni. 2011. The Zimbabwean documentation process: Lessons learned. Johannesburg: ACMS.

Bell, Daniel A. 2006. Beyond Liberal Democracy: Political Thinking for an East Asian Context. Princeton: University Press. 
Bimha, Primrose Zvikomborero Joylyn. 2017. "Legalising the illegal: An assessment of the Dispensation of Zimbabweans Project (DZP) and Zimbabwe Special Dispensation Permit (ZSP) regularisation projects." Master's thesis, University of Cape Town.

Carens, Joseph H. 2008a. "Live-in domestics, seasonal workers, and others hard to locate on the map of democracy." Journal of Political Philosophy 16(4): 419-45. https://doi. org/10.1515/9781400827466.

. 2008b. Of States, Rights, and Social Closure. New York: Palgrave Macmillan.

. 2008c. "The rights of irregular migrants." Ethics \& International Affairs 22(2): 163-86. https://doi.org/10.1111/j.1747-7093.2008.00141.x.

- 2013. The Ethics of Immigration. Oxford: Oxford University Press.

Castles, Stephen. 2006. "Guestworkers in Europe: A resurrection?" International Migration Review 40(4): 741-66. https://doi.org/10.1111/j.1747-7379.2006.00042.x.

Castles, Stephen, and Derya Ozkul. 2014. "Circular Migration: Triple Win, or a New Label for Temporary Migration?" In Global and Asian Perspectives on International Migration, volume 4, edited by Graziano Battistella. Switzerland: Springer International Publishing. https://doi.org/10.1007/978-3-319-08317-9_2.

Deacon, Bob, Marius P. Olivier, and Reason Beremauro. 2014. Social Security and Social Protection of Migrants in South Africa and SADC. Johannesburg: ACMS.

DHA (Department of Home Affairs). 2017. "White Paper on International Migration." Policy Report. Pretoria, South Africa: DHA.

Fauvelle-Aymar, Christine. 2015. "Immigration and the South African labour market." MiWORC Working Paper 2. Johannesburg: ACMS.

Mares, Peter. 2017. "Locating Temporary Migrants on the Map of Australian Democracy." Migration, Mobility, \& Displacement 3(1): 9-31. https://doi.org/10.18357/mmd31201717071.

Mpedi, Letlhokwa George. 2011. "Code on social security in the Southern African development community." De Jure 44(1):18-31.

Johnson, Corey and Carciotto, Sergio. 2016. "The State of Asylum System in South Africa." In States, the Law and Access to Refugee Protection: Fortresses and Fairness, edited by Maria O'Sullivan and Dallal Stevens. London: Bloomsbury Publishing.

Jurgens, Jeffrey. 2010. "The legacies of labor recruitment: The guest worker and green card programs in the Federal Republic of Germany." Policy and Society 29(4): 345-55. https:// doi.org/10.1016/j.polsoc.2010.09.010.

Peberdy, Sally. 2001. "Imagining immigration: Inclusive identities and exclusive policies in post1994 South Africa." Africa Today 48(3): 15-32. https://doi.org/10.1353/at.2001.0060.

Ruhs, Martin, and Philip Martin. 2008. "Numbers vs. Rights: Trade-Offs and Guest Worker Programs." International Migration Review 42(1): 249-65. https://doi.org/10.1111/ j.1747-7379.2007.00120.x. 
Ruhs, Martin. 2012. “The human rights of migrant workers: why do so few countries care?" American Behavioral Scientist 56(9): 1277-93. https://doi.org/10.1177/0002764212443815.

UNGA (United Nations General Assembly). 2017. Report of the Special Representative of the Secretary General on Migration. UN Doc. A/71/728. New York: UNGA. http://www. un.org/en/ga/search/view_doc.asp?symbol=A/71/728\&=E\%20. 


\section{International Migration Policy Report}

In Search of Protection: Unaccompanied Minors in Italy

Pietro Demurtas

Institute for Research on Population and Social Policies, National Research Council

Mattia Vitiello

Institute for Research on Population and Social Policies, National Research Council

Marco Accorinti

Institute for Research on Population and Social Policies, National Research Council

Aldo Skoda

Scalabrini International Migration Institute

Carola Perillo

Fondazione Centro Studi Emigrazione - Roma

\section{Executive Summary}

This paper examines the issue of unaccompanied minors arriving in Italy and how Italy has responded to their need for protection. It contains five complementary sections. Section 1, authored by Pietro Demurtas, provides a statistical overview of unaccompanied minors in Italy between 2014 and 2017. In particular, it discusses unaccompanied minors who request political asylum, those in government reception facilities who do not, and those who have left reception centers without seeking asylum and have become "untraceable." The second section by Mattia Vitiello addresses why unaccompanied minors leave their countries of origin and how they transit to Italy and elsewhere. This section highlights the role of families in the decision to migrate and the migration process. It distinguishes unaccompanied minors who largely seek to "escape from" particular conditions from other migrants who are in search of a better life for themselves and their families. The third section by Marco Accorinti covers Italian reception policies and policymaking challenges, with a particular focus on implementation of Italy's System for the Protection of Asylum Seekers and Refugees. The section argues for reception procedures and interventions that are tailored to the particular vulnerabilities and needs of unaccompanied minors. Section 4, authored by Aldo Skoda, c.s., offers a psychosocial analysis of the phenomenon of unaccompanied child migration. It describes strategies to build the competencies, sense of agency, and 
resilience of unaccompanied minors. The final section, authored by Carola Perillo, details the demands and requirements of acting in the "best interests" of unaccompanied minors. It ends by setting forth minimum principles of protection for unaccompanied minors, which should inform both the Global Compact on Migration and the Global Compact on Refugees.

\section{The Arrival of Unaccompanied Minors by Sea}

Of all the migrants that have crossed the Mediterranean Sea in the last few years, children have been the subject of great attention because a large number of them are unaccompanied minors (UAMs). From January 1st to November 30th of 2017, 15,540 minors arrived in Italy unaccompanied by an adult responsible for them: 25,852 arrived in 2016, 12,360 in 2015, and 13,026 in 2014 (Figure 1).

Of all the migrants that have crossed the Mediterranean Sea in the last few years, children have been the subject of great attention because a large number of them are unaccompanied minors...

Figure 1. Adults and Minors Who Arrived by Sea to Italy in 20142016 (numbers on the left and percentage on the right)

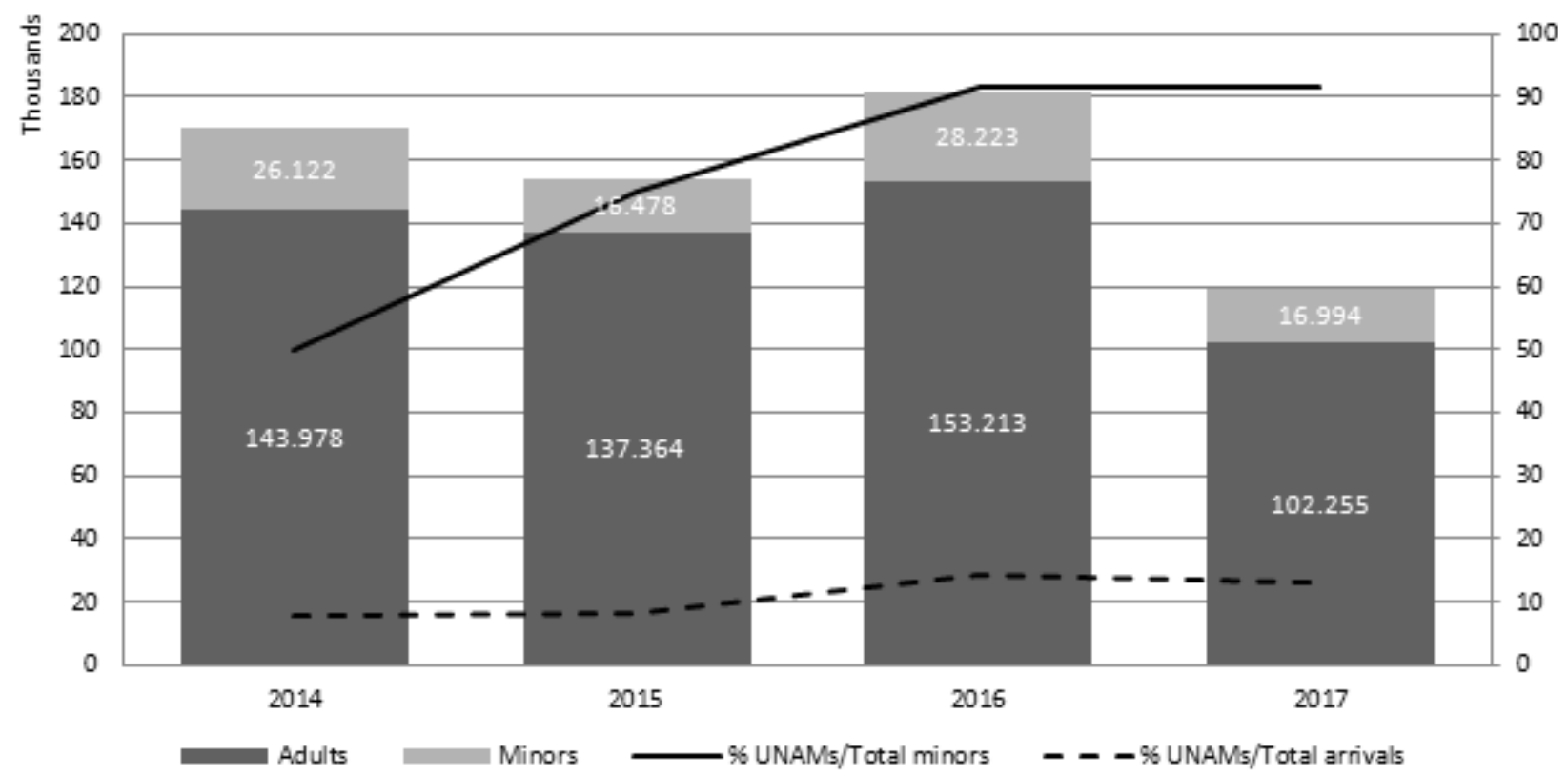

Source: National Research Council - Institute for Research on Population and Social Policies. Elaboration based on United Nations High Commissioner for Refugees (UNHCR) data.

In order to limit the influx of entries by sea, in the summer of 2017, Italy introduced a code of conduct that limited the scope of action of nongovernmental organizations providing rescue and relief, and which led Italian ships to flank the Libyan Coast Guard. Statistics from the UNHCR 
(2017) demonstrate the consequences of such measures: by the end of June 2017, the number of migrants reaching the Italian coast exceeded that of 2016 (+19 percent), while subsequently there was a reduction of -68 percent by November 30th. However, despite a small decrease in the number of unaccompanied minor arrivals in comparison to 2016, the number of arrivals in 2017 was still higher than in 2014 and 2015.

Recently, there has been a decline in the number of Eritrean minors arriving in Italy; meanwhile, there has been a definite increase in the recent years of those arriving from West Africa (in particular, Guinea, Côte d'Ivoire, and Gambia). This goes hand in hand with a large number of young migrants coming from Bangladesh (Figure 2).

\section{Figure 2. Unaccompanied Minors Who Arrived by Sea to Italy in} 2014- 2017* by Country of Origin (numbers at the bottom)

* Up to November 30th, 2017.

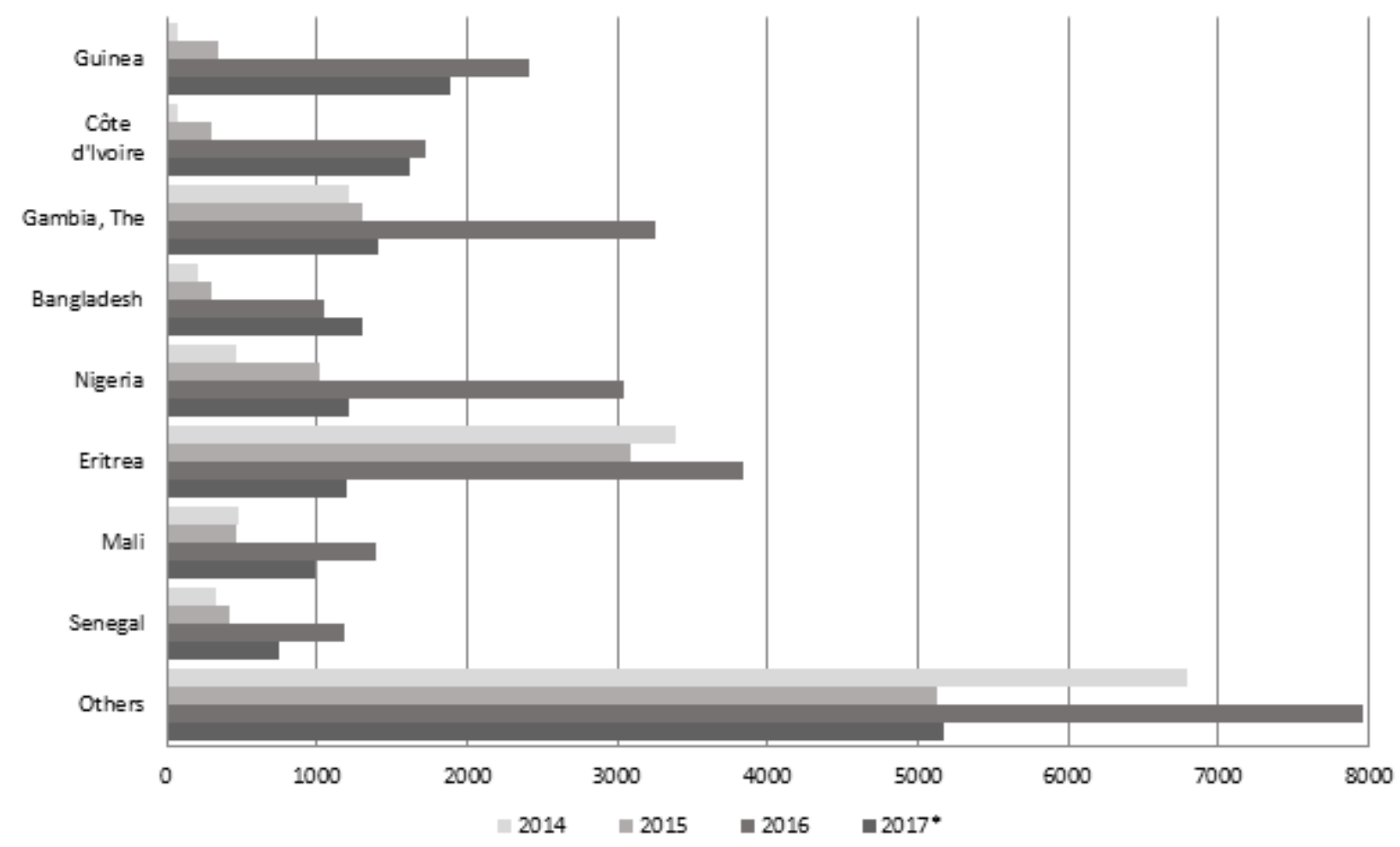

Source: National Research Council - Institute for Research on Population and Social Policies. Elaboration based on UNHCR data.

To better understand the situation of these young persons in detail, on the basis of the statistical data, a distinction can be made between those who request international protection and those who do not. 


\subsection{Unaccompanied Minors Requesting Asylum}

In 2016, Italy was the second most popular destination among the European Union (EU) countries for unaccompanied minor migrants, with 6,020 applications for asylum; the most popular EU member was Germany, with 35,935 requests. Figure 3 illustrates the countries of origin of unaccompanied minors requesting asylum in Italy. It demonstrates an increase in requests for asylum from African minors, particularly those from Gambia, Nigeria, Guinea, and Côte d'Ivoire. Statistics from 2016 reveal that many of them are on the verge of reaching the age of 18; in fact, 16- and 17-year-olds constitute about 93 percent of the total. Furthermore, boys and young men constitute the majority (95 percent of the total), although there are some nationalities in which girls and young women constitute a much larger percentile. In the case of Nigeria, for example, females represent approximately 23 percent.

\section{Figure 3. Asylum Applications Submitted by Third Country National Unaccompanied Minors in Italy in 2014-2016 (numbers at the bottom)}

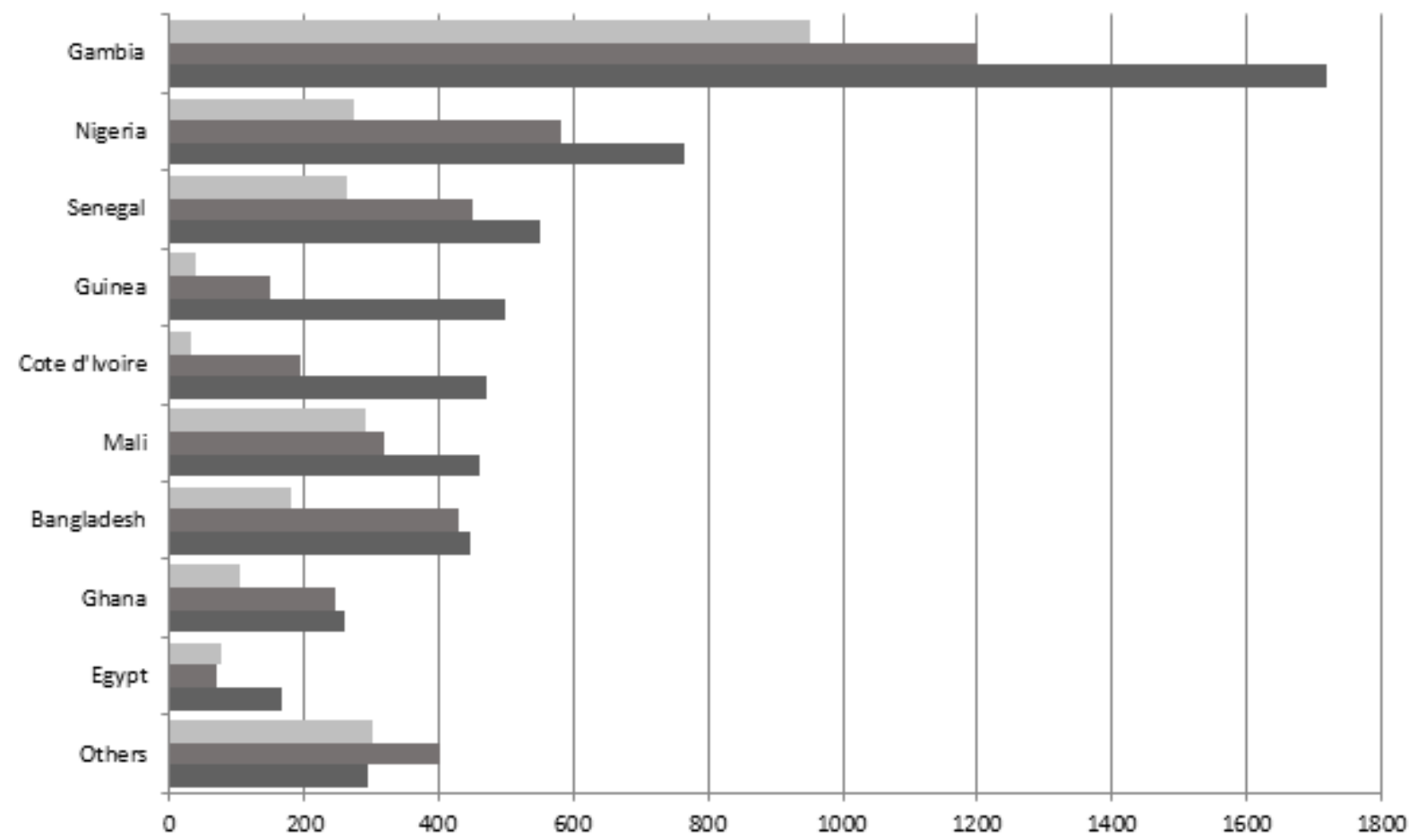

Source: National Research Council - Institute for Research on Population and Social Policies. Elaboration based on EUROSTAT data.

In Italy, unaccompanied minors applying for asylum and those entitled to international and humanitarian protection find refuge in reception centers under the System for the Protection of Asylum Seekers and Refugees (Italian: Sistema di Protezione per Richiedenti Asilo e Rifugiati [SPRAR]). Statistics show that 2,898 unaccompanied minors were accommodated in reception centers in 2016; 1,640 in 2015; and 1,142 in 2014 (SPRAR 2016, 2017). A majority of these cases were minors requesting asylum, but in the recent years the percentage of these minors has decreased: in 
2014, asylum seekers constituted 85 percent of the population while in 2016, they represented only 46.8 percent. In Italy, the latter category constitutes a substantially large group of persons, but only recently have things moved towards a single reception system, capable of overcoming disparity in treatment of minor migrants requesting asylum and those who do not (this was done earlier with the passing of Law 190/2014, and subsequently with Law 47/2017).

\subsection{Unaccompanied Minors Who Do Not Present a Request for Asylum}

Unaccompanied minors arriving in Europe without a residence permit and not applying for asylum are considered irregular migrants by most EU member states. This explains the lack of official statistics regarding these minors (EMN 2015, 2016). However, Italy has developed a reception system that provides support for unaccompanied minors. Generally, this work falls to the Ministry of Labor and Social Policy, which registers their presence and provides statistical data on them. On the other hand, these migrants are not always interested in or have the possibility of entering into the Italian reception system and therefore remain undetected. In other cases, unaccompanied minors decide to voluntarily leave the reception system, which is perceived as being unresponsive to their migration needs and, in this way, they elude the system. Of those uninterested in entering the system, there is no further information regarding them. For those who distance themselves from the system, the meeting/clash with Italian institutions leaves behind a record of their presence. Therefore, they are counted among the official statistics.

Unaccompanied minors arriving in Europe without a residence permit and not applying for asylum are considered irregular migrants by most EU member states.

Over the last several years, the number of unaccompanied minors in reception centers has increased, albeit at a slower rate in 2017 than in 2016 (Figure 4). In 2015, the number of persons who left these facilities and can no longer be traced increased, followed by a smaller increase in 2016 and a decrease in 2017. The most recent decrease can be explained for two reasons: first, that database procedures periodically eliminate migrants who have reached the age of 18 from the system; and second, there has been a decrease in the number of persons arriving at centers in the last year.

As of November 30, 2017, unaccompanied minors in reception centers not seeking asylum were mostly between 16 and 17 years old (83 percent), and the majority of them were male (93 percent). However, it should be noted that young women and girls - although a minority - are particularly at risk: 43 percent of the girls in the centers are Nigerian, and have been considered in the past of being at risk of sexual exploitation (UNICRI and PARSEC 2010).

Regarding the total number of those present in reception facilities, Figure 5 illustrates that, in recent years, migrants coming from Egypt were the largest group but, as of 2017, those coming from countries in West Africa (particularly Gambia and Guinea) have become the majority. 
Figure 4. Unaccompanied Minors Not Seeking Asylum in the Care of Italian Public Authorities, and Those Who Are Reported as Missing in 2014-2017* (numbers on the left and index numbers on the right)

* Up to November 30th, 2017.

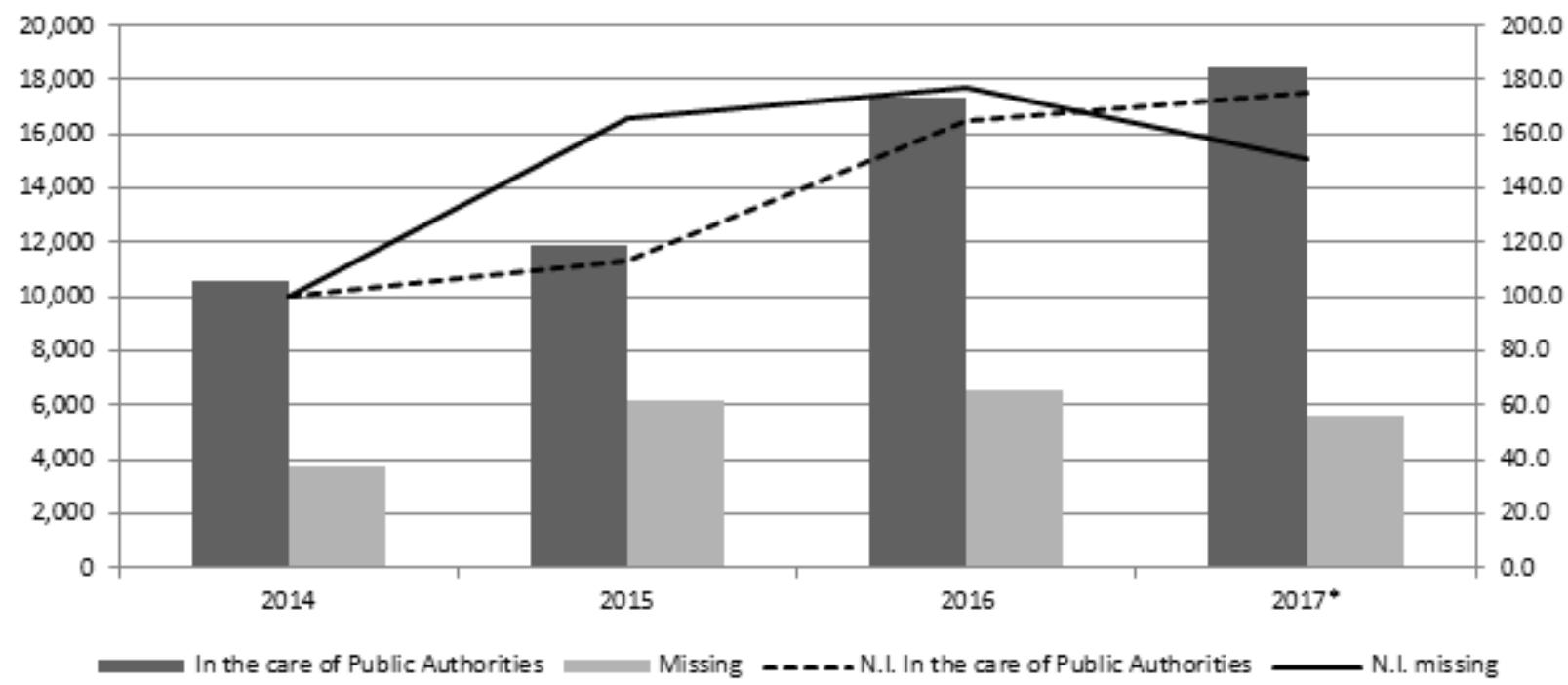

Source: National Research Council - Institute for Research on Population and Social Policies. Elaboration based on data of the Ministry of Labor and Social Policy, Italy.

Figure 5. Unaccompanied Minors Not Seeking Asylum in the Care of the Italian Public Authorities by Country of Origin in 2014-2017* (numbers at the bottom)

* As of November 30th, 2017.

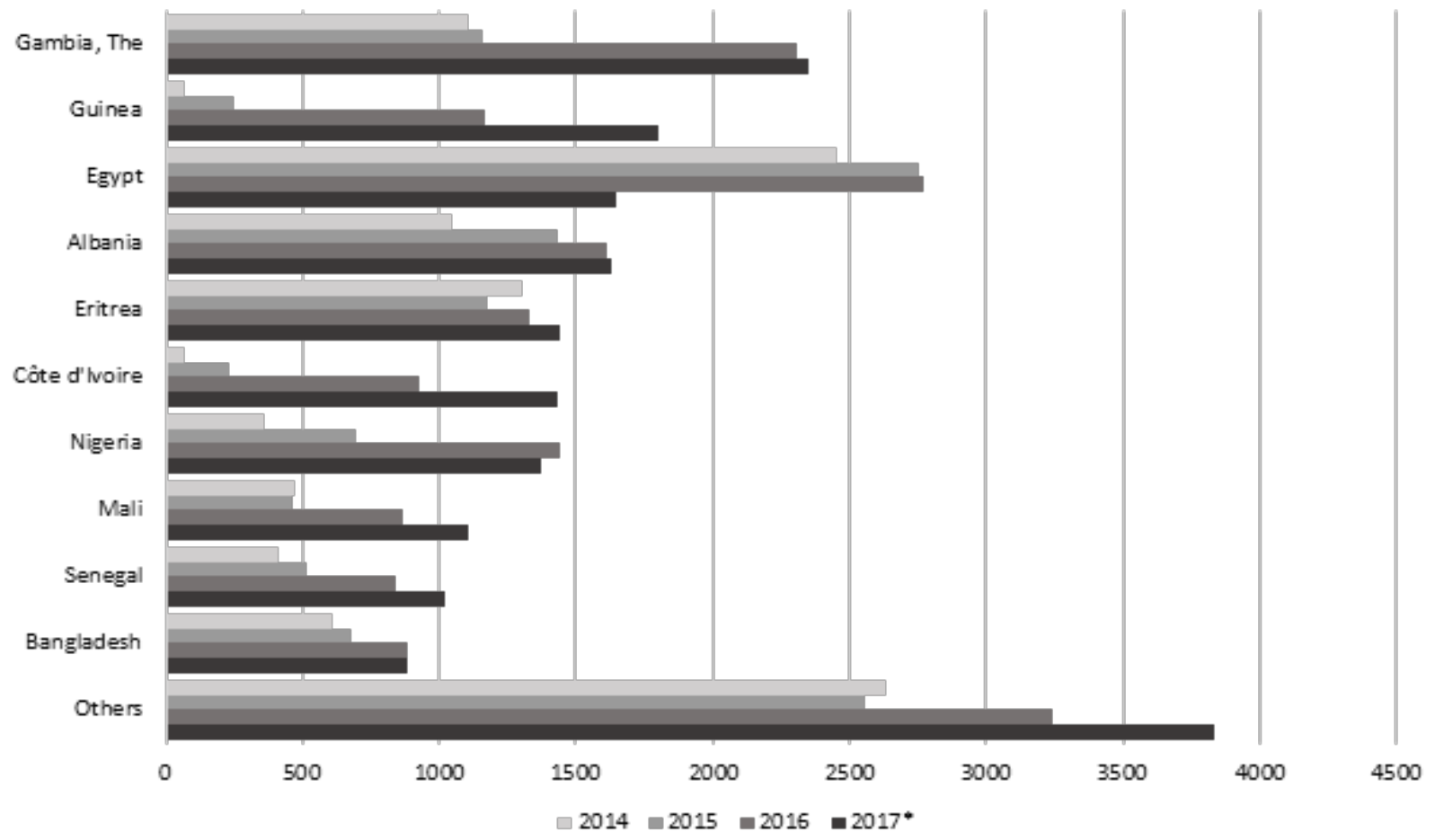

Source: National Research Council - Institute for Research on Population and Social Policies. Elaboration based on data of the Ministry of Labor and Social Policy, Italy. 
It is an open question why minors have left reception centers and not sought asylum. It is possible that they are directed to other European countries, or that they consider the reception programs a restraint to their plans, i.e., they may have more urgent needs of a financial/economic character. The data available makes it possible to observe a large number of Eritrean, Somali, and Afghan nationalities, which are particularly represented among asylum seekers in other EU member countries (Figure 6). Unlike the Egyptians, who are often seen as economic migrants, it is plausible that the minors coming from these countries have disappeared in order to continue their migration to another country, with the intention of presenting a request for asylum in another EU member nation, thus evading the Dublin Regulation requirements.

It is an open question why minors have left reception centers and not sought asylum.

\section{Figure 6. Unaccompanied Minors Not Seeking Asylum Reported as Missing from the Italian Reception Facilities by Country of Origin in 2014-2017* (numbers at the bottom)}

* Up to April 30th, 2017.

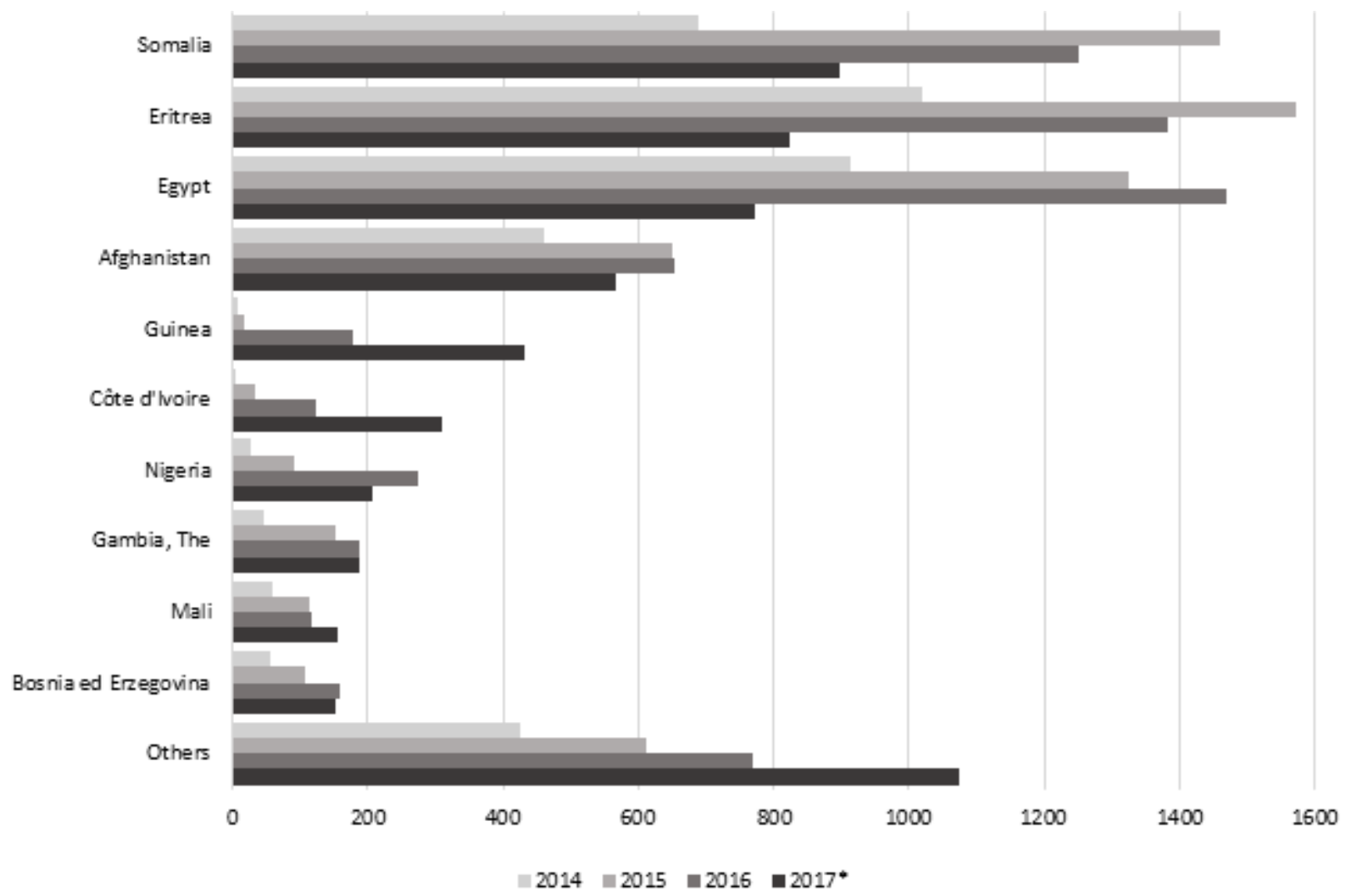

Source: National Research Council - Institute for Research on Population and Social Policies. Elaboration based on data of the Ministry of Labor and Social Policy, Italy.

The profiles of unaccompanied minors set forth in sociological literature focus on their motivations for leaving home and the vicissitudes of their travels. For example, there are references to 
exiled young persons, those sent on the journey by their parents, those who run away, or those who are exploited or are itinerant (Etiemble 2000). Others are attracted to the lifestyles promoted by mass media. Some are driven away by the social decay in their countries of origin (Giovannetti 2008). Additional considerations - raised by qualitative research - will be discussed below.

\section{Why and How Unaccompanied Minors Leave Their Countries of Origin, and the Journey They Undergo}

The decision to leave one's family and social context is not an easy one. Neither is the decision to permanently leave behind the affective and social relationships that accompanied an individual's emotional and physical growth (cf. interviews in CNR-IRPPS and UNICEF 2017). It is not the fruit of a simple decision made in solitude, but the result of discussion and confrontation with family and loved ones. Most of the time, it is the first step in the family's strategy to meet arising needs, to be able to escape a crisis, or to improve their own situation. But even in these cases, the choice is not made through a simple rational calculation of the costs and advantages of such a decision. There is always an element of emotion, derived from everyday life, which imposes an emotional burden and often acts as a decisive influence towards the decision to migrate. This complex system takes an even more intricate form in the case of unaccompanied minors. The migrant's families often play the decisive role not only in the decision to leave, but also in preparation for the journey, and in the choice of destination. But it is also true that, in many cases, the family may play a minimal role, if not a negative one, in that they may be central to the situation that the young person wishes to escape, or may be the principal factor for migrating.

The decision to leave one's family and social context is not an easy one.

Socioeconomic change, caused by unequal or poorly managed development, can be a migration push factor. Often, low- and middle-class families are overwhelmed by such changes and cannot adapt to the new situation. In such a scenario, the family and the family bonds and surrounding settings can assume a fundamental role in the migration decision. The child's departure is seen as an investment and the success of the migratory project represents an accomplishment and the social promotion for the entire family. The family often chooses the eldest son, who most likely has already finished the obligatory schooling and whose study can no longer be sustained.

Such a migratory model of minors can be called the "in the search of" model. First, it is strongly characterized by the desire to work. In these cases, to have a job means to earn, to be autonomous, and to be able to help the family. A certain agreement can be observed between the parents and child regarding the undertaking of such a migratory project, presented in terms of an "investment" (of the parents) both financially and affectively, and a source of hope for the entire family. These are families who are trying to adapt to social and economic changes, and who are only able to do so and remain together through a strategy of coping, which anticipates the emigration of one of its own members. In other words, to escape the process of destitution and disintegration, the family invests one of its own members onto the path of migration. In this way, minors come to the decision to leave their homes, in agreement with their parents, near the age of 16, i.e., at the end of their obligatory scholastic preparation. For many of the minors inter- 
viewed who arrived in Italy, the choice of the country of destination was made by taking into consideration geography, as well as the past history and present situation of Italy. The Italian Republic is located in the Mediterranean Sea, and found in the midst of three different continents (Europe, Africa, and Asia). Italy is seen as a bridge, since it allows migrants to pass from one continent to the other. There exists a widely diffused "know how" of how to reach the peninsula, just as there is a broad knowledge of the various routes. The offers of passage to Italy are as vast as the Mediterranean Sea. This keeps the cost of the journey manageable. It is a rational choice based on the relation between resources and goals, and a calculation of cost and opportunity.

There also exists a different type of migration model of unaccompanied minors whose departure is seen more in the terms of "an escape from." Such an escape can be understood as a search for better opportunity but, as is in many of these cases, the strategic dimension of investment is lacking. This is not a decision made through rational choice, but rather the decision made in order to escape a specific situation or family difficulty, in order to run away from a realistic and genuine danger. Here, the arrival in Italy is most often the fruit of circumstance rather than conscientious choice. The conditions, aspirations, and objectives that give rise to migration by unaccompanied minors suggest that their migration is often forced. These conditions range in a continuum between those leading to economic migration and those creating a need for international protection. Elements from both realities mutually intertwine.

The migrants in this second (economic) model differ from those of the first because difficult relations and economic deprivation essentially mark their family situation. In this context, the family loses the ability to adapt to changes beyond their control and to plan for the future. And it is in such a situation that the child's departure is not only practical, but also preferable and, as such, is implicitly accepted by the entire family. For the young person, running away from such an unbearable home situation is the lesser of two evils; meanwhile, for the family, it is one less thing to worry about - if they are even worried about it, at all. It is a solution accepted by everyone with relief. It must be emphasized, however, that the choice of migration in this case is an escape rather than a departure, and the choice of destination is always a neighboring country. The choice of Europe or Italy as the ultimate destination of emigration is slowly demarcated as the journey continues.

The journey (that is, the route undertaken by migrants to reach their destination) assumes an important role in what will happen after arriving in the final country of destination; even if, among all the events that constitute the various links in the chain within the migratory process, the journey itself is seen as the least important.

Among the many factors that play a role in the configuration of the journey, the number of border crossings is probably the most significant. The more border crossings the journey contains, the greater the chance of being caught. In addition, more border crossings mean an increase in the number of mediators or passeurs necessary to make the journey. Therefore, the price of the journey and its risks increase in relation to the number of border crossings and the specific countries that the migrants find themselves in and which they must cross during their journey.

The length of the border and the points of crossing render the migrant vulnerable and exposed to violence, abuse, exploitation, and human trafficking. The journey can itself be seen as a vulnerability and can increase one's defenselessness, especially that of minors. 
Within the migratory model defined as "an escape from," the potential vulnus that the journey itself can have on a minor is profoundly significant. The events and the experiences of the journey itself lead them to choose Italy as the destination of their journey without it being the exact destination of choice of the minors. More often than not, they would never have considered such a possibility since they generally have little knowledge of the Italian Republic.

\section{The journey can itself be seen as a vulnerability and can increase one's defenselessness, especially that of minors.}

For example, the long journey of child migrants from West Africa is often fragmented into shorter segments, defined by destination cities in which they pass from the hands of one passeur to another. The names of these cities recur in the various accounts and reflect the routes already undertaken by other travelers. During the crossing between Niger and Libya, for example, child migrants are completely at the mercy of border control officers, who are often inclined to corruption. These stops in the journey are the longest, and their duration is dependent on factors beyond the minor's control, and even beyond the control of their guardians and passeurs. During these stops, the child often must work in agriculture or other services. It is probable that, for this reason, the duration of a migrants' stay in Libya keeps getting longer, as it probably plays a role in the functioning of the country's economy.

Such long stops in the journey between one destination and another, spent in countries such as Libya where there are no well-defined laws and the "survival of the fittest" seems to be the dominant law in effect, are often filled with violence and exploitation that are constitutive elements in the experience of the minors interviewed. For a child, even a few months spent in complete affective and existential precariousness can never be seen as a simple parenthesis in their lives, and neither can the weight and burden that these months have on them at such a young age.

Dramatic events, such as the death of a father in Libya during a theft (which left a 15-year-old accompanied minor alone), or the loss of a brother companion forced to climb into another car solely because there was no room and who was never seen again, are the kinds of events that shape the migratory journey.

\section{Reception Policies, Pathways, and Challenges for Policymaking}

The reception of unaccompanied minors in Italy as of 2017 closely tracks the series of institutional interventions set forth in the National Plan of Action to Face the Extraordinary Flows of Non-EU Citizens, Families, and Unaccompanied Minor Migrants (Italian: Piano nazionale per fronteggiare il flusso straordinario di cittadini extracomunitari adulti, famiglie e minori stranieri non accompagnati) and approved by the Unified Conference, an Italian legal institution, on July 10, 2014.

The last three years, in fact, have been characterized by a new approach in reception: The Ministry of the Interior is responsible for organizing the reception process regarding unaccompanied minors, surpassing the way previous legislation distinguished unaccompanied minors seeking asylum from those not seeking asylum. ${ }^{1}$

1 About 8,000 were received in Italian municipalities during this period. 
There are now four principal guidelines for the reception of unaccompanied minor migrants:

1. create highly specialized facilities to assess identity, age, and status, in order to speed up any possible reunification with family members already present in other EU member countries;

2. adapt national procedures for the immediate reception of minors;

3. increase the number capacity of the System for the Protection of Asylum Seekers and Refugees (Italian: SPRAR) in order to guarantee the reception of minors requesting asylum and those who are not requesting it; and

4. boost and finance the second level of reception of all unaccompanied minor migrants in the context of SPRAR, extending them the possibility of receiving training or professional education.

The system, confirmed by Law $142 / 2015$ and more recently by Law $47 / 2017$, specifically concerns unaccompanied minors, and attributes and strengthens the role of the Ministry of the Interior in the governance of unaccompanied minor migrants. Previously, this role was given to the Ministry of Labor and Social Policy. Among other things, the Ministry of Labor and Social Policy financed reception centers, and is still responsible for the Information System on Minors that monitors their presence and tracks their movement and location in Italy.

Despite this change, the reception process is still not fully structured or well-defined. At the end of 2017, the system had 1,000 spaces available for the first reception: these can be found in 70 structures financed by the Asylum, Migration, and Immigration Fund (Italian: Fondo Asilo Migrazione e Integrazione [FAMI]) of the Ministry of the Interior. It also had more than 2,000 places for the second phase within the System for the Protection of Asylum Seekers and Refugees network. Such numbers do not allow Italy to approach the current migration phenomenon from a strategic perspective, but rather force all stakeholders to resort to emergency procedures, which generally are ill-governed, heterogeneous, and financially inefficient.

According to statistics provided by the National Association of Italian Cities (Italian: Associazione Nazionale Comuni Italiani $[\mathrm{ANCl}]$ ), the majority of minors are received into facilities affiliated with local municipalities, rather than facilities organized within the System for the Protection of Asylum Seekers and Refugees. From a social policy standpoint, this type of approach is heterogeneous, even if participants adhere to uniform procedures regarding "admission," appointment of the guardian, reporting to competent authorities, requests for residence permits, assessment of age, and contact with the family of origin (cf. Giovannetti 2016; Giovannetti and Accorinti 2017, among others). The difficulty in identifying a single model of intervention lies in the strong dynamic and continuing evolution of the current migration phenomenon, as well as in the various approaches structured at the local level. Such approaches are more dependent on the relationship and interaction of the actors involved in the care of the minor, rather than being determined by protocol and common methods.

Governmental facilities have been modified. Above all, the various Italian governing bodies have sought to approach the phenomenon by conforming to the existing system for unaccompanied minors requesting asylum. They have created a specific structure within the Ministry of the Interior, and required the prefectures to open 70 facilities of an "extraordinary" character (the 
so-called "CAS minori"), financed by the same ministry. Italy's commitment not to deport unaccompanied minors remains strong, as is a similar commitment that public officials, public service officers, and entities that carry out acts of assistance must - upon becoming aware of an unaccompanied minor - immediately take action and accompany the child to a reception facility.

On the other hand, the most recent legislation has led to the decision to sustain the sectoral policy and has promoted a culture of emergency, as manifested in the opening of CAS facilities without a common directive in terms of the standard of reception and insertion. Such an approach seems to respond more to an organizational dimension in which the child is considered a "migrant" rather than a "minor." From the perspective of a culture of social intervention, this is an important step that seems to forgo the past approach of the social service sector, where things moved slowly away from large and institutionalizing structures, and from opaque and generalist assistance projects.

In the reception facilities, minors are guaranteed every form of protection and care in their best interests, such as room and board, but also an assistance project that includes linguistic formation, education and professional training, health care, and primary socialization. Those placed in centers or in foster families can access the education, formation, and national healthcare systems, and can receive support defined by their legal status - that is, a residence permit for minors, classification of their asylum application, and recognition of their qualifications. They can take advantage of work orientation and socioprofessional integration. ${ }^{2}$ Usually, these types of interventions are managed by those in charge of the facilities where the minors are housed under the coordination of the Social Services division of the local municipality, which typically serves as the child's legal guardian.

Often, however, the educational program conflicts with the expectations of the child and their desire to send funds home as soon as possible in order to pay off the debts incurred for the trip. The minors themselves do not only express such an expectation but so do their families, with whom they have constant contact via modern communication technology and Internet (e.g., chat, blog, Facebook, Whatsapp, Skype, Viber, etc.). As a result, the minors abandon the offered education in order to "work" as handymen, in the kitchens of restaurants, at carwashes, doing physical labor at markets, and picking fruit on farms, completely naive to the fact that they are being exploited by their employers who are often fellow countryman or distant relatives. Exploitation can also take the form of abuse and trafficking, which is a particular risk for young girls. For unaccompanied girls, the rule of law is suspended and a different ethic takes its place: to live, they must learn to suffer violence and oppression on a daily basis.

Furthermore, field research reveals that proposed types of reception do not necessarily correspond to the needs of the children. This can be seen in the fact that the children voluntarily decide to leave the facilities in which they were received. As was indicated in the first section of this paper, "untraceable" minors who have disappeared from the system are those who, by their own initiative, run away from the care offered by the state and throw away the opportunity of finishing the process of their integration and regularization once they reach the age of majority (among others, cf. CNR-IRPPS and UNICEF 2017).

2 In this regard, mention should be made of the initiatives of the Ministry of Labor and Social Policy regarding "aid" and job grants. 
Today's situation is motivating Italian authorities to propose more practical methods of intervention that would entrust minors to fellow nationals in Italy. Other measures include the prevention of the premature departure from reception centers, cultural mediation, peer education, assisted repatriation, and training border law enforcement agencies to identify victims of trafficking. This course relies on solutions that have demonstrated some difficulties but have proven their potential, and could change the course of imposed homogenization, which is still creating problems in the coordination of the different types of facilities, either in the provision of the services provided or in the guarantee of the time required for first reception and assessment of age.

It is necessary to consider how to engage all actors involved with unaccompanied minors, so as to activate procedures of reception suited to the needs of this specific group, and which considers the use of more personalized interventions that take into consideration their additional vulnerabilities, such as psychological distress, exploitation, and trafficking.

\section{Psychosocial Analysis of the Phenomenon of Unaccompanied Minors}

Migration is a process with inevitable repercussions on the well-being of persons, and which requires the redefinition of one's own identity and values, as well as the reconstruction of personal, human, and social biographies. This process can include the loss of a point of reference, experiencing inadequacies in human relations, and undergoing social distress. Under certain aspects, migration - as a complex process - is to be considered a traumatic event for the one who experiences it, especially if that migrant is a child. The separation from one's own living environment, from adults of reference, from peers, and from all the relationships that constitute a secure basis for the development of personal and social identity, can become a difficult ordeal for the psychorelational balance of a child.

To take into consideration the whole migratory journey and to go beyond the current moment that the individual is in means to undertake a space-time exploration which is capable of revealing the "why," the "how," the "when," and the various subjective and objective meanings given to emigration as an event and, consequently, in the re-elaboration of these meanings.

The accounts of many unaccompanied minors include stories of mistreatment, exploitation, journeys through unknown territories, delays in calamitous places, and the presence of ambiguous persons. They are stories that have in common the failure to have the status of children recognized and, as such, their need for care and protection from the adult world. Such events, which demonstrate sociostructural fragility of identity, can be a source of stress or even trauma with long-term consequences.

Many authors speak of a process that can be traced back to the dynamics of mourning, in which the processes of support, elaboration, and reconstruction of past traumatic events must be revisited. In order to develop a process of support, elaboration, and reconstruction, it is necessary to take into consideration the various individual and environmental factors of the migrant - that is, the specific child in question and the situation into which they are inserted.

It is important to consider the dynamics of competency and self-efficacy, which can be seen as 
the foundation of resilience. The concept of competence is an essential element in the theory of personality. It reflects the multiple capabilities of the individual to face problems and to tackle the changing circumstances of life, which include the challenges present in their current situation. These skills reflect not only what we know and therefore transmit (declarative knowledge), but also our habits and the other types of skills that a person naturally puts into action at the right moment (procedural competence).

Of course, it is the situation that determines whether or not a competency is useful or not. Some skills are crucial in one context; in others, they become irrelevant since different contexts present different challenges and require different skills. In addition, the migrant's response to his or her context and the change that this response brings is crucial to his or her well-being. Certain skills are gained after social interaction and observation of the sociocultural world. Certain abilities, which the individual did not possess previously, are learned through new interactions; the change corresponds to the needs and requirements of the context. That is why social agents must procure both intercultural and mediation skills, and why minors who are migrating must be placed in conditions in which they can learn to live and appreciate individual and cultural diversities in such a way so as to acquire specific skills in intercultural dialogue. For social agents, this means acquiring professional skills; for minors in transit, this means acquiring skills in building positive relationships, acceptance, friendship, sharing, and integration.

Under this analysis, we consider self-efficacy alongside competence. Often, people fail to attain certain goals even though they possess the necessary skills, or they simply do not engage themselves intellectually or relationally in new challenges. Self-efficacy is a person's perception of their own ability to act in a situation or to influence the course of events by modifying certain variables, both external and internal. Many studies have demonstrated that people with a higher level of self-efficacy show more curiosity towards new stimuli, tend to react in a positive way to failure, and prepare and choose behavioral strategies that are more appropriate to the context with respect to people with lesser self-efficacy.

In addition to being determined by personal skills and competencies, self-efficacy is also the result of social interaction and the feedback that an individual receives. It serves as the basis for the success or failure in carrying out certain tasks. Verbal, behavioral, affective, and relational stimuli are fundamental for the child's discovery of his own capabilities. Encouragement and stimuli are a strategy to overcome certain failures and personal trauma. For example, if an individual is separated in certain activities on the basis of his alleged cultural or ethnic diversity, or on the basis of his initial poor performance due to the novelty of the context, this could create a situation in which the child, and those with whom they share their relational context, matures in the belief of their own low self-efficacy. These subjective perceptions directly influence a person's self-image and their behavior. For unaccompanied minors, this process becomes even more consequential, not only in reference to the journey, but also to the relational dynamics that are formed with this context and which provide positive or negative feedback.

Finally, all this translates into a process of stimulation and strengthening of resilience, understood as the ability to resist, overcome, and thrive after much adversity. Resilient individuals have the sensation that they are able to control their fates, even if this destiny has given them a devastating blow. They react and respond with what they possess, and use the situation constructively. It 
is not just personal traits and lifetime experience that affect resilience, but - once again - the dimensions of social relations established within that context which can assist in situations of hardship.

Various forms of racism or other types of discrimination in the host society can diminish selfesteem and the ability of minors to develop a coherent and positive sense of self. The experience of failure in socialization or the lack of social inclusion (e.g., scholastic inclusion) worsen the migrant's overall situation. Perceived discrimination is a factor of psychosocial stress, with negative implications for the psychosocial health of these minors, and one that will have an impact on their adult life. Many studies distinctly illustrate the negative effects of discriminatory behavior or attitudes on mental health, which can take the form of depression, social withdrawal, and even juvenile delinquency.

Various forms of racism or other types of discrimination in the host society can diminish self-esteem and the ability of minors to develop a coherent and positive sense of self.

The contextual factor is just as important, since it is intrinsically tied to the individual one. A tendency towards a more integrated system in which the individual is seen in reference to the various relational networks in which they are inserted appears to be a more advantageous way to deal with complex social situations and phenomena, particularly those related to the migration of unaccompanied minors. Such a vision has at its core a specific environmental analysis (ecosystem) of the milieu in which the individual is placed. This is even more relevant in reference to children, for whom the relational dimension is constitutive. When it comes to working with minors on the move, the influence of the physical and social surroundings on their behavior and the interdependence between individuals within the context of specific social groups (understood as communities) are aspects requiring the attention of both agents and institutions.

Changes in self-perception - that is, in the perception of one's own effectiveness and competence - is the result of a co-construction of rich and solid histories. This requires the establishment of a relational stability to the situational context, so that this relationship forms the solid base on which it is possible to promote the personal growth of minors by increasing their confidence in the future. By demonstrating with approval and acceptance the success they are able to achieve, new and more complex life goals become more desirable and attainable to them.

The environmental factor takes on a real and transformational relevance only if it does not intensify dysfunctional models already interiorized by the minors themselves. Their unwavering need to survive and to overcome difficulties is expressed in both an asserted autonomy and their intolerance to the rules of the adult world, with which they find it difficult to establish bonds of trust and to which they may respond with social withdrawal and even violence. For this reason, the presence of specialized agents knowledgeable in the socio-cultural context of the country of origin and the dynamics of psychosocial development are the basis for establishing a meaningful, trustful and strong relationship. The milieu is therefore structured as a place that welcomes, protects, cares, promotes, and integrates. 
The host community must be formed in the light of the best interests of the child, and with particular attention to the individual needs of each child. Overcrowded communities that disperse attention and the continual change of figures of reference naturally lead to disengagement. Only in a nurturing community will everyday life assume a structural meaning, capable of supporting in minors processes of constructive self-consciousness, of strengthening their own identity, and of relating to the surrounding reality.

Everyday life is a world of habits, of what is common, of the continual relationship with meaning, objective, and relations. Everyday life is, and must be, built in an assuring way so as to be foreseeable and capable of supporting a regular rhythm, and creating a recognizable and perceptible equilibrium at the mental level. Such dynamics contribute to the strengthening of a minor's empowerment and to their participation in the social context in which they have been inserted. Often, the relational dynamics are defined not so much in terms of true negotiation processes, but rather in terms of relationships based on strength which are determined by age of the interlocutors, social status, and access to the institutions where decisions are made. Individual stories may vary, but during the migratory process, minors are at the mercy of other adults and have little decision-making power even with regards to simple things such as when to sleep or eat. To demonstrate this better, psychology uses the term "empowerment," which in Italian literally means "an increase and growth in power."

To empower means to restore subjectivity and individuality, but also to restore the ability to see one's self as an actor in a relational context in which personal and social identity can be strengthened. As a result, the concept of participation refers to the commitment and responsibility of the individual within a relational context geared towards achieving a collectively determined goal. It is a process in which the subject actively takes part in the decision-making process and the dynamics that concern them or in which they are involved. Participation brings about in the child openness to collaboration and cooperation, stimulating changes at the cognitive (amendment of stereotypes), affective (perceptive), and active levels.

\section{Recommendations for the Protection of the Human Rights of Unaccompanied Minors and Young People Coming of Age}

The phenomenon of unaccompanied children and young people who become adults after arriving in Europe calls into question not only juridical/legal, policy, and governance issues, but first and foremost, ethical and social considerations (Di Lorenzo 2014; Human Rights Council 2016).

There is a substantial body of law and standards on minors in matters of asylum and migration at the international level, and it has been integrated into European legislation. EU legislation recognizes children as applicants for international protection in their own right and defines procedural guarantees and protection measures. The most recent proposals attempt to address the gaps identified in current legislation like the need for a revision of the principle of the "best interest of the child"; the need for more effective protection and treatment provisions; the need to protect minors from the moment of their arrival; and the need to train staff (including those of border agencies) who directly interact with children. 
The "best interest of the child" is the guiding principle of all the legislation regarding child protection, and it ensures that, in all decisions concerning minors, the legislator or adjudicator takes into account the child's best interests. Therefore, every judicial decision is geared towards promoting the psychophysical well-being of the child, and privileging those aspects that are more favorable for their balanced growth and development. This rule demands that the rights of adults must yield to the rights of children.

The rights of adults, with regards to family, acquire a "functional" scope for the protection of the child (who is the weaker subject within the relationship), and therefore in need of greater protection. The unaccompanied minor experiences traumatic fragility due to separation or the events that have shaped their situation, and therefore requires a higher level of protection.

Whether one takes into consideration the country of origin, country of transit or that of destination, it is necessary to adopt an unambiguous approach to the human rights of minors and to assume shared responsibilities at the European level for their protection. Human rights of children are not proper only to one nationality, and nor do borders define them. The "best interest" of the child constitutes a basic standard in the decision-making process and in actions undertaken on behalf of individual minors, whether at the national, European, or international levels. The right to life, the right to survival, and the right to the best possible development of the well-being of children and adolescents are the rights of all minors, including unaccompanied or separated minors. As such, they are to be given the maximum protection with regards to their lives, as well as the possibility to grow and develop integrally through access to the necessary economic and social resources, so as to be able to reach their maximum human potential.

If, on one hand, both European and Italian jurisdictions have espoused the principle of the "best interest of the child" at the level of implementation, they still experience many difficulties at the level of intervention. First, the evaluation of a child's best interests and the evaluation of what elements are key for the achievement of a child's psychophysical well-being require the presence of capable specialists in both places of arrival and of transit. Furthermore, the identification process of the child and the consequent allocation to a specific reception center cannot be entrusted to general protocol or norms of identification applicable to all migrants. Such general norms and protocols are already lacking in reference to adult migrants, and even more so, are lacking in reference to the greater fragility of child migrants.

The first priority must be the assessment of a minor's state of health, even before the identification process, which is a legal aspect for the host country. Well-being should not be solely understood as the physical health of an individual, but it also entails their psychological state. Consequently, there is need for dialogue with experts and it may require a longer period of time to accurately diagnose the condition of the subject.

From the perspective of international cooperation policies, shared responsibilities, and the reception and solidarity obliged by the human rights of children, it is recommended that each member state follow the minimum principles of protection of unaccompanied minors, which could be summarized as follows.

1. With regard to the country of origin, the legislative, administrative, financial and political commitments must be strengthened in order to prioritize the rights of minors; to address the 
gaps in basic education and training requirements such as education and vocational training; and to provide specific social protection against all forms of marginalization, poverty, violence, and discrimination. The basic reasons for leaving one's home country unaccompanied should be addressed. Local, national, regional, and international protection systems should be revised and strengthened. In a majority of cases, the problem is not so much the lack of legislation or programs designed to protect child migrants, but rather the lack of efficacy in their application, or the lack of an effective readiness of funds for their implementation and sustainability over time.

2. Plan and implement migration policies that are guided by a child's best interests, and ensure that there is specific funding for matters regarding the migration of minors. Shared action should be based on human rights, and should take into consideration the financial, social, cultural, and administrative aspects of child migration. In particular, it should aim to prevent the trafficking and exploitation of minors, as well as any other forms of exploitation for illegal purposes, or abuses to which children may fall victim.

3. Adopt international standards in the protection of the rights of minors at the national level, and revise practices and laws that are obsolete. Many countries of origin are still lacking with regards to the laws established by the Convention on the Rights of the Child. For example, the legislation regarding expulsion and the procedures to follow in its implementation are not often specifically mentioned in the legislation of many African countries of transit. At the same time, legislation that aims to protect minors does not take into consideration the particular situation of unaccompanied minors; even in cases of more clearly defined legislation in terms of rights protection (such as the case in the recent revisions of Italian law), there are still normative gaps that have very tangible consequences in the care of young adults coming of age who have left the protection system of minors and are suddenly "by themselves" without the necessary autonomy or competencies necessary, and therefore fall into situation of social marginalization and illegality.

4. Eliminate disparities between the living conditions of unaccompanied minors entrusted to institutions and their fellow peers with which they interact. Unaccompanied minors should not live in situations of discrimination and marginality solely due to their migratory status. They are individuals that require special attention because of the traumatic fragility that has marked them; yet at the same time, the social care they receive should not transform into a type of "institutionalization." The effect on the development of the migrant's identity, which the stigma of being taken under the care of social services leaves behind, must be considered.

5. Establish commissions that permit countries of origin, of transit, and of destination to meet and discuss mutual matters and problems of common interest in order to coordinate together in the provision of efficient care and to increase the efficacy of the protection of the rights of unaccompanied minors.

6. Whenever possible, and when it is in the best interest of the child, favor family reunification or the reunification with other relatives who can provide proper care to the minor.

7. Develop policies to train personnel at all levels of migration and reception. Personnel should be specifically trained to interact with children and must be competent in the protection of 
the rights of minors. Furthermore, every member state of the European Union should promote programs of formation for all public border agency officials in reference to the interaction with, and the provision of care for, unaccompanied minor migrants.

8. Guarantee that reception centers have distinct and secure housing (with specialized personnel) for unaccompanied minors.

9. Establish specific programs for unaccompanied minor in centers and reception communities which are geared towards the relational and social integration of child migrants, their interaction with peers, their insertion into the educational and formational system (including language classes), and offering support in training, educational programs, and the preparation for independent adult life.

10. Strengthen empowerment and restore the ability of minors to perceive themselves as actors in a relational context, so that they may be able to strengthen their personal and social identity.

11. Prepare and provide information to child migrants which is adapted to their age and cultural upbringing, uses simple and clear language, and is supported by the assistance of interpreters and linguistic mediators.

12. Rapidly and efficiently process asylum applications made by unaccompanied minor migrants and ensure that these applicants, in the meantime, are housed in communities that meet international standards as understood by the human rights of a child.

13. Monitor the integration process of unaccompanied migrant minors in their country of destination, in coordination with the first country of arrival and the country of final destination (if different), in order to support their transition into adulthood in their new social context and to ensure a solid and positive social integration process.

14. Offer continued support to young adults coming of age if the process of their formation and integration, initiated as a minor, has not yet reached a satisfactory level of insertion into the social, relational, professional, and communal systems.

15. In the design of policies and programs, take into consideration the different categories of unaccompanied minor migrants and their specific characteristics and stories, so as to promote their human rights, while never abandoning a holistic approach to the rights of children in general.

As member states of the United Nations formally negotiate both the Global Compact on Refugees and the Global Compact for Migration, they should incorporate these recommendations into the documents as best practices for responding to the needs of unaccompanied children so that they are protected by and can integrate into their new societies. 


\section{References}

CNR (Consiglio Nazionale delle Ricerche)-IRPPS (Institute for Research on Population and Social Policies) and UNICEF (UN Children's Fund). 2017. Sperduti-Storie di minorenni arrivati soli in Italia. Rome: UNICEF. https://www.unicef.it/Allegati/Bambini_Sperduti.pdf.

Di Lorenzo, Nadia. 2014. "Il superiore interesse del minore sottratto supera l'applicazione della Convenzione dell'Aja 1980." In Rivista del Diritto di famiglia e delle persone. https://www. unikore.it/index.php/numero-4/di-lorenzo-nadia.

EMN (European Migration Network). 2015. Policies, practices and data on unaccompanied minors in the EU Member States and Norway. Synthesis Report. https://ec.europa.eu/ anti-trafficking/publications/policies-practices-and-data-unaccompanied-minors-eumember-states-and-norway_en.

2016. EMN Annual Report on Immigration and Asylum 2015. https://ec.europa.eu/homeaffairs/what-we-do/networks/european_migration_network/reports/nationalreports_ en.

Étiemble, Angélina. 2008. "Parcours migratoires des mineurs isolés étrangers, catégorisation et traitement social de leur situation en France. " E-migrinter 2: 180-85.

Giovannetti, Monia. 2008. L'accoglienza incompiuta: le politiche dei comuni italiani verso un sistema di protezione nazionale per i minori stranieri non accompagnati. Bologna: II Mulino.

Giovannetti, Monia, ed. 2016. Minori stranieri non accompagnati. Rome: Anci-Cittalia.

Giovannetti, Monia, and Marco Accorinti. 2017. “I minori stranierinon accompagnatitra accoglienza e integrazione.” Minori Giustizia 3: 96-105. https://doi.org/10.3280/MG2017-003009.

Human Rights Council. 2016. Global issue of unaccompanied migrant children and adolescents and human rights. UN Doc. A/HRC/33/53. Geneva: Human Rights Council.

SPRAR (Sistema di Protezione per Richiedenti Asilo e Rifugiati). 2016. Rapporto sulla protezione internazionale in Italia 2016. Rome: SPRAR.

2017. Rapporto sulla protezione internazionale in Italia 2016. Rome: SPRAR.

UNICRI (United Nations Interregional Crime and Justice Research Institute) and PARSEC. 2010. Trafficking of Nigerian Girls in Italy: The Data, the Stories, the Social Services. Torino: UNICRI and PARSEC. http://www.unicri.it/documentation_centre/publications/series/ docs/trafficking_nigeria-italy.pdf.

UNHCR (United Nations High Commissioner for Refugees). 2017. "Italy weekly snapshot - 31 Dec 2017." https://data2.unhcr.org/en/documents/download/61461. 


\title{
International Migration Policy Report
}

\section{The Global Compact for Safe, Orderly, and Regular Migration: Will It Live Up to Its Name?}

\author{
Kevin Appleby \\ Center for Migration Studies
}

The member states of the United Nations - absent the United States - have begun their work on producing a Global Compact for Safe, Orderly, and Regular Migration ("the Compact"), an international agreement that would establish a multilateral framework for migration governance. The Compact, as reflected in the Revision 1 zero draft ${ }^{1}$ document, contains 22 objectives which lay out "actionable commitments" by member states to improve how global migration - irregular, regular, and "mixed" movements - is managed.

While the objectives are progressive and based on human rights principles, based upon the negotiations to date, it is becoming clear that they go too far for some governments which have been offering amendments to the text to reaffirm their sovereignty and lessen their obligations to joint goals. There are several areas of contention which could derail the effort and produce a document which does little, if anything, to impact the status quo. This paper examines these points of disagreement and offers improvements to the text which could make the Global Compact for Migration a meaningful, if not unprecedented, achievement.

\section{General Observations}

Before analyzing specific issues, general observations should be made which provide context to the negotiations and highlight factors which could impact the effectiveness of the Compact. Of greatest concern, the Compact is 1) legally non-binding, 2) does not contain specific targets for member states to achieve by a certain date, and 3) has an ill-defined implementation strategy. Combined with the uncertainty of any funding to build member state capacity to implement the agreement, it is possible that the lofty goals within the Compact may never be realized. In the end, member states may not have the resources to implement effective policies to advance the Compact and, without objective metrics to determine success, progress could be assessed only anecdotally, if at all.

Second, the Compact only mentions the role of civil society in achieving the goals sparingly and does not acknowledge the role of faith-based organizations at all. Civil society organizations have been valuable partners with governments in implementing effective migration policies. Faithbased organizations in particular - which are present in sending, transit, and destination countries - often fill service gaps that governments cannot or will not fill. Language should be added to reinforce the role of civil society, and specifically faith-based groups, in the implementation of the Compact, making them trusted partners with member states, consistent with a whole-of-society approach to migration.

1 Revision 1 of the zero draft reflects revisions suggested by member states. See https://refugeesmigrants.un.org/ sites/default/files/180326_draft_rev1_final.pdf. 
Third, the tension between the rights of the sovereign to manage migration versus the commitment to multilateral cooperation has been prevalent throughout the negotiations. This conflict has been reflected by many governments in addressing the drafts, which have introduced such language as "in accordance with national laws" and "pursuant to existing policies" into many provisions. Specific issues, such as the use of firewalls ${ }^{2}$ in providing social services to migrants; the distinction between regular and irregular migrants and the obligation of member states to each group; and border management and the rights of migrants in vulnerable situations have become flashpoints for reasserting national sovereignty rights, rather than emphasizing mutual cooperation. How the member states resolve this tension throughout the Compact may determine whether the Compact fosters progress or reaffirms the status quo.

Advocates and supportive member states will need to fight to ensure that migrants in vulnerable situations are protected and their needs addressed, ideally in both compacts.

Finally, an ongoing issue is how the Global Compact for Migration and the Global Compact on Refugees complement each other, and whether one or both compacts will address the plight of migrants in vulnerable situations. To date, the Global Compact on Refugees has reaffirmed the current legal framework governing refugees while increasing responsibility sharing, thus precluding the addition of populations within the current refugee protection mandate. This would include persons who are internally displaced, driven from their countries by climate change or natural disaster, and fleeing general violence or persecution by nonstate actors.

In the Global Compact for Migration, however, there are member states who want to strictly limit the document to the management of migrants, either those with legal status or those who are driven primarily by economic or family reunification interests, and not by protection needs. As such, both compacts could fail to adequately address the migrants who may fall through the international protection cracks. Advocates and supportive member states will need to fight to ensure that migrants in vulnerable situations are protected and their needs addressed, ideally in both compacts.

\section{Needed Improvements to the Revised Zero Draft}

In order for the Global Compact for Migration to make a difference on the ground - which is a stated goal of the co-facilitators to the process - improvements must be made to at least five areas of the zero draft: 1) legal immigration; 2) border management and detention; 3) access to social services; 4) return and reintegration; and 5) migrants in vulnerable situations. While not exhaustive, this list includes consequential issues on which there is not consensus.

\section{A. Legal Immigration}

Despite focusing on safe, orderly, and regular migration, the Global Compact does not call for an increase in legal immigration avenues as a principle, which is one of the primary methods of guaranteeing safe and orderly migration. The absence of such a declaration leaves the impression that the Compact would be more focused upon preventing irregular migration than replacing it with legal avenues.

2 A "firewall" is a policy which prohibits a member state from using the personal information of migrants for enforcement purposes. 
To be fair, Objective 5 of the document, which focuses upon legal pathways, provides several options for legal immigration, focused mainly upon labor mobility. In one case, it calls for member states to "expand" options for labor migration. But the section does not recommend an increase in legal pathways, much less set any targets for achieving certain levels of legal immigration globally, ideally in conjunction with the 2030 Sustainable Development Goals (SDGs). ${ }^{3}$ Coupled with a lack of clarity on accountability measures, the absence of specific targets by which to increase legal migration is one of the Compact's greatest weaknesses.

One possible process, suggested by the Scalabrini International Migration Network (SIMN) ${ }^{4}$, would be for member states to ascertain the size of their undocumented populations and work to reduce or eliminate the number of undocumented by creating legal avenues, including regularization, by 2030. Such a concrete goal, which would be transparent and offer accountability, would provide the "headline" - the singular achievement - that the Compact needs.

To explain, Objective 2 of the document lays out commitments for gathering more accurate immigration data, including on the number of undocumented. Having member states commit to garnering accurate information on their immigrant populations would be a good first step in assessing the type of policies needed to assist them, including the deployment of legal avenues and regularization programs.

\section{LABOR IMMIGRATION}

Objective 5 prioritizes labor migration as a means for legal immigration, which raises issues of labor rights and immigration status, particularly the issue of permanence. As a general matter, nations have preferred a temporary labor model, often referred to as circular migration, while human rights advocates have maintained that labor migrants should have the opportunity to obtain permanent residence, either upon entry or after a reasonable amount of time. Immigration status often can determine the leverage that a migrant may have in the workplace, and whether she enjoys portability in employment (can work for more than one employer) and is eligible for certain benefits, including retirement benefits.

The Compact contains language that allows migrant workers to change jobs and employers, despite requests from a few member states to eliminate the language (Objective 6, paragraph $21[\mathrm{~h}])$. It also provides the same rights to migrant workers extended to all workers, including wage protections, the right to organize, and privacy protections (Objective 6, paragraph 21[j]).

However, it does not contain language that would encourage the adjustment of temporary workers, over time, to permanent status. As Sergio Carciotto (2017) points out in his study of Zimbabwean migrant workers in South Africa, migrant workers should be able to earn the right to apply for permanent residence after a certain time, so that they can leverage their rights more effectively.

\section{FAMILY-BASED IMMIGRATION}

With regard to family-based immigration, language is included that emphasizes the importance of family reunification "at all skill levels," and promotes provisions in migration laws and policies that remove barriers to the realization of the "right to family unity and to family life" (Objective 5,

3 See https://sustainabledevelopment.un.org/post2015/transformingourworld.

4 See www.simn-global.org. 
$20[\mathrm{~g}])$. These barriers include income requirements as a condition of legal immigration, language pre-tests, length of stay, and type of regular status, all of which would prevent family reunification. Pro-integration provisions include providing family members access to "work authorization and access to social security and services." Some member states have asked that the prohibitions on legal immigration restrictions on families be taken out of Revision 1, so that such barriers could be used to prevent the entry of low-income and less educated family members.

The Compact also does not specifically encourage the creation of visas based on a family relationship or stipulate that "integrating provisions in migration laws and policies" would mean that a laborer could petition for family members to join them after some time. However, many studies have shown that family unity can contribute to the economy, as families are economic actors who start businesses, create jobs, support each other, keep their members off of public assistance, and strengthen local communities and a nation's social fabric.

Zoya Gubernskaya and Joanna Dreby (2017) argue that family-based immigrants are more upwardly mobile in the workplace because of the support of their families and because they are not tied to an employer. A study by the National Academies of Sciences, Engineering, and Medicine (2016) found that the US immigration system, based upon family-based immigration, has benefitted the nation's "economic growth, innovation, and entrepreneurship."

Another danger of only encouraging the development of labor-migration schemes, as the Compact does, is that nations might eliminate family-based visas in order to create room for additional labor visas, in order to keep legal immigration at a net zero level.

In fact, the Trump administration has endorsed a proposal that would cut legal immigration in half by eliminating a large portion of the family-based immigration system. The proposal would create a merit-based system, in which family membership would be minimized, thus altering the diversity and skill levels of immigrants to the United States. Put another way, it would discriminate against low-skilled workers and immigrants of color (Nakamura 2017).

\section{REGULARIZATION}

Finally, the issue of regularization - another method for decreasing the undocumented population worldwide and encouraging their integration - should be specifically mentioned in the Compact. While facilitating access to "regularization options" was included in the zero draft, it was altered in Revision 1 and replaced by "procedures towards residence status" (Objective 16, paragraph 16[g]).

In other words, it does not encourage member states to create new regularization programs, but simply to facilitate access to existing procedures that can lead to permanent status that do not necessarily include eligibility for citizenship.

Regularization programs carry many benefits to the host nation, as it allows migrants to integrate into society and become full contributors to the nation's economy. It also increases the amount of remittances sent home, as legal workers often can earn more in the workplace than undocumented workers without full rights.

During the 2013 immigration debate in the United States, for example, the nonpartisan Congressional Budget Office (CBO) $(2013,3)$ found that legalizing 11 million undocumented 
people in the United States would increase gross domestic product (GDP) by 3.3 percent in 10 years and 5.4 percent in 20 years.

Moreover, the International Organization on Migration (IOM) $(2004,2)$ found in a report that legal status has a positive impact on the size of remittances: "The immigration policies of destination countries and the legal status of migrants can have important impacts on their possibilities for sending remittances. Legal migrants have opportunities for upward mobility in the labour market and better access to information on human and labour rights. This increases their chances of social integration and higher earnings, which in turns allows better access to formal channels of money transfer as well as enhanced options for investment."

Regularization programs carry many benefits to the host nation, as it allows migrants to integrate into society and become full contributors to the nation's economy.

Thus, destination counties which increase legal status and legal avenues for migrants economically benefit their own nations, as well as sending nations - a win-win strategy.

\section{Recommendations for the Global Compact for Migration on Legal Immigration}

1. The Compact should state in the preamble and in Objective 5 that member states should commit to an increase in legal immigration channels as a preferred means of creating safe, orderly, and regular migration.

2. The Compact should maintain language in Objective 6, paragraph $21(\mathrm{~h}-\mathrm{k})$ that gives migrant workers portability in employment and flexibility in their terms of employment as well as the rights and protections extended to all workers.

3. The Compact should add language that encourages member states to give temporary workers an option to apply for permanent residency after a reasonable amount of time working in a nation.

4. The Compact should make clear that family-based immigration should be promoted and should not be eliminated or reduced in order to create additional employment-based or merit-based visas.

5. The Compact should include language including regularization schemes as a means of decreasing the number of undocumented workers in their nations, with the goal of eliminating their undocumented populations by 2030, in conjunction with the 2030 SDGs. A regularization program can be linked to the SDGs as a means of increasing the support of diaspora communities to the development of their source countries.

\section{B. Border Management and Detention}

One of the more controversial and significant issues in the Compact which has received minimal attention to date is border management. Objective 11, titled, "Manage borders in an integrated, secure, and coordinated manner," addresses this issue, and focuses upon the cooperation between nations in managing international borders. 
Border management provides the basis for nations to work together either to protect large movements of migrants and refugees or deter them, as has been seen in many contexts over the past several years. In their article analyzing deterrence policies, Bill Frelick of Human Rights Watch, Ian Kysel of the American Civil Liberties Union, and Jennifer Podkul of Kids in Need of Defense (2016) provide many examples, such as the interdiction and off-shore processing utilized by Australia; the cooperation of the United States and Mexico in controlling the flight of Central American children and families from gang violence in the Northern Triangle; and the agreement between the European Union and Turkey to prevent the migration of Syrians to Europe in 2016.

These deterrence policies are characterized by interdiction, detention, pushbacks at borders, and the closing of borders at source and destination countries. In some instances, destination countries have conditioned aid upon a source country limiting migration from their territories. The authors conclude that these deterrence tactics and schemes deny due process protections to bona fide asylum seekers (Frelick, Kysel, and Podkul 2016, 196-98).

In a statement delivered to the 2017 International Dialogue on Migration (IDM), SIMN stated that the success of the Compact would be measured by how it mitigated these deterrence policies and replaced them with protection policies. Instead of providing support to "the externalization of borders," the Compact should include and promote an "externalization of protection." ${ }^{5}$ At a minimum, multilateral cooperation to address large movements should include a protection component based upon responsibility sharing, both regionally and internationally.

At a minimum, multilateral cooperation to address large movements should include a protection component based upon responsibility sharing, both regionally and internationally.

While the language in Revision 1 does affirm protection mechanisms in border management efforts, it also reinforces the right of nations to cooperate to ensure "security," in "accordance with national sovereignty" (Objective 11, paragraph 26).

For example, it encourages the development of "technical cooperation agreements that enable States to request and offer assets, equipment and other technical assistance to strengthen border management," which essentially gives cover to a destination nation that wishes to outsource enforcement to another country, even though it specifies "in the area of search and rescue, as well as other emergency situations" (Objective 11, paragraph 26[f]).

In contrast, three sub-paragraphs of Objective 11, properly interpreted, could hold member states accountable to a protection system in their border management cooperation agreements. First, it seeks to enhance "regional and cross-regional border management cooperation on proper identification, timely and efficient referral, human rights protection and assistance for migrants in situations of vulnerability at or near international borders, in compliance with international human rights law" (Objective 11, paragraph 26[b]).

Objective 11 goes further, committing member states to "strengthen oversight of procedures and due process at international borders, including individualized assessments, in compliance with

5 Statement of the Scalabrini International Migration Network for International Dialogue on Migration, April 19, 2017, http://www.simn-global.org/news_post.php?category=press\&news_id=346. 
international human rights law" (Objective 11, paragraph 26[e]). This language ensures that some screening is pursued at international borders, consistent with human rights standards.

Moreover, Objective 11 contains strong language to ensure that "child protection authorities are able to commence procedures for the determination of the best interests of the child once a child crosses an international border, particularly in the case of unaccompanied or separated children ... in accordance with international law" (Objective 11, paragraph 26[g]). This language is a step forward in international protection for children as such screening does not exist universally, and should be maintained in the Compact.

Thus, the Compact does encourage member states to adopt measures which protect migrants, rather than rely on deterrence initiatives. In an ominous turn, however, the European Union has requested that deterrence language be inserted into the opening paragraph (chapeau) of Objective 11 and in paragraph 27(f) of the section. For the reasons articulated above, the cofacilitators should not add such language to the next draft, as it would undermine the entire purpose of the Global Compact. ${ }^{6}$

\section{DETENTION}

Objective 13, titled, "Use migration detention only as a measure of last resort and work towards alternatives," is a strong section which addresses the deterrence tactic of detention, employed in responding to large movements of migrants and refugees. It calls for the monitoring of the conditions of detention to ensure its use as a measure of last resort, and encourages the broad use of alternatives to detention, including "community-based care arrangements." Studies have shown that community-based alternatives to detention are cheaper, ensure that migrants show up at their court hearings, and are more humane. ${ }^{7}$

Objective 13 also discourages the use of detention as a "deterrent" or "punishment to migrants," and holds authorities accountable for "violations of human rights abuses." Detention conditions also are addressed, requiring, at a minimum, "access to food, healthcare, legal orientation and representation, and adequate accommodation, in accordance with international human rights law" (Objective 13, paragraphs 28[c],[e]). These strong principles should be maintained in the final draft of the Compact.

Perhaps the most significant paragraph in the Compact, if it is agreed to, is paragraph 28(g), which calls for "ending the practice of child detention in the context of international migration." Paragraph 28(g) further states that children should be placed in alternatives to detention, including allowing children to "remain with their family members or legal guardians in noncustodial contexts" (Objective 13, paragraph 28[g]).

This language is a step forward from the New York Declaration for Refugees and Migrants, which maintained that member states can detain children as a "last resort," a huge loophole, with member states working "toward ending" child detention (UNGA 2016, paragraph 2.12). Ending child detention would mark a significant achievement for the Global Compact for Migration. Any regression to the standard included in the New York Declaration should be opposed.

6 Statement of Austria on behalf of 27 EU member states during UN negotiation session, April 6, 2018.

7 See CLINIC (n.d.). 
In their intervention with the co-facilitators during the second phase of negotiations, SIMN requested the addition of "parents" to the list of family members with whom children should remain, in order to address the deterrence tactic of family separation at international borders. In fact, a sentence specifically discouraging the separation of children from their family members, including parents, at international borders should be added. ${ }^{8}$ The Trump administration informally has begun separating parents from their children at the US-Mexico border, a cruel policy that has led to the removal of over 700 children from their parents since January 2017 (Dickerson 2018).

\section{Recommendations for the Global Compact on Border Management and Detention}

1. Deterrence tactics such as detention, border closings, family separation, interdiction, and pushbacks, among others, should specifically be discouraged in the Global Compact. Technical cooperation agreements in paragraph 28(f) should specifically exclude the transfer of equipment for enforcement purposes to bolster deterrence tactics.

2. Paragraphs 26(b), (e), and (g) should be maintained and strengthened, as they enhance regional cooperation on protection and assistance for migrants in vulnerable situations.

3. Objective 13 on detention should maintain an emphasis on alternatives to detention, especially in community-based care arrangements, ensure that detention standards are humane, and hold accountable authorities who violate human rights.

4. Paragraph $28(\mathrm{~g})$ calls for the end of child detention and should be maintained. Specific language prohibiting the separation of children from their parents and other family members should be added.

\section{Irregular Migrants: Access to Services}

An issue which has emerged in the early rounds of negotiations has been the distinction between irregular and regular migrants and how member states treat or provide services to each distinct group. A parallel issue is whether, in gaining access to such services, a migrant's privacy information - address, country of origin, and legal status - would be kept confidential and not shared for law enforcement purposes.

Some member states have advocated that a distinction between irregular and regular migrants be inserted throughout the document, particularly with regard to any actionable commitments made by member states to migrants in general. To their credit, the co-facilitators of Mexico and Switzerland avoided such a detailed distinction in Revision 1, opting to limit the definition to the preamble.

One problem in their language, however, is the declaration that migrants "unlike refugees, are not inherently vulnerable, but their human rights must be respected under international human rights law at all times, in particular when they face an increased risk of violations and abuses" (preamble, paragraph 3).

Stating in an international document that migrants are not "inherently vulnerable" sets a dangerous precedent which immigration opponents could use to justify the denial of a multitude

8 During the last round of negotiations, the Holy See delegation requested that a sentence prohibiting family separation at international borders be added to the Compact. 
of rights to migrants, regardless of the qualifying human rights language in the sentence. Several member states objected to this definition and requested that it be changed. But to what?

The reality is that migrants who are in transit are often extremely vulnerable, as they are subject to harassment, human trafficking, gender-based violence, unjustified detention, and possible death. Many do not have the luxury of flying in on a plane and overstaying a visa, for example, but are forced to journey in remote regions, including across deserts and oceans.

The reality is that migrants who are in transit are often extremely vulnerable, as they are subject to harassment, human trafficking, gender-based violence, unjustified detention, and possible death.

As such, the language "inherently vulnerable" must be struck from the Compact and replaced with a more precise definition between refugees and migrants. The most precise distinction is that migrants do not meet the definition of refugees found in the 1951 Refugee Convention or its 1967 Protocol.

A sub-issue flowing from the irregular/regular distinction is the services regular migrants are entitled to and that irregular migrants should be provided. During the negotiations, the Holy See and a number of member states led by the Philippines and several Latin American countries made the argument that migrants, regardless of legal status, are entitled to certain necessities, such as healthcare, education, and housing, based on their human rights.

However, in Revision 1, language detailing such benefits was struck and replaced with the phrase, "basic services, necessary to exercise their human rights." From this language, it is unclear the services to which an irregular migrant may have access, as it could be interpreted widely by member states. In its response, the Holy See asked for clarification regarding the new language and restoration of a list of benefits. In its own statement, Caritas Internationalis also argued for a restored list of services available to irregular migrants.

As "human rights protection" is used in various forms throughout the revised draft, SIMN asked that the term be clarified by linking it to the United Nations' approved international human rights instruments. ${ }^{9}$

\section{FIREWALLS}

Another major issue related to access to services is the issue of "firewalls," or an explicit barrier between the use of personal information obtained from irregular migrants for purposes of benefits and for the purposes of enforcement. In other words, a government would be prohibited from using personal information - name, location, and other personal data - for deportation purposes.

The problem also arises in terms of data collection, when nations attempt to determine how many irregular migrants live in their territories. While it is vital to collect such information for public policy purposes, it is equally vital to ensure the information is not abused and that immigrants are not afraid to seek services or provide information about themselves.

9 These instruments could include, among others, the International Covenant on Civil and Political Rights and the Universal Declaration of Human Rights. 
Even without sharing personal information with law enforcement, demographic data - such as where irregular migrants are concentrated in a country - can be used for law enforcement purposes, as well as to limit federal government funding to local jurisdictions with a large number of undocumented persons.

Some have argued, including SIMN, that such demographic data should not be used for enforcement purposes and that the question "country of citizenship" should not be used in census or other survey questions. In the United States, the Trump administration has proposed a "country of citizenship" question for the 2020 census, which has been greeted with much controversy (Wines and Baumgaertner 2018).

Revision 1 weakens firewall language in some places. For example, in Objective 15 regarding access to services, it removes firewall language and provides that states must "ensure that personal data is not reported" to immigration enforcement "authorities, and migrants are not apprehended at places of service delivery." The new language obviously gives member states wide discretion on how to keep personal information from being used for law enforcement purposes, if at all.

The European Union, Australia, and other nations have argued that firewall language undermined the "whole of government" approach in the Compact, as all agencies of government should be used to manage migration, including enforcement agencies. Other nations, consistent with civil society, have argued that removal of such language undercuts a "whole of society" approach, in which "such measures allow for irregular migrants to safely report crimes, gender discrimination, and unfair labour practices." 10

The firewall issue is another conflict in the Compact which pits one view of managing migration - through legal and inclusive means - with another - through the use of enforcement. In order for human rights protection to be maintained in the Compact, firewall language must be used consistently throughout the text, in the context of both access to services and data collection.

\section{Recommendations on Irregular Migrants and Access to Services in the Global Compact for Migration}

1. Language in the first revision which proclaims that migrants are "not inherently vulnerable" should be removed and replaced with language that defines migrants as persons who do not meet the 1951 Refugee Convention's definition of a refugee.

2. The benefits which should be made available to irregular migrants should be listed in the text, and human rights protection should be linked to relevant human rights instruments.

3. Firewall language should be maintained in the Compact and not weakened, in relation to both access to services and data collection.

4. Demographic data should not be used for the purposes of targeted enforcement and to deprive local jurisdictions with large immigrant populations of funding support.

10 "Civil Society Open Letter to UN Member States on the Global Compact for Safe, Orderly and Regular Migration,"

May 3, 2018, http://www.madenetwork.org/sites/default/files/Open\%20Civil\%20Society\%20Letter\%20on\%20 GCM_3May_FINAL_EN.pdf. 


\section{Return and Reintegration of Migrants}

An area which many predicted would be controversial is how migrants are returned to their home countries. During the consultation phase of the Compact, several member states raised this as a concern, claiming that all member states have an obligation to receive their nationals.

Several issues arise under this topic, including whether a migrant is returned in violation of the principle of non-refoulement - which could include being forced to "voluntarily" return through various coercive tactics. For example, the interdiction of migrants, through interception at sea or on land in a transit country, often can lead to refoulement, as asylum procedures and adjudicators may not be available.

A second sub-issue is how a returned migrant is re-integrated into their home country and whether services are provided to ensure a secure re-integration into the country, as some migrants may have valid fears of smugglers, human traffickers, gang members, or even governmental authorities.

Objective 21 of the Compact, titled "Cooperate in facilitating dignified and sustainable return, readmission, and reintegration," covers the area, but several sections of the Compact complement it, including Objective 18 on skills development, which can be applied to returning migrants.

Revision 1 features new language which asserts that returning nationals should be received, "in accordance with the obligation of States to readmit their own nationals" (Objective 21, paragraph 36). As mentioned, such language was included in response to the complaint from certain nations that countries of origin do not fully cooperate in facilitating the return of their citizens, particularly in issuing travel documents. SIMN and others have responded that destination countries have an obligation to ensure due process for migrants, to treat them with respect and dignity, and not return them to possible harm.

Objective 21 also outlines the preference of voluntary, rather than forced, return. The distinction between "voluntary" and "forced" return can often be blurred, as vulnerable migrants often are coerced by enforcement authorities to sign documents that facilitate their return. ${ }^{11}$

Prolonged detention, as well, can force a migrant to return "voluntarily" rather than stay for a long time in difficult detention conditions in order to receive an asylum hearing. Paragraph 36(a) states that return should be in compliance with "international human rights law." However, coercion can be hard to prove and, in many cases, migrants have no avenue to make a complaint or remedy an injustice. Specific language should be added to the Compact which strictly prohibits the use of coercive tactics to force migrants to waive their rights and return "voluntarily."

The Compact also does not specifically prohibit the use of interdiction to stop migrants from reaching the territory of a nation or returning them to a country without due process. Denying access to a nation can take the form of not allowing a migrant to cross an international border or intercepting them in a transit country and returning or forcing them back across a border. Under such conditions, the principle of non-refoulement is frequently violated (Frelick, Kysel, and Podkul 2016, 196-98).

Objective 21 is instructive of how forced return should be measured against international protection norms, stating that returns "follow an individualized assessment of the circumstances

11 The absence of counsel, and language barriers, can lead to coercion. 
that may weigh against the return, such as risks of torture or other irreparable harm, in compliance with due process guarantees and in accordance with international human rights law" (Objective 21, paragraph 36[f]).

This language, however, does not explicitly prohibit return in compliance with the principle of non-refoulement or international refugee law, which is an additional standard of protection which should be added to the end of the paragraph, as follows: "in accordance with international law and the principle of non-refoulement." In his discussion with member states, Volker Türk, assistant high commissioner for protection of the United Nations High Commissioner for Refugees (UNHCR), stated that non-refoulement can apply to those who have not been formally identified as refugees under international law. ${ }^{12}$

\section{REINTEGRATION}

With regard to the reintegration of migrants into their home communities, Revision 1 recommends that governments provide returned migrants "equal access to social protection and services, psycho-social assistance, vocational training, employment opportunities, recognition of skills acquired abroad, and financial services." The key word here is "equal," as it implies that migrants be provided access to services available to the nation's citizens and that are presumably already in place.

In reality, returned migrants do not have easy and immediate access to these services, plus they are often inadequate to ensure they can live a life with dignity. Reintegration programs should focus solely upon the needs of the returned migrants, including their physical security, so they are able to access and utilize services - job training, employment placement, basic necessities - tailored to their needs. Physical security is needed, as often returnees face threats from smugglers, human traffickers, and gang members.

Thus, reintegration programs designed for returnees should be created, ideally financed in part by destination nations that are returning migrants. Such programs, if effectively implemented, can ensure that migrants remain in their country and do not attempt to again migrate irregularly.

Graziano Battistella (2018) of the Scalabrini Migration Center in Manila, Philippines, has proposed return and reintegration programs based on a conceptual policy framework, pairing the types of return to the services needed upon return. He points out that not all returnees are alike - some are voluntary, some are forced, and some return at the end of their contract, despite wanting to stay - and that the services provided to them upon return can vary, depending on their needs. As such, there is not a "one-size fits all" approach to reintegration.

As an example, SIMN has implemented an entrepreneurship and innovation program in several countries, including Mexico and Central America, that helps returning migrants learn a skill and either find employment or start their own business, with good success. The program targets returnees who have been deported from host countries and has placed 15,000 migrants per year in permanent employment. Such a model should be replicated in other nations and fully supported by both origin and destination countries. ${ }^{13}$

12 Briefing of Member States on Global Compact on Refugees, United Nations, April 13, 2018.

13 Scalabrini International Migration Network, "Employment, Entrepreneurship, and Social Innovation of Migrants and Refugees Model,” http://www.simn-global.org/anuncios/485/5adf894fd8741.pdf. 


\section{Recommendations for Return and Reintegration in the Global Compact}

1. Language should be added to Objective 21 of the Compact that prohibits the use of coercive tactics to force migrants to sign documents to "voluntarily" return to their countries without benefit of due process.

2. Interdiction policies which return migrants to their home countries without due process protections should be prohibited.

3. The principle of non-refoulement should be applied to migrants in Objective 21 .

4. Reintegration programs, which ensure that returned migrants receive a full range of services to reintegrate into society, including physical security, should be available in origin countries and funded by both countries of origin and countries of destination.

\section{E. Migrants in Vulnerable Situations}

Perhaps the most challenging issue of both the Global Compact for Migration and the Global Compact on Refugees is migrants in vulnerable situations. Who are they? They include migrants who flee natural disasters or climate change; migrants who are fleeing generalized violence; or special groups such as unaccompanied alien children, victims of domestic violence, or victims of human trafficking. They all have one thing in common: they would be at risk of harm if returned to their countries.

The draft of the Global Compact on Refugees does not specifically address these vulnerable groups, while the Global Compact for Migration includes some vulnerable groups but is vague as to what means of protection should be offered to them. In Revision 1, the co-facilitators insert a human rights protection standard to these groups, but, as mentioned, it is uncertain exactly what protection this standard affords them unless it is tied to human rights instruments or to enumerated rights in the text.

Objectives 5 and 7 of the Global Compact for Migration attempt to address vulnerabilities in migration. Objective 7 commits states to "protect and assist migrants in accordance with our obligations under international human rights law . . . arising from personal characteristics, the reasons for leaving their country of origin, the circumstances under which they travel or the conditions they face upon arrival" (Objective 7, paragraph 22). This broad definition of potential grounds of vulnerability necessarily captures a large group of migrants who are in vulnerable situations.

More specifically, Objective 7 speaks of migrants who "may require a heightened duty of care," such as "victims of sexual and other gender-based violence, workers facing exploitation and abuse, domestic workers, minorities, marginalized groups, and persons with disabilities" (Objective 7, paragraph 22[d]). However, it only directs member states to "develop partnerships to raise awareness and provide gender-responsive policy recommendations" for these groups, not necessarily to take steps to protect them.

As for victims of climate change or natural disasters, the Compact in Objective 5 encourages nations to provide "protection and reception of tailored duration on humanitarian grounds" for persons fleeing "sudden on-set natural disasters, slow-onset environmental degradation, 
emergency situations, and serious violations of human rights." It suggests that "humanitarian visas, private sponsorships, access to education for children, and temporary work permits" be provided (Objective 5, paragraph 20[f]). SIMN has stated that member states should add these tools and others to their "legal toolbox."

While the language encourages nations to protect these vulnerable groups in different ways, it does not require protection measures or commit them to any plan of action. The term "serious human rights violations," contained in the same paragraph, can be interpreted to mean that certain migrants fleeing situations of generalized violence should receive international protection, despite the fact that some nations do not recognize generalized violence as sufficient to gain asylum.

Studies have shown that providing temporary protection to migrants in vulnerable situations can benefit a host country. A Center for Migration Studies of New York report found that 88 percent of the over 200,000 nationals of El Salvador, 50,000 Haitians, and 57,000 Hondurans who received temporary protected status (TPS) from the United States participated in the workforce (Warren and Kerwin 2017). Another study found that their deportation would reduce the US GDP by $\$ 45.2$ billion and that it would cost $\$ 3.1$ billion to deport them (ILRC 2018).

The issue of migrants who fall through the cracks of protection should be seriously addressed in both compacts, ideally by including identical paragraphs or language in each drafted by a panel of international law experts. As one member state representative put it, it is better that the two compacts have overlapping language than gaps in protection.

\section{Recommendations on Migrants in Vulnerable Situations for the Global Compact for Migration}

1. The standard "human rights" protection should be more precisely defined in the Global Compact for Migration, so that member states are committed to a standard level of protection for migrants in vulnerable situations. Ideally, the definition should be tied to human rights instruments, such as the International Covenant on Civil and Political Rights and the Universal Declaration of Human Rights, among others, and to enumerated rights in the text.

2. Member states, working individually and collectively, should be required to provide temporary, if not permanent, legal protection to victims of climate change and natural disasters. The Global Compact on Refugees should more directly address the protection of migrants in vulnerable situations, with both compacts having identical paragraphs or language on the subject.

3. Migrants who experienced "serious human rights violations" should be considered for asylum protection by an appropriate legal authority.

4. A panel of experts should be appointed to advise member states on the issue of migrants in vulnerable situations, so as to ensure that the compacts together fill any gaps in their protection.

5. Nations should add legal tools to their "toolboxes" of protection for migrants in vulnerable situations, including humanitarian visas, TPS, and group-specific visas. The UNHCR 10-Point Plan in Action on refugee protection and mixed movements provides best practices that should be implemented. 


\section{Conclusion}

The Global Compact for Safe, Orderly, and Regular Migration represents a unique opportunity for the global community to forge common approaches toward the treatment of migrants worldwide. Given that the full title includes "safe, orderly, and regular," the Compact should encourage, if not require, the adoption and implementation of policies that replace irregular migration with regular migration.

As laid out, this would include increasing legal avenues for migration, including regularization programs, ideally tied toward reducing irregular migration by a certain percentage by 2030, in conjunction with the sustainable development goals. Besides an opportunity to utilize legal channels for migration, irregular migrants should also be ensured basic services, regardless of their status, to ensure their well-being.

Nations also should add more legal tools to their toolbox by adding visas that can be used to protect migrants in vulnerable situations, including humanitarian visas and visas tailored toward specific vulnerable populations, such as victims of human trafficking and domestic violence, unaccompanied children, the disabled, and those in need of temporary protection. Migrants who have experienced "serious human rights violations" should be protected under international refugee law.

In the end, the Global Compact for Migration will be successful if it creates a new approach to governing global migration that emphasizes the carrot and not the stick, legal pathways rather than enforcement and deterrence.

The Compact should not promote deterrence and enforcement tactics as a means of reducing irregular migration, because these tactics are certainly not "safe" for the migrant. Deterrence policies can place migrants in danger by de facto removing due process protections through detention, interdiction, pushbacks, the closing of border, and other tactics. Instead of externalizing borders, nations should promote responsibility-sharing mechanisms that externalize protection.

Return and reintegration policies should be governed by the principle of non-refoulement. Tactics which force migrants to "voluntarily" return to their countries without due process should be prohibited. Reintegration programs should be tailored to the needs of returned migrants and include job training and placement, physical and social protection, and basic needs support.

In the end, the Global Compact for Migration will be successful if it creates a new approach to governing global migration that emphasizes the carrot and not the stick, legal pathways rather than enforcement and deterrence. Certainly, enforcement policies are part of the equation, but migration is better managed if there are legal avenues that migrants can use to escape harm or to support their families.

Will the Global Compact for Safe, Orderly, and Regular Migration live up to its name? The jury is still out. What is needed is a paradigm shift globally, away from the deterrence model now in use and toward mutual cooperation marked by responsibility sharing and an increase in legal avenues for migration. If the Compact can achieve this shift, it could change migration governance for the better into the future. 


\section{References}

Battistella, Graziano. 2018. "Return Migration: A Conceptual Framework." New York: Center for Migration Studies. http://cmsny.org/publications/2018smsc-smc-return-migration/.

Carciotto, Sergio. 2018. "The Regularization of Zimbabwean Migrants: The Case of Permanent Temporariness." New York: Center for Migration Studies. http://cmsny.org/ publications/2018smsc-sihma-zimbabwe-regularization/.

CLINIC (Catholic Legal Immigration Network, Inc). n.d. "Alternative to Detention Programs." Washington, DC: CLINIC. https://cliniclegal.org/sites/default/files/cara/Alternatives-toDetention-Backgrounder.pdf.

Congressional Budget Office. 2013. The Economic Impact of S. 744, the Border Security, Economic Opportunity, and Immigration Modernization Act. Washington, DC: Congressional Budget Office. https://www.cbo.gov/sites/default/files/113th-congress-2013-2014/ reports/44346-immigration.pdf.

Dickerson, Caitlin. 2018. "Hundreds of Children Have Been Taken from Parents at the US Border." New York Times, April 20. https://www.nytimes.com/2018/04/20/us/immigrant-childrenseparation-ice.html.

Frelick, Bill, Ian Kysel, and Jennifer Podkul. 2016. "The Impact of Externalization of Migration Controls on the Rights of Asylum-Seekers and other Migrants." Journal on Migration and Human Security 4(4): 190-220. https://doi.org/10.14240/imhs.v4i4.68.

Gubernshaya, Zoya, and Joanna Dreby. 2017. "US Immigration Policy and the Case for Family Unity." Journal on Migration and Human Security 5(2): 417-30. https://doi.org/10.14240/ imhs.v5i2.91.

ILRC (Immigrant Legal Resource Center). 2017. Economic Contributions by Salvadoran, Honduran, and Haitian TPS Holders. https://www.ilrc.org/report-tps-economic-cost/.

IOM (International Organization for Migration). 2004. "Gender, Migration, and Remittances." https://www.iom.int/sites/default/files/about-iom/Gender-migration-remittancesinfosheet.pdf.

Nakamura, David. 2017. "Trump, GOP Senators introduce bill to slash legal immigration levels." Washington Post, August 3. https://www.washingtonpost.com/news/post-politics/ wp/2017/08/02/trump-gop-senators-to-introduce-bill-to-slash-legal-immigrationlevels/?utm_term=.8acfcbe6e88d.

National Academies of Sciences, Engineering, and Medicine. 2016. The Economic and Fiscal Consequences of Immigration. Washington, DC: National Academies of Sciences, Engineering, and Medicine.

UNGA (UN General Assembly). "New York Declaration for Refugees and Migrants." UN Doc. A/ RES/71/1. New York: UNGA. http://www.un.org/en/ga/search/view_doc.asp?symbol=A/ RES/71/1. 
Warren, Robert, and Donald Kerwin. 2017. "A Statistical and Demographic Profile of the US Temporary Protected Status Populations of El Salvador, Honduras, and Haiti." Journal on Migration and Human Security 5(3): 577-92. https://doi.org/10.14240/imhs.v5i3.99.

Wines, Michael, and Emily Baumgaertner. 2018. "At Least Twelve States to Sue Trump Administration over Census Citizenship Question." New York Times, March 27. https:// www.nytimes.com/2018/03/27/us/census-citizenship-question.html. 


\section{Section 3: The Role of Faith-Based Organizations in Supporting Migrants in Vulnerable Situations}




\title{
International Migration Policy Report
}

\section{Meeting the Needs of Women and Girl Migrants and Refugees in the Comprehensive Refugee Response Framework: The Unique Role of Faith- Based Organizations}

\author{
Laurie Carafone \\ Kids in Need of Defense
}

\section{Introduction}

The purpose of this paper is to outline major challenges that highly vulnerable women and girl migrants and refugees face, and then to provide suggested approaches to meeting those challenges with a focus on the role of faith-based organizations (FBOs). The articulation of the protection needs of this population, and the framework of suggested best practices for meeting those needs, is not new. However, what may be new is the opportunity to look very critically and closely at the unique position of FBOs to be a profound contributor at this historical moment. The 2016 New York Declaration for Refugees and Migrants ("the Declaration") and its Comprehensive Refugee Response Framework (CRRF) lay out a shared responsibility model in which civil society and $\mathrm{FBOs}$ play a central role in protecting refugees and vulnerable migrants. FBOs' centrality in this model provides a point of departure for the 2018 Global Compacts on refugees and migrants and, more importantly, their fulsome implementation in the weeks, months, and years to come (UNHCR 2018b; United Nations n.d.).

\section{The Current Migration Crisis: Historical, Political, and Moral Framework}

We are in a moment of grave humanitarian crisis. At this writing, there are more than 68.5 million forcibly displaced persons, including over 25.4 million refugees. The former is the largest recorded number in history (RefugePoint and Women's Refugee Commission 2016; Grandi 2017). This mass movement has arisen out of war, conflict, persecution, violence, and unprecedented and growing disparities in access to food, water, education, health, employment, economic vitality, political agency, stability, environmental security, and religious tolerance and freedom. ${ }^{1}$ Those with heightened vulnerabilities stemming from longstanding cultural and social inequities, such as women, girls, and those with disabilities, experience these disparities with more intensity (UNHCR 2018a, 16). Particularly vulnerable individuals also have little in the way of a safety net in the eventuality of a crisis. When terrorism, war, gang or narcotrafficking violence, environmental disaster, or political uprising and attendant dictatorial crackdowns arise with a backdrop of overall insecurity and gender inequality, women and girls may find that they have no other choice than to run for their lives (UNHCR 2015). Gender-related vulnerabilities are then further amplified in the chaos and exposure of the migration journey, and even in reception and destination sites. 


\section{Vulnerabilities in Places of Origin}

Before they are forced to flee, women and girls often face enormous and entrenched inequities that threaten their daily safety and well-being. They often suffer from poverty, violent governmental or criminal actors who operate with impunity, and structural racial and ethnic inequalities that affect their village, city, or broad swaths of the country. However, when gender inequities are also deeply woven into the cultural and historical fabric, women and girls suffer uniquely and intensely because they have little access to the limited resources within an already tenuous setting. The following is a short rendering of some major categories of pervasive gender inequality faced by women and girls. These challenges were cited by refugee women themselves in dialogue with the United Nations High Commissioner for Refugees (UNHCR) beginning in 2010 and reported on in 2013 (UNHCR 2011).

Gender-related vulnerabilities are then further amplified in the chaos and exposure of the migration journey, and even in reception and destination sites.

\section{Education}

In their communities of origin, girls are often excluded from scarce educational opportunities: in a choice between sending a boy or a girl to school given limited resources, the girl is often passed over. Where girls are permitted to attend primary school, the opportunity to continue on to secondary and tertiary schooling is comparatively rare (UNHCR 2011, 24). Attending school often requires traveling long distances through unsafe territory with the constant threat of violence including rape and physical attacks en route. Girls are further curbed in their ability to learn by lack of access to adequate sanitation materials and basic health care. The consequences are profound for girls, their families, and their communities. When women and girls are denied education, they are then less skilled, less self-reliant, and less able to protect their families and children in times of crisis, including where a male provider dies or becomes disabled. Without education, women and girls are also more readily excluded from positions of power and decision-making (ibid., 14). By contrast, among other benefits, education of women and girls reduces rates of maternal and infant mortality, child marriage and teen pregnancy, and increases child vaccination rates (UNHCR 2016).

\section{Employment}

Women and girls are often relegated to a limited sphere in and around their homes, with little access to broader employment and training opportunities (Pittaway, Bell, Bartolomei 2016, 5). In contrast, men and boys are often permitted to move more freely and they benefit from jobs and training in urban areas. When women and girls work in an urban area without male accompaniment or protection, the same entrenched normalization of gender-based violence can leave them vulnerable to physical and sexual abuse, as well as to modern forms of slavery or indentured servitude. With lower levels of education and limited prospects for employment, women and girls also are more vulnerable to being lured by bad actors with the false promise of marriage or a job, and may end up trapped in a labor or sex trafficking web from which they cannot escape. To the extent that they escape following sexual violence, return to their home community is often impossible as they are shunned and viewed as "damaged goods" that bring shame upon their families. 


\section{Sexual and Gender-Based Violence (SGBV)}

Women and girls are routinely subjected to sexual and gender-based violence (SGBV) including rape and sexual slavery (UNHCR 2011, 16; KIND and Human Rights Center Fray Matías de Córdova 2017). The risk of SGBV is heightened when an already misogynist culture is compounded by violent criminal actors who are allowed to victimize women and girls with impunity. In many countries and communities of origin, justice systems fail to protect, and indeed further victimize, women and girls. Law enforcement may refuse to investigate or arrest perpetrators of violence, and police often view domestic violence as a private matter with which they should not interfere. Specifically, authorities often disregard or refuse to intervene in reports of domestic battery, marital rape, forced child marriage, or incest, particularly where such acts are condoned by powerful men and institutions, including those claiming religious authority. For women and girls, reporting crimes can bring retribution without protection. Criminal actors such as gangs follow through on threats of violence if women or girls dare to report violence, both to set an example and to terrorize communities. Women have little access to legal representation and information, and prosecution and conviction rates for crimes of violence and retribution against women and girls are often abysmally low, leading many women and girls not to report crimes at all (UNHCR 2011, 22).

Before they are forced to flee, women and girls often face enormous and entrenched inequities that threaten their daily safety and well-being.

Where the perpetrators are powerful organized criminal actors, police may fear taking any action, and tell women or girls that they cannot protect them - and in some cases even advise them to leave the country to survive. Police themselves may also be complicit in or part of such gangs or transnational criminal operations (UNHCR 2015, 25). Women and girls who are victims of rape or other forms of SGBV are often stigmatized and ostracized, increasing the likelihood that they will be revictimized. Mental health and medical services are woefully under-resourced, forcing victims including young girls to navigate their ongoing trauma without support. Compounding oppression, girls may be forced into child marriages where the parent fears an alternative of destitution.

Women and girls often lack access to basic health care for a number of intersecting reasons including gender inequities.

\section{Health}

Women and girls often lack access to basic health care for a number of intersecting reasons including gender inequities. In many communities of origin, there are insufficient health centers and emergency ambulances, medications are prohibitively expensive, and women and girls without economic means and independence have difficulty obtaining the transport, money, and translation services needed to access facilities (UNHCR 2011, 30). Women and girls are systematically unable to obtain adequate medical and mental health care in the areas of gynecology and obstetrics, as survivors of rape, and as mothers to children born of rape including those with HIV.

This is the backdrop of the lives of many refugee women and girls before a single step is taken on the migration journey. A tenuous hold on safety, health, education, and opportunity in daily life is only amplified in the chaos of crisis, such as war, political instability, terrorism, or other push- 
factors leading women and girls to flee. When inequality is quite literally the point of departure for a dangerous journey to seek safety, the challenges ahead must be faced with few resources and little or no cushion between the refugee and an onslaught of dangers to come.

\section{Vulnerabilities in Transit, Reception, and Destination Sites}

Women and girls typically choose to flee as a last resort - when a triggering event makes the already tenuous situation untenable. For example, a girl who lives in a deeply misogynist culture in which she is denied schooling, subjected to physical and sexual abuse, forced to work long hours in dangerous conditions, and lacks access to basic health care or reliable sources of food and water, may nonetheless remain at home where she has some familial and community support. In addition to lacking the financial means to readily relocate, women and girls may be particularly reticent to flee because the potential dangers of rape, trafficking, and death during the journey may outweigh the known risks of staying. However, they may experience an event or events that push that calculation to the side of flight, however terrifying. For example, a woman or girl may be targeted by a gang member and "chosen" to serve as a sexual slave under threat of death. She may have seen her family and peers targeted for rape, torture, or killing by a powerful criminal entity - and know that she is likely next if she remains, particularly as she comes of age into puberty. When a woman or girl chooses to flee in such circumstances, the baseline inequities, vulnerabilities, and gendered dangers expand during the journey, and indeed tragically often at the point of reception and in the host community as well.

Migrant women and girls need "protection against gender discrimination in all phases of the migration process" (GMG 2017, 153). The UNHCR Heightened Risk Identification Tool elucidates categories of refugees with special protection concerns including women at risk, unaccompanied children, child-headed, and single-parent households, and victims of trauma and sexual violence (UNHCR 2010). Women and girls fit into a number of these risk categories. Refugee and migrant children, in particularly unaccompanied children, are at increasingly grave risk in transit. A recent UNHCR report notes:

In 2016 and 2017, children were disproportionately affected by refugee crises, with children representing 51 per cent of the global refugee population, compared to only 31 per cent in the general population. Children who move across international borders face significant risks, including trafficking, forced recruitment into armed groups, SGBV, kidnapping, child labour, child marriage, and separation from parents and other family members.

(UNHCR 2018a, 3)

Take the example of Anna, a composite story among thousands similarly occurring in 2018. Anna is young girl of 14 fleeing the rampant violence in El Salvador in the Northern Triangle of Central America. Anna was among the more than half of all El Salvadoran women that report experiencing violence, including physical or sexual violence in a quarter of the cases (KIND 2018). Anna was abandoned by her father at a young age and sexually abused by her mother's boyfriend who was a member of the powerful MS-13 gang that operates with impunity in her community and in many parts of the country as a whole. Anna was not permitted to continue in school past age 12 because the family did not have enough money to send both her and her brother. Instead, starting at age 13, Anna worked as a maid in the home of a couple that physically abused her and denied her food. When an older man promised to marry and protect her, Anna was relieved until 
he locked her in a room and allowed members of his gang to take turns raping her. Anna learned that the man was also a powerful member of the MS-13 gang. He told Anna that she belonged to him now and that she could never leave or he would kill her and her family. The gang had also recruited her brothers and uncles, and controlled their local community, demanding payments under threat of death.

Terrified for her life and that of her daughter, Anna's mother paid a guide, or coyote, to bring them to the United States. A cousin in the United States said that he would help Anna's mother find a job and support Anna so that she could go to school. Anna and her mother traveled in a group with the coyote, but were attacked by armed Mexican cartel members who took their money and documents at gunpoint. The guide abandoned the group in the desert, and without sufficient water, many of them died.

Anna and her mother arrived at the US border and turned themselves in to a border patrol agent, exhausted and begging for protection. The border patrol agent told them that he knew they had come just to work illegally, and that there were no more "slots" available for asylum so they would have to return to El Salvador. Anna and her mother were then separated. Anna was placed in a holding cell with other children while her mother was moved to an adult detention facility. The border agent told Anna that they were separating her from her mother to send a message that other "illegals" should not try to come to the United States.

Anna was terrified and freezing in the holding cell, which was kept at a very low temperature. She had no warm clothing and older boys took the one thin blanket that Anna had been given. Children around her were crying for their parents. Anna was given food that she did not recognize and could not eat easily. She felt sick with worry for her mother and herself. Later Anna was moved to a shelter for children but no one at the facility could tell her where her mother was or when she might see or speak with her. Because Anna's documents, including her birth certificate, had been stolen on her journey, the shelter workers could not confirm her identity and so she could not leave for a long time.

After a few months, Anna was released to the custody of her male cousin but her mother was kept in detention. When Anna started living with her cousin, he tried his best to help her and brought her to school to register her so she could start classes. However, the school official told them that Anna could not enroll in school because she did not have the right documents. When Anna finally was permitted to begin school, she was amongst the oldest in her grade. As she had not been in school for many years, she found the classwork daunting and feared that she was failing her cousin even as he offered her the opportunity. She missed her mother and wondered when she would see her again. Anna wondered whether if she had done something differently, her mother's boyfriend would not have abused her or maybe the other gang member would have left her alone. She felt it was all her fault. She went to the school counselor and talking helped a little but her school counselor was very busy. Anna had heard about therapists and thought going to one might help, but she did not have insurance or money and her cousin did not know how to help her. Anna felt discouraged, especially because some of the other children in her class had started telling her that the president hated her and would make sure she and the other "illegals" went home. Anna's teacher heard the children, but said nothing. Anna was terrified that she would be sent back to El Salvador and the gang member who said he owned her would lock her up or even kill her for betraying him by fleeing. Anna felt isolated and did not know where to turn for help. She had always had strong faith and she hoped that God would protect her. She thought that maybe God was punishing her because she had done something wrong, and this thought took away one of the only forms of comfort she had remaining. 
Stories like Anna's illustrate the complex, interconnected, and multifaceted challenges faced by women and child migrants in their home countries, in flight, and in their host communities. Even those who reach expected points of safety may find themselves face-to-face with policies and practices born out of new 12 levels of protectionism and cruelty. The Trump administration's practice of systematically separating children from their parents at the border, and then prosecuting parents who ask for asylum is one example, though there are numerous others in the United States and across the globe as fervent resistance to welcoming refugees grows (Podkul and Shindel 2018).

\section{What Can FBOs Do?}

FBOs have a vital role to play in the protection of women and girls in their places of origin, in transit, and in destination sites. FBOs are also uniquely positioned to make a profound and durable impact by virtue of their geographic, moral, and political reach and influence. FBOs and faith leaders have long moved with fluidity amongst stakeholders including refugee and migrant populations, government leaders, international bodies, and civil society, and even have a singular point of entry in many cases to reaching nongovernmental perpetrators of violence (UNHCR 2014, 13). FBOs also can avoid the power dynamic at times attendant to the humanitarian organization worker serving the victim. Through the equalizing commonality of faith, the FBO may approach service from an ethic of equality and a posture of humility: "there but for the grace of God go I."

FBOs have a vital role to play in the protection of women and girls in their

places of origin, in transit, and in destination sites.

International humanitarian entities may have a more short-term, less grounded commitment due to more limited missions, resources, and time. Faith institutions, by contrast, are often committed to and entrenched in communities of origin, liminal spaces of transit, and receiving communities. By their nature, they cross temporal or geographic bounds. The tenets of the faith, and the moral framework therein, survive even when buildings and villages are destroyed. This permanence is particularly important because the flow of migrants shows no signs of abating. Faith institutions will continue to play a critical role in spaces of transit and host communities, serving as vessels for protection, integration, and mutual commitment and understanding between migrants and host communities.

\section{Addressing Root Causes}

FBOs and the faith institutions also often have a long-term, deeply connected presence in countries of origin from which refugees and migrants flee. As such, they are well-positioned to help address the root causes of violence and instability that prompt migrants to leave. Because of their longterm presence and deep roots in the community, as well as in local and national centers of power, faith leaders have the best chance of reaching individual hearts and minds within corrupt political, insurgent, and transnational criminal regimes that may be otherwise untouchable by the arguments of international governance bodies. In particular, faith leaders have the moral authority to unravel narratives of myopic interpretation of religion used by power brokers to justify gender-based violence and oppression in the first place. If a reframing of righteousness can happen in the country of origin - particularly by amplifying the voice of the marginalized such as women and girls who should have equal claim to the application of religious tenets and textual interpretations - larger shifts in home countries and communities may occur. Indeed, 
we have seen that individual and community resistance to violence perpetrated or tolerated by the government often has spiritual or religious underpinnings. For example, boys who refuse to join gangs or other criminal organizations, and even those who join but then repudiate and resist them, often cite religious and moral beliefs as grounds for opposing violence. Further, as faith institutions may stay long after international agencies or other humanitarian actors have left, they can continue to work on long-term change (UNHCR 2014, 8).

\section{Opening Hearts and Minds - Beyond Politics, Xenophobia, and "Cultures of Scarcity"}

The resources that have been committed to ensuring the safety and well-being of our vulnerable brothers and sisters fleeing their home countries in search of safety, remain profoundly lacking. Indeed, tragically but not coincidentally, the enormity of need and the wide-scale movement of desperate persons within and across borders is now being met in many instances with a backlash of nationalism, xenophobia, and profound unwillingness to welcome the stranger and bring her into the fold of safety and protection. In a vicious cycle that appears to be rippling and replicating across nations and continents, this insular nationalistic posture is both responsive to, and a cause of, political leaders peddling profoundly uncharitable and false narratives about refugees and migrants. The multiple forms of violence and exclusion that the migrant experiences in transit and destination sites, in turn, breed marginalization, lack of ability to self-sustain due to restricted opportunities, and in some instances, radicalization. The view of the refugee "other" as non-integrating and non-contributing becomes a self-fulfilling prophecy precisely because the proverbial door of inclusion is shut to the stranger at every turn.

The explicit calling out of the current widespread nationalism and xenophobia within the text of the New York Declaration and CFFR is vital to making clear that the international community will not tolerate this response, which runs directly counter to agreed-upon norms and obligations. ${ }^{2}$ Strong and unambiguous condemnation by member states is necessary for bright-line moral and legal strictures within which the global compacts on refugees and migrants and implementing frameworks will be developed. But these compacts and the implementing processes that grow out of them will not alone reach the hearts and minds of those who increasingly view the refugee other as an "illegal" violator of borders who brings inevitable danger and an intolerable drain on precious resources.

Historically, faith leaders have posited that such primal fear and zero-sum protectionist mindsets need to be broken open in the spiritual language that runs deeply in hearts, across numerous traditions and communities. In the context of a global refugee crisis that asks for those who are already in varying degrees of need to open their doors to others, the siren call of incendiary political leaders, fear-mongering, and scapegoating is strong. It is perhaps only a deeply humanistic and spiritual song that can compete through the moral imperative that the other simply cannot be pushed away without also pushing away the divine, which is a cost too burdensome to bear.

Upon arrival, the refugee has profound needs and often may not be in an immediate position to fully contribute to the host community. FBOs and faith leaders can help shepherd all parties through this liminal period that otherwise may devolve if the host community views the refugee as permanently taking and not giving. The spiritual language of grace is key at this moment: faith leaders can acknowledge that the host community is suffering from the same forces of globalization

2 G.A. Res. 71/1, ๆ 14 (Sept. 19, 2016). 
and structural inequity that caused the refugee to flee, and yet ask for the community to extend grace nonetheless. The pause of grace to receive the stranger as she is - tired, in need of shelter and healing - can create a new self-fulfilling prophecy in which the refugee, taking energy from the trust engendered by that space of grace, will engage, solve, and expansively benefit the host community in turn. The shift that faith leaders and organizations can help engender then is a movement from a "culture of scarcity" (Brené Brown) to a culture of abundance and a sense that when the divine promises the possibility of plenty for all, abundance will follow precisely because all will be cared for and in turn strengthened to serve and contribute.

But over the long-term, in order to sustain the willingness of destination sites to welcome the stranger, spiritual imperatives will not be enough. FBOs must continually and explicitly acknowledge the mutual and multiplicative suffering of refugees and their receiving communities, and provide ongoing opportunities for one-to-one interaction by both sides. Indeed, FBOs, places of worship, and interfaith spaces themselves can serve as apt locations for precisely the kind of "direct personal contact between host 17 communities and refugees and migrants" that the Secretary General has cited as vital to countering xenophobia and intolerance (UNGA 2016, 15). ${ }^{3}$ Moreover, FBOs must devise thoughtful and synergistic long-term solutions that benefit both migrants and the host community. FBOs will succeed only where all parties reap the benefits of their presence and attendant strengthening of institutions and broader import of skills and resources.

Once the spiritual, political, and economic space is opened up for the migrant to claim agency and begin to contribute in the new community, the FBO can also help ensure that solutions become durable, meaning that all players are committed and present - physically and otherwise - for the long term. This void is particularly deep: less than 3 percent of refugees have access to permanent settlement in a safe country, legal integration into the country of asylum, or repatriation (Refugepoint and Women's Refugee Commission 2016).

\section{Subverting Gender Paradigms - Making Women and Girls Leaders and Teachers}

It is clear that grace by the host community is vital, because migrant women and children arrive with a backdrop of having been deeply mired in inequities that have stripped them of internal and external resources. And yet, this reality should not dampen the redemptive possibility that a new homeland can provide with separation from the limitations of the past. Women and girl refugees have incredible reserves of strength, talent, and latent power that can be released in the new setting (Paik 2014). Shed of economic and social-political gender inequalities, and in some cases, perverse religious justifications for gender oppression, refugee women and girls can be agents to subvert gender norms, teach and mentor, and find solutions not only for themselves and other migrants, but also for the communities in which they are resettling:

Crisis changes social and cultural structures quickly, which can serve as opportunities to redefine gender norms and contribute to the balancing of power in gender relations.

(IASC 2017, 25)

In many cases, the FBO can help facilitate the front-and-centering of women and girls in the diaspora precisely because of the moral authority of faith leadership to disrupt claimed religious 
norms that served as tools of oppression. The shift from dependency to agency through the disruption of gender paradigms is another way that the FBO can benefit both refugees and their host communities, by helping to alleviate oppression in all its forms and locations.

\section{FBOs at Work}

FBOs have long served as key partners to UNHCR in providing services and protection to refugees and migrants. Large FBOs have consistently been among UNHCR's top implementing partners. In 2013, the Lutheran World Federation and Islamic Relief Worldwide were amongst UNHCR's top 10 international implementing partners, and Caritas was amongst the top 10 of UNHCR's national faith-based organization partners (UNHCR 2014, 8). Across the globe, FBOs and faith institutions serve in extraordinarily challenging settings. Interfaith collaboratives spring up in emergent moments, filling a vital need. For example, after the 2011 Côte d'Ivoire presidential elections, over half a million people were displaced. Local faith institutions and FBOs including parishes of the Roman Catholic Church, Caritas, Muslim mosques and communities, and Charismatic groups, stepped up to provide immediate emergency shelters and humanitarian assistance (ibid., 11).

An April 2018study by Foundations and Donors Interested in Catholic Activities (FADICA) and Boston College's Center for Social Innovation highlighted dozens of pioneering faith-based programs providing protection for refugees and migrants (FADICA 2018, 1). These programs address root causes of migration, provide protection in transit, and facilitate successful resettlement through the provision of shelter, skills training, and trauma-healing. The FADICA study points to the faith community's global and local structures, relationships, spiritual principles, and resources that can be "repurposed to solve new problems," including the mass migration crisis (Schlumpf 2018).

Small-scale faith-based programs can have a huge impact for individuals to whom they serve as a lifeline in the midst of a treacherous journey. The Home for Migrants Shelter "Bethlehem" in Tapachula, Mexico at the Guatemalan border is one such program (SIMN 2014). Under the leadership of Scalabrinian priest Father Florenzo Rigoni, c.s., the shelter provides respite and vital services for migrants regardless of their identities and complexities. Pregnant girls, individuals with HIV and other infectious diseases, victims of sex trafficking, former prostitutes, and transgender individuals, are all welcomed and served through the on-site provision of wrap-around medical, financial, educational, and spiritual support at the shelter. The shelter exemplifies a unique blend of innovative and integrative faith-based programming providing vital interdisciplinary services for the most vulnerable in tenuous settings. In his role as a faith leader in action, Father Rigoni lives and serves fearlessly in a border zone under threat of reprisal from criminal actors, and then pivots with fluidity and ease to present in Geneva and move mountains on behalf of those he serves: "Father Rigoni is a political animal. He's become a masterful fundraiser for his shelter and can move seamlessly between the worlds of poverty and money" (Fernandez De Castro 2016). Faith leaders, institutions, and organizations like these are at the forefront of innovative protection programming for refugees and migrants, and they will be crucial to the effective and durable implementation of the promises of the Global Compacts.

\section{References}

FADICA (Foundations and Donors Interested in Catholic Activities). 2018. "Catholic Social Innovation in Today's Global Refugee Crisis." Washington, DC: FADICA. https://reliefweb. int/report/world/catholicsocial-innovation-today-s-global-refugee-crisis. 
Fernandez De Castro, Rata. 2016. “Mexico's 'Immigration Saint' wants the pope to see the 'Syria at our gate.'" Fusion, February 12. https://fusion.tv/story/267958/mexicosimmigrationsaint-wants-the-pope-to-see-the-syria-at-our-gate/.

GMG (Global Migration Group). 2017. "Handbook for Improving the Production and Use of Migration Data for Development." Washington, DC: KNOMAD (Global Knowledge Partnership for Migration and Development), World Bank. https://www.knomad.org/ publication/handbook-improving-production-and-use-migration-data-development- 0 .

Grandi, Filippo. 2017. "Statement to the Third Committee of the General Assembly, 72nd Session." New York, November 1. http://www.unhcr.org/en-us/admin/hcspeeches/59fb689a4/ statement-thirdcommittee-general-assembly-72nd-session.html.

IASC (Inter-Agency Standing Committee). 2017. The Gender Handbook for Humanitarian Action Second Edition. Inter-Agency Standing Committee. https://interagencystandingcommittee. org/system/files/2018-iasc_gender_handbook_for_humanitarian_action_eng_0.pdf.

KIND (Kids in Need of Defense) and Human Rights Center Fray Matías de Córdova. 2017. Childhood Cut Short: Sexual and Gender-based Violence against Central American Migrant and Refugee Children. Washington, DC and Tapachula, Mexico: KIND and Human Rights Center Fray Matías de Córdova. https://supportkind.org/resources/childhood-cut-short/.

KIND. 2018. "Sexual and Gender Based Violence (SGBV) \& Migration Fact Sheet." https:// supportkind.org/wp-content/uploads/2018/05/SGBV-Fact-sheet.-April-2018.pdf.

Paik, Kathryn. 2014. "Strong Girls, Powerful Women: Program Planning and Design for Adolescent Girls in Humanitarian Settings." Washington, DC: Women's Refugee Commission. https:// www.womensrefugeecommission.org/resources/document/1036-strong-girlspowerfulwomen-report.

Pittaway, Eileen, Charlotte Bell, and Linda Bartolomei. 2016. Strengthening the Response to Refugee Women and Girls in the Comprehensive Refugee Response Framework. Sydney, Australia: University of New South Wales Forced Migration Network and the Australian National Committee on Refugee Women. http://www.unhcr.org/595b7f344.pdf

Podkul, Jennifer, and Cory Shindel. 2018. "Death by a Thousand Cuts." Washington, DC: KIND. https://supportkind.org/wp-content/uploads/2018/05/Death-by-a-ThousandCuts_May2018.pdf.

RefugePoint and Women's Refugee Commission. 2016. "Self-Reliance Initiative Refugee Point." http://www.refugepoint.org/wp-content/uploads/2016/02/Refugee-Self-RelianceInitiative-Overview_web-version.pdf.

Schlumpf, Heidi. 2018. "Catholic Groups Use 'Social Innovation' to Help Refugees." National Catholic Reporter, April 21. https://www.ncronline.org/news/people/catholic-groupsseeksocial-innovation-help-refugees.

SIMN (Scalabrini International Migration Network). 2014. "Scalabrinian Priest Honored in Lengthy Newspaper Article." http://www.simnglobal.org/news_post.php?category=all\&news_ $\mathrm{id}=9022$. 
UNGA (UN General Assembly). 2016. In Safety and Dignity: Addressing Large Movements of Refugees and Migrants. UN Doc. A/70/59. https://refugeesmigrants.un.org/sites/ default/files/in_safety_and_dignity_-_ _ addressing_large_movements_of_refugees_ and_migrants.pdf.

UNHCR (UN High Commissioner for Refugees). 2010. The Heightened Risk Identification Tool, Second Edition. http://www.refworld.org/docid/4c46c6860.html.

- 2011. "UNHCR's Dialogues with Refugee Women: Progress Report on Implementation of Recommendations." http://www.unhcr.org/511d160d9.pdf.

- 2014. Partnership Note on Faith-Based Organizations, Local Faith Communities and Faith Leaders. Geneva: UNHCR. http://www.unhcr.org/protection/hcdialogue\%20/539ef28b9/ partnership-note-faithbased-organizations-local-faith-communities-faith.htm.

- 2015. Women on the Run: First-hand Accounts of Refugees Fleeing EL Salvador, Guatemala, Honduras, and Mexico. http://www.unhcr.org/en-us/publications/ operations/5630f24c6/womenrun.html.

_. 2016. "Missing Out: Refugee Education in Crisis." http://www.unhcr.org/57d9d01d0.

- 2018a. Policy on Age, Gender and Diversity. UN Doc. UNHCR/HCP/2018/1. http://www. unhcr.org/5aa13c0c7.pdf.

- 2018b. "Towards a global compact on refugees: Written contributions." http://www. unhcr.org/595259bd4.

United Nations. N.d. "Compact for Migration." https://refugeesmigrants.un.org/migrationcompact. 


\title{
International Migration Policy Report
}

\section{Protecting Families and Facilitating Their Integration}

\author{
Linda Rabben ${ }^{1}$ \\ University of Maryland
}

"Our shared response may be articulated by four verbs: welcoming, protecting, promoting and integrating migrants and refugees."

- Pope Francis I, August 2017

\section{Who Are the Migrants? Where Do They Come From? Where Are They Going?}

Individuals and families around the world flee from their homes every day because of war or civil conflict, natural disasters, climate change, persecution, discrimination, and dire poverty. In response, governments are developing two Global Compacts, one on refugees and the other on "safe, orderly and regular migration," under United Nations (UN) auspices. These agreements are nonbinding, aspirational documents intended to set the parameters of governmental and intergovernmental actions and policies in the coming years. Both compacts are supposed to be adopted by the end of 2018.

Meanwhile the recent crisis in the United States, with the government separating migrant children from their parents and then proposing to detain them together indefinitely, has drawn increasing public attention to the often-dire situation of migrant families. As they become aware of the immediate problem, more and more people are asking what they can do to protect vulnerable migrant families from mistreatment and help them integrate into their new societies.

As they become aware of the immediate problem, more and more people are asking what they can do to protect vulnerable migrant families from mistreatment...

For citizens and migrants to understand and address the crisis, it is necessary to get a grip on its character and magnitude. At the end of 2017, the UN High Commissioner for Refugees (UNHCR) reported 68.5 million forcibly displaced people worldwide. Of those, 24.5 million were classified as refugees; 19.9 of the 24.5 million were under UNHCR's mandate; and 5.3 million were Palestinians under UN Relief and Works Agency for Palestine's (UNRWA) mandate. Internally displaced people numbered 40 million, and 3.1 million were asylum seekers. UNHCR could account for 3.9 million of the estimated 10 million stateless people around the world.

1 An associate research professor of anthropology at the University of Maryland, Linda Rabben has worked for a refugee resettlement agency and campaigned on behalf of migrants. She has published Sanctuary and Asylum: $A$ Social and Political History (2016) and other books, reports, and articles on migration and human rights. 
Developing countries hosted 85 percent of refugees. The top eight refugee host countries were: Turkey (3.5 million); Uganda (1.4 million); Pakistan (1.4 million); Lebanon (998,900); Iran $(979,400)$; Germany $(970,400)$; Bangladesh $(932,200)$; and Sudan $(906,600)$. Major western receiving countries in 2017 included France, the United States, Greece, and Canada.

Almost 2 million new asylum claims were filed in 2017. The United States received 331,700 asylum applications, followed by Germany, with 198,300; Italy, with 126,500; and Turkey, with 126,100. Only Germany had fewer new applications than in 2016. Some 3 million asylum seekers were waiting for decisions. Because of a huge backlog of cases, US immigration courts handed down only 65,600 decisions. The highest numbers of asylum applications came from Afghans $(124,900)$, Syrians $(117,100)$, Iraqis $(113,500)$, Venezuelans $(111,600)$, and Congolese from the Democratic Republic of Congo (104,700). Central American and Mexican asylum seekers were nowhere near the top of the list.

Syrians comprised the largest forcibly displaced population: Out of a national population of 20 million, 6.3 million were refugees living outside the country, and 6.2 million were internally displaced. Some 4.8 million Afghans were refugees or asylum seekers, and more than a million were internally displaced. A long line of countries followed, each with more than 2 million internally or externally displaced people. The top seven exporters of migrants in 2017 were Syria, Colombia, Afghanistan, South Sudan, the Democratic Republic of Congo, Iraq, and Somalia. Most refugees flee to neighboring countries, but more than a million have arrived in Germany from developing countries since 2015 (UNHCR 2018c).

Children under the age of 18 comprised 52 percent of the world's refugee population in 2017, and the UN Children's Fund (UNICEF) estimated 50 million child migrants worldwide. One out of every 200 children was a refugee, and one out of four asylum applicants in the European Union was a child in 2015-2016. During the first half of 2016, some 60,000 children arrived by sea in Greece from Syria, Afghanistan, and Iraq (EFRC 2016/2018). Unaccompanied and separated children numbered 138,700 in 2017.

It is very difficult to determine exactly how many families have recently sought refuge outside their home countries, particularly in states without a strong, accurate, and continuous registration system (GMG 2017, 55). In Europe the predominant pattern has been for young males to arrive alone and try to bring their families later. In 2016 the German government issued 105,000 visas to family members (mostly wives) joining (mostly male) relatives already in Germany, but its migrant family-reunification program was much larger than those of other receiving countries (Deutsche Welle 2017). Many families probably entered host countries without authorization, and so their numbers are under-recorded. One can only estimate that hundreds of thousands of families perhaps millions of people - have fled to safety around the world in recent years.

Although numbers of refugees, asylum seekers, and other migrants entering some host countries (such as Germany, Austria, Sweden, and the United States) have decreased since their height in 2015-2016, medium- to long-term issues of resettlement and integration are demanding greater attention and resources. The traditional approaches of voluntary repatriation, resettlement and local integration "have proven inadequate ... as a growing number of people ... remained in precarious situations and with little hope of a durable solution in the future" (UNHCR 2017, 24). Thus the magnitude of the challenges to be addressed by the Global Compacts continues to grow. 


\section{What Do Refugee and Migrant Families Find?}

Reception of migrants and refugees varies. Some countries erect legal or physical barriers that hinder or limit their entry, sometimes for months or years. Police and border guards may abuse them. Governments may detain or even summarily expel migrants, including children, in violation of international law. Refugees and migrants often experience discrimination and social isolation. Language barriers, lack of access to physical and mental health services, exclusion from education, exploitation, unemployment, inadequate housing, and destitution make everyday survival difficult. They may encounter a warm and sympathetic welcome at first, but over time stresses and tensions lead to hostility or indifference from host populations. Separation from family, loss of dignity, and traumatic experiences before, during, and after arrival may take a severe psychological toll. Resettlement may be accomplished in months, but integration into the new society often takes generations.

Refugee and migrant families face special challenges during and after their journeys to safety.

Refugee and migrant families face special challenges during and after their journeys to safety. Members may become separated or lost en route or after arrival. Children and adolescents are especially vulnerable to abuse, exploitation, and trafficking. Detention of migrant children is of special concern. Unaccompanied children are also at particularly high risk of destitution. The lack of guardians for children has been problematic in Austria, Finland, France, Sweden, Italy, and Greece, which has no guardianship system at all (FRA 2018). As a result, children have been placed in inadequate or unsafe reception centers or simply abandoned.

Even after resettlement, family reunification may be delayed for months or years. The consequences of separation may include physical injury or severe emotional trauma. Additional threats to family integrity include: denial of protected status and documentation; lack of full protection for asylum seekers while their cases are considered; acute economic hardship; lack of authorization to work; high living costs and debt; and family breakdown as a result of separation, detention, and deportation.

On the other hand, refugees and migrants may find individuals, community groups, religious institutions, and civil society organizations that are eager to help them in myriad ways. Some well-established, international, national, and local organizations run effective programs with highly qualified staff and adequate budgets. Other groups provide limited services coordinated by volunteers. Families and individuals may offer various kinds of informal help. A patchwork of programs, projects, and initiatives, sometimes sporadic or duplicative, is available in many countries, but these are not always easy to find. In some countries humanitarian assistance may be unavailable outside of refugee camps, such as in urban areas where many refugees live. This "means that local communities find themselves ill-equipped ... to cope with the high influx of forced migrants with complex needs" (Mavelli and Wilson 2017, 183).

As the number of migrants fell in 2017, reception centers closed, leaving remaining facilities unable to cope with new arrivals. The most vulnerable, including children, sick and disabled people, and the elderly, suffered damage to their well-being as a result. But as UN Deputy Secretary General Amina Mohammed pointed out, "Around the world, faith-based organizations are found on the front lines of crisis, providing food, shelter, education, and medical and psychological support to 
migrants and refugees. [They] work tirelessly to assert human rights and dignity, independent from national and regional political interests" (quoted in Auza 2018).

\section{What Do They Need?}

Refugee, asylum-seeker, and other migrant families need many kinds of assistance, from legal representation, health services, and language instruction to financial aid, guardianship, and help navigating complex bureaucratic structures (GCIR 2016).

Migrant children, who are particularly vulnerable, need special attention at borders, between states, in reception centers, and during and after resettlement. A comprehensive child protection system is imperative. Its guiding principle should be the child's best interests. Important protection issues in transit include: trafficking; separation from family; inadequate reception facilities; gaps in guardianship; lack of access to education and health care; delays in family reunification; and lack of information for children, among many others.

Furthermore, the right to family life and family unity is enshrined in the Universal Declaration of Human Rights, the Convention on the Rights of the Child, and many other international treaties and agreements (Nicholson 2018). The Office of the UN High Commissioner for Human Rights (OHCHR) has emphasized that human rights protections, especially for migrants in vulnerable situations, should be central to the Global Compacts.

Even migrants outside the categories of the 1951 Convention Relating to the Status of Refugees ("Refugee Convention") should be protected, because of the situations they fled, the circumstances of their travel, the conditions on arrival, their identity, sexual orientation, disability, or health condition. OHCHR principles and guidelines for the protection of migrants include decriminalization of migration, the end of detention of children and families, development of non-custodial, community-based alternatives to detention, and prevention of refoulement and collective expulsion.

OHCHR has published "key messages for the Global Compacts," including: respect for the dignity and human rights of all migrants; police protection; access to justice, housing, health care, education, social protection, and labor rights; protection against torture and gender-based violence; arbitrary detention; and attention to serious health issues. Finally, OHCHR stresses that migrants themselves should participate in the development of the Global Compacts (Al Hussein 2018).

Faith-based organizations can take the lead in emphasizing and advancing these human rights principles in their work. An eloquent expression of these values may be found in UNHCR's 2013 statement, "Welcoming the Stranger: Affirmations for Faith Leaders."

\section{Who Helps?}

In addition to governments, nongovernmental and faith-based organizations have undertaken numerous initiatives to help migrants as they wend their way across the world. For more than 100 years the American Friends Service Committee (Quakers) has worked with other religious and secular organizations to provide humanitarian relief to refugees, asylum seekers, and other migrants in many countries (Rabben 2018). Some governments have partnered with private 
organizations or given them significant financial support. For example, in the United States nine nonprofit, voluntary agencies, of which six are faith-based, run the refugee resettlement program under contract with the federal government.

In many countries, old and new faith-based groups are providing direct or indirect assistance of diverse kinds to migrants. Jesuit Refugee Service established the Welcome project in 2009, after discovering that asylum seekers were sleeping on the street near the Gare de l'Est in Paris. The project's coordinator, Jean-Marie Carrière, wrote: "Welcome is a network of families and religious communities hosting asylum seekers in their home on a short-term basis. The goal is to provide an asylum seeker that the state has not hosted an alternative to living in the street. The refugee stays five weeks in a family, and if he remains in the network, he will then join another family or another community. He will be helped by the network for several months, until a more stable situation can be found" (Mavelli and Wilson 2017, 151).

Also in France, volunteers from religious congregations in Britain, Holland, and other countries keep arriving to deliver humanitarian supplies or work in the warehouse in Calais, where a community kitchen prepares meals, and thousands of pounds of clothing, shoes, and other items wait to be sorted and distributed to destitute migrants. Some of the Calais volunteers have gone on to greet migrants on the beaches of Lesvos or the Italian coast.

In the Middle East and Africa, Islamic Relief Worldwide has sponsored interfaith meetings between migrants and communities, "to facilitate mutual understanding and build bridges based on sympathy and compassion" (Mavelli and Wilson 2017, 185). Islamic Relief USA (n.d.) "provides relief and development in a dignified manner regardless of gender, race or religion," collaborating with the Jewish relief organization HIAS, as well as Christian organizations like Lutheran Immigration and Refugee Service, Catholic Relief Service, and World Vision (Christina Tobias-Nahi, telephone interview, Takoma Park, MD, May 14, 2018).

In 2016-2017 the Catholic Community of Sant'Egidio began collaborating with the Federation of Evangelical Churches, the Waldensian Church, the Methodist Church, the Protestant Federation of France, the Conference of Bishops of France, Federation de l'Entraide Protestant, and Secours Catholique, to establish "humanitarian corridors" from the Middle East to Italy and France. With government cooperation they arrange for vulnerable migrants - victims of persecution, torture, and violence, families with children, the elderly, sick, and disabled - to obtain humanitarian visas and fly to safety. After their arrival, the migrants stay in private homes, learn Italian or French, and get help to find work. Some 2,000 migrants have participated in the project over the past two years (Community of Sant'Egidio n.d.; Francis 2017).

Soka Gakkai, an international Buddhist sect, organized a community project in conjunction with UNHCR and the Muslim Aid Foundation, to help refugees in Malaysia. In 2016, 50 local sect members helped paint a Muslim school that houses more than 80 Rohingya refugee children (SGM 2016).

Eurodiaconia, a Christian network of 40 organizations, institutions, and churches, provides social and health services and education in more than 30 European countries. Based in Brussels, it is supported by local and national governments, the European Community Program for Employment and Social Solidarity, the Organization for Security and Cooperation in Europe, and UNHCR. Some of its projects in Austria, the Czech Republic, Finland, France, Germany, Hungary, Kosovo, Norway, Poland, Serbia, and Sweden focus on migrant families. 
For example, one of Eurodiaconia's Austrian projects provides care to unaccompanied minors, aged 13 to 18, including accommodation, healthcare, education, German language instruction, legal aid, counseling, and leisure activities. A project in Germany trains migrant mothers to "develop more self-confidence, become bridge-builders within the local community and gain valuable professional skills" (Roy 2014, 18). The mothers provide counseling in migrant families' homes.

Diakonie Kosova provides leisure activities and language instruction to Roma, Ashkali, and Egyptian children and families who were forcibly returned to Kosovo. (Ashkali and Egyptians are Albanian-speaking ethnic groups in Kosovo. They are similar to but separate from the Roma.)

The Ecumenical Humanitarian Organization (EHO) in Serbia administers a shelter for Roma street children who are excluded from schools and out of touch with their families. The project's purposes are to prevent or reduce damage to the children's physical and mental health, connect them with state institutions, advance their human rights, and integrate them into Serbian society. EHO's Roma Resource Center serves those who lost residence permits in other European Union (EU) countries and were forcibly returned to Serbia. The center provides school shoes, legal aid, job-search help, grants for Roma-run enterprises, and construction materials for houses.

In Norway the Salvation Army runs a family workshop program that provides food and clothing to migrants. They also facilitate women's rights discussions. The project is supported by the International Organization for Migration and the Norwegian government.

Catholic bishops in Argentina, Bolivia, Brazil, Chile, Colombia, Ecuador, Paraguay, and Peru have created Bridges of Solidarity, a program to assist Venezuelan migrants traveling through or settling in neighboring countries. Conferences of Catholic bishops in Asia, particularly the Philippines, maintain strong ties with and seek to protect their citizens abroad. Parishes, local Caritas offices, and other Catholic institutions provide shelters and centers for vulnerable migrants; help with job and housing searches, work and residence permits, and social inclusion; facilitate access to education and health services; and train church workers to provide assistance and raise awareness (Glatz 2018). The Scalabrini Network of Shelters serves more than 250,000 migrants and refugees a year, providing them with protection, food, lodging, clothing, legal services, and job training and placement programs.

These are only a few of the thousands of faith-based initiatives for migrants taking place in scores of countries around the world.

\section{Faith-Based Organizations and the Global Compacts}

Addressing the complex problems and needs of millions of refugees, asylum seekers, and other migrants, including families, has overwhelmed many governments, from Denmark to South Africa. Migrant families' difficulties - including separation, prolonged detention, lack of access to legal representation, and inadequate health care, employment, education, or housing - are especially challenging to address. Even when governments provide significant financial and human resources to resettlement, reunification, and integration initiatives, citizens often react negatively, feeling that their pressing needs are not being given proper attention or priority. Political and social reactions against migrants exacerbate their isolation, forestall integration, and may put them in danger. 
Yet thousands of individuals, congregations, and organizations have shown readiness to assist refugees over the years: "Many faith-based organizations have a longstanding tradition of being able to mobilize resources and networks for a wide variety of altruistic activities, ranging from local, social, and community work, to help deliver humanitarian aid and disaster relief in countries around the world" (Lyck-Bowen and Owen 2018, 3). Assistance by faith-based organizations is especially important at times like the present, when migrants are under political or even physical attack.

Religious institutions can also provide an important social-support network to new migrants.

Religious institutions can also provide an important social-support network to new migrants. As sanctuaries for undocumented migrants, houses of worship can help to facilitate integration in host societies. Local faith groups have developed community-based initiatives that help meet the needs of vulnerable migrants. These projects mobilize in-kind, financial, business, educational, and other forms of assistance (FADICA 2018).

International faith-based institutions can create "a culture of solidarity" that crosses borders, while cultivating and advancing lay leadership on all levels. The Roman Catholic Church, for example, has been known as a "church of immigrants" in the United States and other countries since the nineteenth century, and it views its connection to the migration experience - both historical and current - as central to its identity (Kerwin and George 2014).

Applying human rights principles, faith-based organizations can address both co-religionists and followers of other faiths. Since 84 percent of the world's population identifies as belonging to a religious group, religious belief and practice provide a "powerful coping mechanism for the forced migration community ... a source of spiritual solace ... a means by which to make sense of acute loss and suffering; enabling a sense of shared identity and belonging among host societies; and allowing disparate migrant groups to build new communities" (Mavelli and Wilson 2017, 176, 178).

In light of UNHCR's finding that more than 50 percent of the world's refugees come from Muslimmajority countries, interfaith collaboration is urgently needed, especially in the many countries where Muslims are in the minority (IOM 2009).

Collaboration among religious groups, secular organizations, and governments, both within and beyond societies, faces many challenges, however:

- antagonism toward or exclusion of members of disparate faiths;

- hate speech or incitement to violence against individuals and communities;

- proselytization and pressure to convert as a condition of assistance;

- early marriage or other harmful traditions;

- gender stereotypes and disregard for women's rights, children's rights, and vulnerabilities;

- stigma and discrimination toward people with AIDS and LGBTI individuals and groups;

- $\quad$ power inequalities in interactions between service providers and receivers;

- neglect of rights-based approaches to problems;

- lack of coordination in emergency situations; and

- power imbalances between large international organizations and small, local institutions (Türk, Riera, and Poirier 2014). 
Faith-based organizations can counter these problems by:

- $\quad$ working and advocating to keep families intact and well-supported;

- providing physical protection and facilitating access to humanitarian aid;

- deterring violence through presence and accompaniment;

- mediating tensions among migrants, internally displaced people, and host communities;

- promoting reconciliation and peacebuilding;

- combating xenophobia and discrimination;

- preventing and responding to forced recruitment, exploitation, and sex- and gender-based violence;

- improving reception conditions and accompanying detainees;

- providing legal aid and asylum case management;

- advocating reforms in immigration systems; and

- supporting refugee resettlement and local integration efforts (Turk et al. 2014).

Multireligious cooperation can do much to forestall the criticisms commonly leveled at sectarian organizations. For example, in Germany faith-based groups (usually Muslim) with little experience in integration initiatives have successfully partnered with groups (usually Christian) that have more experience in assisting migrants. Muslim volunteers in Sweden, with language and cultural expertise in the cultures migrants came from, helped church groups that had greater institutional knowledge of immigration procedures.

In the process, diverse communities have built better relationships, humanized migrants and hosts, and broken down damaging stereotypes. Furthermore, multireligious initiatives have helped faith communities "establish themselves as important contributors to the welcoming and integration of migrants" vis-à-vis secular and government organizations (Lyck-Bowen and Owen 2018, 18). By advancing family unity, faith-based groups enable refugees and migrants to make significant social and economic contributions to the host society over the long term. Through their actions, they model cooperation, collaboration, and solidarity in building peaceful and diverse societies.

\section{What Can Faith-Based Organizations Do?}

Drafts of the Global Compacts have focused more on migrant and refugee children than on families, which are mentioned in passing. Among other things, they recommend that governments:

- facilitate migrant family reunification;

- consider the migrant child's best interests in guardianship decisions;

- assist migrant trafficking victims, especially children;

- end migrant child detention and allow children to remain with family members or guardians in noncustodial situations;

- facilitate migrant family remittances;

- provide basic services, including education, to migrant children;

- invest in national child protection systems; and

- establish emergency resettlement facilities for women and children (UNHCR 2018a,b).

The Migrants and Refugees Section of the Vatican Dicastery for Integral Human Development has insisted that the compacts highlight the broad need to protect and promote the "integrity and well-being of the family" (Migrants and Refugees Section, Vatican Dicastery for Integral Human Development 2018, para. 14). In particular, it recommends that states embrace family 
reunification "independently of financial requirements"; permit family members to work; search for lost family members; combat the exploitation of minors; and ensure that work does not undermine members' health or right to education (ibid.). The Section also supports alternatives to detention for minors that are separated from their families or unaccompanied, as well as centers to identify and process migrants and help to reunify families (ibid., para. 7).

Lutheran Immigration and Refugee Service (LIRS) (2016) has made numerous recommendations for nongovernmental action on behalf of refugee children and families in its report, Childhood Interrupted. These include:

- developing and implementing a family-based care model for migrants;

- advocating removal of barriers to family reunification;

- $\quad$ promoting special weight and consideration to family unity in immigration policy;

- providing support for children and families on arrival in the host country. Such support includes child-welfare, health, and educational services, accommodation, and family tracing and reunification efforts;

- sponsoring programs for children who are out of school;

- supporting anti-bullying and social-cohesion programs for children and families;

- training parents, educators, and others in authority in positive disciplinary techniques;

- helping families with school-related expenses;

- funding medical equipment and mental-health services for children and families; and

- providing technical assistance for implementation of family integration strategies to communities, resettlement agencies, local groups, ethnic and faith-based organizations, and schools.

Thanks to their capacity for empathy and altruism, their respect for human rights, and their extensive networks and experience in assisting refugees, asylum seekers, and migrant families, faith-based organizations have much to contribute to the development of the Global Compacts and, perhaps more importantly, to their implementation.

\section{References}

Al Hussein, Zeid Ra'ad. 2018. “Open letter from the United Nations High Commissioner for Human Rights on protecting and promoting the human rights of all migrants within the global compact on safe, regular and orderly migration." Geneva: Office of the High Commissioner for Human Rights.

Auza, Benardito. 2018. "Sharing the Journey of Migrants and Refugees: An Interfaith Perspective on the Global Compacts." New York: United Nations.

Buber-Ennser, Anne Goujon, Judith Kohlenberger, and Bernhard Rengs. 2018. "Multi-layered Roles of Religion among Refugees Arriving in Austria around 2015." Religions 9(5):1-16. https://doi.org/10.3390/rel9050154.

Community of Sant'Egidio. N.d. "Humanitarian Corridors for Refugees." http:// archive.santegidio. org/pageID/en/humanitarian-corridors-for-refugees.html.

Deutsche Welle. 2017. "Many more family members join refugees in Germany." Deutsche Welle, January 17. www.dw.com/en/many-more-family-members-join-refugees-ingermany/a-37186133. 
EFRC (European Forum on the Rights of the Child). 2016/2018. "The Protection of Children in Migration. General Background." Tenth European Forum on the Rights of the Child, November 29-30, 2016.

FADICA (Foundations and Donors Interested in Catholic Activities). 2018. "Catholic Social Innovation in Today's Global Refugee Crisis." Washington, DC: FADICA.

FRA (European Union Agency for Fundamental Rights). 2018. "Migration to the European Union: Five persistent challenges." Brussels: FRA.

Francis, Céline. 2017. "Humanitarian Corridors for Refugees." http://www/europe-infos.eu/ humanitarian-corridors-for-refugees.

GCIR (Grantmakers Concerned with Immigrations and Refugees). 2016. “Central American Refugee and Migrant Children and Families Seeking Protection in the United States. Updated Recommendations for Philanthropic Response." Sebastopol, CA: GCIR.

Glatz, Carol. 2018. "Bishops' conferences join efforts to help Venezuelan refugees." Catholic News Service, May 7. https://cruxnow.com/global-church/2018/05/07/bishops-conferencesjoin-efforts-to-help-venezuelan-refugees/.

GMG (Global Migration Group). 2017. "Handbook for Improving the Production and Use of Migration Data for Development." Washington, DC: KNOMAD (Global Knowledge Partnership for Migration and Development), World Bank. https://www.knomad.org/ publication/handbook-improving-production-and-use-migration-data-development-0.

Gubernskaya, Zoya, and Joanna Dreby. 2017. "US Immigration Policy and the Case for Family Unity." Journal on Migration and Human Security 5(2): 417-30. https://doi.org/10.1177 /233150241700500210.

IOM (International Organization for Migration). 2009. "Integration: A Multifaith Approach. 20072009. Project Report." Helsinki: IOM.

Islamic Relief USA. N.d. “Mission, Vision, and Values."http://www/irusa.org.

Kerwin, Donald, and Breana George. 2014. US Catholic Institutions and Immigrant Integration: Will the Church Rise to the Challenge? Rome: Lateran University Press.

LIRS (Lutheran Immigration and Refugee Service). 2016. "Childhood Interrupted: Lost Years for the Children of the Syrian Refugee Crisis." Baltimore: LIRS.

Lyck-Bowen, Maibritt, and Mark Owen. 2018. "A Multi-religious Response to the Migrant Crisis in Europe: A Preliminary Examination of Potential Benefits of Multi-religious Cooperation on the Integration of Refugees." Journal of Ethnic and Migration Studies. https://doi.org/10. 1080/1369183X.2018.1437344.

Mavelli, Luca, and Erin K. Wilson. 2017. The Refugee Crisis and Religion: Secularism, Security and Hospitality in Question. London/New York: Rowman and Littlefield.

Migrants and Refugees Section, Vatican Dicastery for Integral Human Development. 2018. "Towards the Global Compacts on Migrants and on Refugees." Vatican City: Vatican Dicastery for Integral Human Development. 
Nicholson, Frances. 2018. "The Right to Family Life and Family Unity of Refugees and Others in Need of International Protection and the Family Definition Applied." Geneva: UNHCR.

Rabben, Linda. 2018. “The Quaker Sanctuary Tradition." Religions 9(155): 1-8. https://doi. org/10.3390/rel9050155.

Roy, Heather, ed. 2014. "The Integration of Children and Families with a Migration Background. An Overview of Projects among Eurodiaconia Members." Brussels: Eurodiaconia.

SGM (Soka Gakkai Malaysia). 2016. "SGM Selangor Helps Paint School for Refugees.” www.sgm. org.my/en/?cur=news/view\&id=515\&title=SGM_Selangor_Helps_Paint_School_for_ Refugees.

Türk, Volker, José Riera and Marie-Claude Poirier, eds. 2014. On Faith-Based Organizations, Local Faith Communities and Faith Leaders. Geneva: UNHCR.

UNHCR (United Nations High Commissioner for Refugees). 2013. "Welcoming the Stranger: Affirmations for Faith Leaders." http://www.unhcr.org/en-us/protection/ hcdialogue/51b6de419/welcoming-stranger-affirmations-faith-leaders.html. Geneva: UNHCR.

- 2017. Global Trends: Forced Displacement in 2016. Geneva: United Nations.

_. 2018a. "Global Compact for Safe, Orderly and Regular Migration." Draft revision 1, March 26.

_. 2018b. "The Global Compact on Refugees." Draft 2, April 30.

—. 2018c. Global Trends: Forced Displacement in 2017. Geneva: UNHCR. 


\title{
International Migration Policy Report
}

\section{The Role of Faith-Based Organizations in Immigrants' Health and Entrepreneurship}

\author{
Mike Nicholson \\ Center for Migration Studies
}

As of 2017, over 258 million people lived outside of their home country, an increase of almost 50 percent relative to 2000 (UN DESA 2017). Many of these people, including countless women and children, were forced from their homes and families by violence and natural disasters. Many live and work under precarious and exploitative conditions, often facing the specter of deportation. Others are victims of human trafficking, subject to violence and exploitation.

As migration flows continue to mount, policies protecting vulnerable migrants' rights, particularly their right to basic health care and work, are critical to safeguard their dignity and facilitate their successful integration into host societies. Policies enhancing migrants' access to health care and promoting migrant entrepreneurship, in particular, strengthen vulnerable migrants' self-sufficiency and enable them to lead fulfilling lives. While governments and international organizations increasingly recognize the need for such policies, migrants' access to health care remains limited across much of the globe. Indeed, migrants' foreign citizenship or lack of legal status often impedes such access. Even when health care is available, providers often lack the linguistic and cultural skills necessary to treat migrants effectively.

Migrants also frequently face labor market difficulties. Jobs are often scarce, and foreign-earned skills credentials often go unrecognized in host states. Some employers prefer to hire natives, particularly when migrants do not speak their host societies' languages. In such contexts, entrepreneurship constitutes a promising way for migrants to support themselves and their families. Those wishing to start businesses, however, are often hampered by a lack of startup capital or knowledge of local business law.

This paper highlights the potential of faith-based organizations to improve the health and work outcomes of vulnerable migrants. Faith-based organizations are defined as agencies founded on the principles of faith and religion. They include religious congregations (e.g., churches, mosques, synagogues, or temples), programs or projects sponsored by a religious congregation, and nonprofit organizations founded by religious congregations or individuals motivated by religion (Ebaugh, Pipes, Chafetz, and Daniels 2003). Such organizations possess valuable networks and resources that can support migrants' access to health care and productive employment even under challenging circumstances. They often play a vital role in strengthening the livelihoods of the world's most vulnerable migrants, including refugees, asylum seekers, and migrants without legal status.

This paper will proceed in two parts. Part I will describe obstacles to the provision of adequate health care to migrant populations. It describes how faith-based organizations expand health care to underserved populations and play a vital role in building trust between health care providers and migrant communities. Part II describes obstacles to migrant employment and explains how faith-based organizations are promoting migrant entrepreneurship through training, referrals, 
and targeted micro-loans, among other services. The paper concludes with a brief discussion of how the international community might support faith-based organizations' efforts in these areas. In particular, the Global Compact on Migration should recognize faith-based organizations' unique resources and credibility among vulnerable migrant populations. It should also emphasize the potential for productive cooperation between international organizations and faith-based organizations in the areas of migrant health care and entrepreneurship.

\section{Migrant Health: Challenges and Responses}

Access to health care is vital to migrants' ability to lead fulfilling lives. Such access is a fundamental right enshrined in international law. Article 25 of the 1948 Universal Declaration of Human Rights emphasizes that "[e]veryone has the right to a standard of living adequate for the health and well-being of himself and of his family, including food, clothing, housing and medical care and necessary social services." Likewise, Article 2.2 of the International Covenant on Economic, Social, and Cultural Rights stipulates that all individuals must have access to health care. States are expressly prohibited from discriminating against non-nationals on the grounds of "race, colour, sex, religion, language, religion, political or other opinion, national or social origin, birth or other status." Per international law, then, governments are obligated to provide migrants with adequate health services, support the prevention, treatment, and control of diseases, and facilitate health education. This includes providing affordable health insurance, treatment, and essential medications. States are responsible for ensuring that health care is provided equitably to all individuals within their borders, regardless of their immigration status.

Access to health care is vital to migrants' ability to lead fulfilling lives.

\section{a. Migrant Health Challenges}

Despite these international legal obligations, states frequently bar noncitizens from receiving health care, particularly when they are unauthorized or awaiting adjudication of their asylum claims. Some countries provide such migrants access only to emergency care, while others provide only rudimentary health services at detention centers. As of 2016, unauthorized migrants had immediate access to universal health care only in Thailand, and even there some hospitals refused to provide them with insurance (Yan 2016).

Barring migrants from health care constitutes a violation of their rights under international law. Migrants' exclusion from health care is based on the misperception that treating noncitizens would place a heavy burden on national healthcare systems. In general, however, migrants tend to be younger and in better health than native-born populations (IOM 2013). Barriers to health care in receiving countries, however, can put their health at risk. Health problems left untreated can worsen over time, and limiting migrants' access to health care can ultimately lead to longer hospital stays, more acute health crises, and higher mortality rates (Ruiz-Casares et al. 2010).

Migrants in detention may face particularly acute health risks. Doctors and nurses are not always available in detention facilities, and those available do not always have the authority, equipment, or medicine to properly treat patients. In the United States, a lack of adequate medical staffing at many detention facilities has created significant treatment delays and backlogs, contributing to the deaths of numerous detainees (Priest and Goldstein 2008; Yu 2018). The availability of specialized health services is often limited. Pregnant detainees, in particular, often lack adequate 
care (IOM 2013). Detainees also frequently lack access to counseling and psychiatric care. Indeed, a majority of Immigration and Customs Enforcement (ICE) detention centers lack mental health providers (Seattle University School of Law International Human Rights Clinic and OneAmerica 2008; AIC 2018).

Detention centers are also frequently overcrowded and possess poor sanitation. This can increase the prevalence of diseases, particularly infectious and psychiatric disorders (Semenza et al. 2016). A study of over 2,200 unauthorized immigrants in Malta found that a majority of health problems experienced by detained migrants resulted from overcrowding, poor hygiene, and poor nutrition at detention centers (Padovese 2016).

Migrants' exclusion from health care not only increases their vulnerability, but also exposes their host societies to greater financial costs and public health risks. Indeed, medical conditions left untreated may become more expensive and difficult to treat over time. Waiting for treatment may ultimately lead to longer hospital stays, placing a burden on healthcare systems. Finally, contagious conditions may spread to migrants' communities and to native populations. Antiretroviral treatments, for example, are not available to irregular migrants in many European countries, heightening the risks of HIV transmission (European Center for Disease Prevention and Control 2016).

Even when migrants have legal access to health care, it is difficult for them to receive adequate treatment. For one, they often have health needs that differ from those of native-born populations, complicating their treatment. For example, many suffer from trauma due to exposure to violence or loss prior to migration. Those displaced due to conflict or natural disasters may be at greater risk of adverse outcomes (European Center for Disease Prevention and Control 2016). ${ }^{1}$ They have often experienced traumatic events en route to their host countries or upon arrival (ibid.). Those who left family members behind or who lack legal status are particularly prone to psychological stress, which can exacerbate physical ailments (Semenza et al. 2016). A 2017 study of young immigrants in the United States found that refugee youth are exposed to more violence than other immigrants on average, and consequently experience higher rates of dissociative symptoms, traumatic grief, somatization, and phobic disorders (Betancourt et al. 2017).

Migrants also arrive from regions with different epidemiological and health profiles than their host countries, or have genetic predispositions to conditions that are uncommon in those countries. Tuberculosis, iron deficiencies, micronutrient deficiencies, and dental diseases are particularly common (Betancourt et al. 2017). HIV and syphilis are also very common. They may also lack formal medical records or histories, complicating health providers' efforts to provide accurate diagnoses and effective prescriptions (Jensen et al. 2011).

Migrants also frequently work in environments where they are at risk of work-related injuries. Studies suggest that they are at higher risk of workplace-related accidents than natives (Eurofound 2007; Sri Lanka Bureau of Foreign Employment 2009). Many work in hazardous sectors such as mining, construction, and agriculture. A survey of nearly 30,000 workers in 31 European countries revealed that migrants were more likely than native-born workers to be exposed to high temperatures, loud noises, and strong vibrations, and to stand for long periods of time (Ronda Perez et al. 2012). They often work long hours and sometimes develop fatigue, putting them at risk of occupational accidents. They might also be exposed to pesticides and other chemicals. Furthermore, migrants might be reluctant to report dangerous working conditions or exploitative

1 See also Pumariega, Rothe, and Pumariega (2005); Kumar, Seay, and Karabenick (2015). 
practices, particularly if they lack legal status and fear deportation. In some countries, they are not allowed to form or join trade unions to advocate for better working conditions (ibid.). Linguistic limitations can also impede their understanding of safety procedures and limit their ability to file complaints, placing them at further risk.

Female migrants are also at high risk of sexual exploitation in the workplace, particularly if they lack status or earn their living as domestic workers. They might be reluctant to report rape or abuse by their employers for fear that they will be deported or lose their livelihood. Such individuals might be at a particularly high risk of sexually transmitted diseases.

Migrants are also often unaware of services available to them, particularly when little information about health care is available in their own languages. In particular, they are frequently unaware of options for pre- and post-natal care. In Western Europe, this has contributed to higher rates of mortality and morbidity among migrant women than among the native-born (Ronda Perez et al. 2012).

Unauthorized migrants are particularly unlikely to seek care. They often fear that seeking health care will place them or their families at risk for deportation. Correspondingly, a 2007 study of Mexican immigrants in California found that unauthorized immigrants were 27 percent less likely than their authorized counterparts to have visited a doctor in the previous year (Bustamante 2012).

In many countries, unauthorized migrants lack access to health insurance and must pay for their health care out of pocket. Many, thus, delay treatment when they lack financial means. They may also be unable or unwilling to provide proof of residency or other documentation that is necessary for referrals and prescriptions in some countries. Irregular status often also limits migrant children's access to basic health care. In some countries, parents must be documented in order to obtain birth certificates for their children and enroll them in national health care systems.

When unauthorized migrants receive health care, it is often inadequate.

When unauthorized migrants receive health care, it is often inadequate. Providers often do not know how to process migrants outside of national health insurance schemes. Some providers may fear the legal ramifications of providing services (Jensen 2011). In some cases, doctors may be unwilling to write referrals or prescriptions for uninsured immigrants since such services may create financial hardships for migrants and even put them at risk of deportation if they must be enrolled in national health registries (ibid.).

Migrants also have logistical difficulties accessing health care. They regularly lack transportation to health clinics or hospitals. In a study of migrants' health in rural eastern North Carolina, for example, 80 percent of respondents considered transportation as a major obstacle to receiving health care (Weathers et al. 2004). They also frequently have inflexible work schedules that impede their ability to request time off for health care. Finally, they may live in remote or rural areas with few providers.

Healthcare workers often have limited to no knowledge of immigrant languages and cultures. Mistranslation can lead to misinterpretation of symptoms, which can result in postponed care, 
clinical errors, or even death. Furthermore, language barriers can limit medical professionals' ability to explain the side effects of treatments and obtain proper consent. They can also limit providers' ability to provide psychological support to immigrants and can impede the development of provider-patient trust. Language barriers can be a particularly severe impediment to treating HIV-positive populations, who may be reluctant to seek treatment from fear that their status will be disclosed (European Center for Disease Prevention and Control 2016).

Miscommunication can also undermine migrants' trust in healthcare providers and willingness to take medications and undergo medical procedures. Many cultures view health care as spiritual and holistic as well as physical (Salant and Lauderdale 2003). Employing traditional healers, combining traditional medicine with modern treatments, or incorporating spiritual or cultural elements into medicine can build improve migrant health outcomes (Georgetown University Child Development Center 2001). Specifically, such practices could improve the effectiveness of health education, build trust between patients and providers, and encourage migrants to follow through with medical advice.

\section{b. Faith-Based Organizations and Migrant Health Outcomes}

Globally, faith-based organizations of many denominations play a critical and unique role in extending health services to underserved migrant populations. Empirical evidence suggests that faith-based programs can improve health outcomes among vulnerable populations (DeHaven et al. 2004). This section highlights several key ways that faith-based organizations strengthen migrants' health care. First, faith-based organizations are trusted and respected by migrants and government actors alike, granting them access to vulnerable populations that many organizations lack. Second, they often possess devoted networks of volunteers that enable them to reach underserved populations. Extensive volunteer networks and knowledge of local communities also facilitate the delivery of linguistically and culturally appropriate health services. Finally, they are effective at sensitizing authorities and service providers to the needs of migrants.

Faith-based organizations are often widely trusted and respected by governmental actors and migrants alike. This trust and respect grants them access to vulnerable populations that other organizations lack, including from irregular migrants and asylum seekers. In Nicaragua, for example, the Council of Protestant Churches and the Managua mosque have direct access to immigrant detention centers (UNHCR 2014). The United Nations High Commissioner for Refugees (UNHCR) partnered with these organizations and Caritas to improve migrants' reception conditions and provide support to asylum seekers. In Lebanon, Dar-el-Fatwa, an Islamic organization, assists UNHCR's efforts to provide health care to Syrian refugees, including individuals residing in areas to which the United Nations lacks access. Dar-el-Fatwa has helped the UNHCR gain refugees' trust and expanded its reach through a large network of volunteers (ibid.). The International Catholic Migration Commission (ICMC) facilitated the pre- and post-natal care of 2,000 pregnant Syrian women in Jordan and provided psychological support to thousands of refugees in Jordan and Greece, including many children. In Brazil, faith-based organizations such as Caritas work in remote areas and border regions to provide emergency assistance and referrals for asylum claimants and to sensitize service providers to migrants' needs (ibid.). In Haiti, the Missionaries of Saint Charles, Scalabrinians, established a healthcare and dental clinic that provides health and dental services for more than 350 people a day, most of whom were displaced from the 2010 earthquake. Similarly, the Scalabrinians established a health and dental clinic in Delray Beach, Florida, providing services for migrants. Catholic diocesan health committees and bishops' health commissions across the globe are also working to improve migrants' healthcare outcomes. 
Religious organizations can also be effective at addressing sensitive public health topics. In Iran, Muslim leaders partnered with the UNHCR to endorse and disseminate materials on genderbased violence to Afghan refugees. Muslim leaders added legitimacy to efforts to help women overcome social stigma and seek support. Similarly, in Ethiopia, faith leaders worked with the UNHCR to de-link female genital mutilation from Islamic teaching (UNHCR 2014).

Second, faith-based organizations often have access to volunteer networks that can facilitate the provision of health care to underserved migrant communities. Many such networks have trained doctors and nurses. These networks enable faith-based organizations to provide timeconsuming or resource-intensive services beyond the scope of most health providers. Volunteers, for example, provide transport to clinics or hospitals or home health care services. These services bring health resources closer to patients and can be vital in rural regions with few doctors or clinics. Volunteers also can provide health care on evenings and weekends, facilitating access for migrants who work long shifts (Georgetown University Child Development Center 2001). Some also provide childcare services, giving migrants more flexibility to seek health care. In addition to volunteer support, faith-based organizations also frequently provide venues to disseminate health-related information. They host health seminars and talks and even organize basic health screenings (ibid.). ${ }^{2}$

Faith-based organizations often possess strong knowledge of and ties to immigrant communities that facilitate the provision of culturally and linguistically sensitive care. They often serve as "cultural brokers" between immigrant communities and healthcare providers. Cultural and religious values often shape migrants' responses to health education and interventions. When medical advice is presented from a host-country viewpoint, it may lack relevance to migrants' cultural and religious contexts (Georgetown University Child Development Center 2001). Some recommendations may even contradict cultural and religious beliefs or practices.

Many migrants rely on their social networks and communities for information about health care. In close-knit communities, migrants place greater weight on the attitudes and opinions of community and faith leaders than of host-country doctors and nurses (Georgetown University Child Development Center 2001). Faith-based communities can tap into the credibility of faith leaders to provide health information and encourage healthy behaviors. They also partner with healthcare providers to enhance the effectiveness of health interventions. The ARK in Chicago, Illinois, for example, partners with Mount Sinai Hospital to help Russian- and Yiddish-speaking immigrants without insurance. Many of ARK's volunteers are Russian and Yiddish speakers familiar with patients' cultural and religious needs (ibid.). ARK provides its patients in-home care as well as eye and dental examinations.

In many cultures, spiritual counseling and traditional medicine are critical components of the healing process. Without these elements, migrants' trust in health care may be limited. Faithbased organizations can tap into their networks to provide patients with traditional healing and spiritual support. The ACCESS Community Center in Dearborn, Michigan, for example, partners with the Oakwood Healthcare System to provide Islamic pastoral support and halal meals for Arabic-speaking immigrants. Furthermore, it provides Arabic-language health education materials incorporating Muslim religious principles (Georgetown University Child Development Center 2001).

2 See also Catholic News Service (2017). 
Ultimately, such services can build trust between health care providers and immigrant communities. Increased trust can strengthen migrants' compliance with medical advice and promote healthy behaviors. It can also build rapport between immigrant communities and health providers, increasingly the likelihood that migrants will consistently follow up in regard to their care.

Faith-based organizations are particularly critical in providing health care to undocumented migrants. Such migrants are often reluctant to seek health care out of fear of deportation (Nguyen and Gill 2016). Migrants may be more likely to seek health care when providers are recommended by trusted faith community leaders because they trust that their religious leaders would not lead them into harm's way (Coddou 2017). In the United States, for example, partnerships between churches and federally qualified health centers have been shown to facilitate irregular Mexican migrants' access to medical and dental care (López-Cevallos, Lee, and Donlan 2013).

Faith-based organizations also play a critical role in raising community awareness of migrants' healthcare needs. They often lobby government authorities, for example, on behalf of migrant communities. In April 2018, for example, nearly 250 faith leaders wrote a letter to ICE condemning the detention of pregnant immigrant women. ${ }^{3}$ Through such actions, faith-based organizations can sensitize authorities to the needs and concerns of migrant communities.

Faith-based organizations also play a critical role in raising community awareness of migrants' healthcare needs.

In conclusion, faith-based organizations improve immigrants' access to health care and facilitate the provision of culturally and linguistically appropriate services. Faith-based organizations' credibility and volunteer networks allow them to build trust between immigrant communities and health providers, supporting positive health outcomes.

\section{Entrepreneurship}

The International Covenant on Economic, Social, and Cultural Rights also stipulates that all individuals have the right to productive employment and satisfactory working conditions. ${ }^{4}$ Productive work helps migrants achieve economic self-sufficiency and promotes their integration into their host societies. In practice, however, many migrants have limited opportunities for employment. Many reside in regions with tight labor markets. They thus face steep employment competition with natives who speak local languages and possess strong social networks. Some migrants' job prospects are limited by a lack of fluency in host languages (Marchand and Siegel 2015)..$^{5}$ Many also lack formal work authorization, limiting their employment options. Others lack proof of education or training from their homelands, and what formal credentials they possess may not be recognized by host societies. Finally, they frequently face discrimination on the basis of their legal status or ethnic or religious background (Zhou 2004). These obstacles can limit migrants' prospects for gainful employment.

In light of these obstacles, entrepreneurship constitutes an important vehicle to improve migrants' socioeconomic mobility (Zhou 2004; Constant, Shachmurove, and Zimmermann

3 See https://www.fcnl.org/updates/nearly-250-faith-leaders-and-faith-based-organizations-decry-the-detentionof-pregnant-immigrant-women-1391.

4 Part 3, Article 6.

5 See also Mora and Davila (2007). 
2007; Irastorza 2010). Opening small businesses helps immigrants support themselves and their families. Entrepreneurship also creates jobs for other migrants and can positively impact local economic growth (Hosler 1996; Rath and Kloosterman 2000). Migrant-owned businesses also provide their communities with familiar food and clothing, uniting communities and fostering a sense of normality even under difficult conditions (Marchand and Siegel 2015).

Despite these benefits, prospective migrant entrepreneurs face many barriers. In particular, it can be difficult for them to acquire the capital necessary to start a business. Migrants often possess few savings, particularly if they fled their homelands due to violence or natural disasters (Evans and Jovanovic 1989; Evans and Leighton 1989). Banks are also often reluctant to provide potential migrant entrepreneurs with credit (OECD 2001). Migrants often have limited or nonexistent credit histories in their host countries, making it difficult for them to obtain loans (Bruder, Neuberger, Räthke-Döppner 2011; Desiderio 2014). They are also less likely to possess collateral than natives (Desiderio 2014). Banks might also be unwilling to lend to migrants on short-term visas or without legal permanent residency (ibid.). Finally, migrants are often profiled on the basis of their immigration status or ethnicity or race (Blanchflower, Levine, and Zimmermann 2003). Those who succeed in securing loans may pay higher interest rates than native-born entrepreneurs (Albareto and Mistrulli 2010).

Prospective migrant entrepreneurs also face significant administrative challenges. They are frequently unfamiliar with host-country taxation rules as well as labor, social security, and safety regulations. Furthermore, language barriers and limited social networks can make it difficult for migrants to navigate bureaucratic regulations and procedures (Desiderio 2014).

Across the globe, faith-based organizations of many denominations are active in promoting employment and entrepreneurship among migrants, including refugees in highly tenuous socioeconomic situations. By tapping into volunteer networks, they provide prospective entrepreneurs with business contacts, training, and visa support. Drawing from public grants and community donations, they also provide small grants and loans for startups. Religious communities such as parishes and mosques also provide migrant entrepreneurs with opportunities to publicize their goods and services and expand their customer base (Drakopoulou Dodd and Seaman 1995; Yoo 1998; Zhou and Cho 2010). Some churches and organizations also offer childcare services that afford migrant entrepreneurs flexibility to pursue their business goals. Some also offer "rotating credit clubs" in which members pool resources and offer loans to community members in need, including prospective entrepreneurs (Bae-Hansard 2015).

The International Catholic Migration Commission, for example, provides small grants and vocational training to Afghan refugees in the Khyber-Paktunkwha region of Pakistan. It also provides refugees with linkages with employers and it sponsors visits to shops and markets to strengthen their networks and business skills. With ICMC's support, refugees have become successful shoemakers, carpet weavers, dressmakers, beauticians, and motorcycle repairpersons. In Jordan, ICMC supports entrepreneurship by Syrian refugees, providing vulnerable youth between 18 and 30 years of age with small grants and loans, vocational training, and support in obtaining work permits. In Malaysia, ICMC provides Rohingya refugees with small grants to promote the development and sale of art objects and crafts (ICMC 2016).

The Scalabrini International Migration Network (SIMN) also actively supports migrant entrepreneurship programs. It provides support in obtaining work authorization, business skills training, and skill certification, and provides employment referrals, microfinance, and other 
services. Across its 34 countries of operation, it places more than 15,000 people per year in permanent jobs.

The Hebrew Immigrant Aid Society (HIAS) provides small grants and loans, business skills training, and mentorship to refugee entrepreneurs in countries as diverse as Ecuador and Chad. Among other programs, it supports refugee women's entrepreneurship in 12 camps in eastern Chad. ${ }^{6}$ It also works with Jewish Family Services to support refugee entrepreneurship through training and financial support in 20 cities across the United States. ${ }^{7}$

Many faith-based organizations also partner with local governments to promote immigrant entrepreneurship. In Massachusetts, for example, Jewish Vocational Services and Lutheran Social Services partnered with the state office for refugees and immigrants to provide loans to more than 75 immigrants in the Boston area. ${ }^{8}$ Participants in this program have successfully opened a variety of businesses, many of which provide goods and services that cater to underserved populations.

In sum, faith-based organizations provide valuable support to prospective migrant entrepreneurs around the world.

In sum, faith-based organizations provide valuable support to prospective migrant entrepreneurs around the world. Their credibility enables them to recruit volunteers and raise funding to provide such individuals with loans, training, contacts, and visa support, among other services. These services are particularly important given that migrants often face tight labor markets and employment discrimination. Their efforts can help migrants achieve economic self-sufficiency and integrate into their host communities.

\section{Conclusion and Recommendations}

Many migrants around the world have limited access to adequate health care and employment. Often, migrants in the most precarious situations, such as asylum seekers and irregular migrants, face the most severe barriers as they are barred from many forms of government support. Faithbased organizations play a vital role in supporting the livelihoods of migrants, including women, children, and other vulnerable individuals. In the area of health care, faith-based organizations leverage their volunteer networks to provide care to underserved populations. They are often widely respected and able to provide services to populations that are inaccessible to international organizations and NGOs, including detainees and refugees in camps. They also provide culturally and linguistically appropriate care, building trust between migrant communities and health practitioners.

In the area of entrepreneurship, faith-based organizations leverage their resources to provide migrants with microloans, training, and business contacts, among other services. By supporting migrant entrepreneurship, they enhance migrants' ability to provide for themselves, their families, and their communities.

6 See https://www.hias.org/entrepreneurship-refugee-camp.

7 See https://www.hias.org/hias-united-states.

8 See https://blog.mass.gov/hhs/children-youth-and-families/office-for-refugees-immigrants/refugee-entrepreneu rs-growing-our-economy/. 
Globally, many vulnerable migrants continue to live without adequate health care and opportunities for work. To better serve such populations, the international community should support and leverage faith-based organizations' unique resources and access to migrants.

The Global Compact on Migration should formally recognize the contributions of such organizations as well as the need to build their capacity. It should also identify possibilities for collaboration in the areas of health care and work and recommend periodic coordination meetings. In particular, states and international organizations could work with faith-based organizations to identify and rectify challenges to migrants' health and self-sufficiency, including linguistic and cultural factors that shape the effectiveness of health interventions. States and other stakeholders could also provide training and equipment to volunteers from faith-based organizations, strengthening their capacity to reach underserved populations.

The Global Compact should also call upon states and other stakeholders to offer health care to all migrants, regardless of their legal status.

The Global Compact should also call upon states and other stakeholders to offer health care to all migrants, regardless of their legal status. It should formally recognize faith-based organizations' unparalleled access to irregular and other vulnerable migrants and call upon authorities to work with such organizations to improve these groups' health outcomes. Likewise, it should recognize faith-based organizations' access to refugee camps in conflict zones and call upon states and international organizations to strengthen their capacity.

Partnerships between international organizations and faith-based organizations could also facilitate the collection of data on health and economic outcomes among vulnerable populations. The trust accorded to faith-based organizations by vulnerable migrants and government actors could greatly strengthen data collection efforts, which could lead to improved policy interventions and strengthen migrants' livelihoods.

\section{References}

AIC (American Immigration Council). 2018. "Complaint Filed with DHS Oversight Bodies Calls for Improvements to Medical and Mental Health Care of Immigrants in Aurora Detention Center." Washington, DC: AIC. https://www.americanimmigrationcouncil.org/news/ complaint-filed-dhs-oversight-bodies-calls-improvements-medical-and-mental-healthcare.

Albareto, Giorgio, and Paolo Emilio Mistrulli. 2010. "Bridging the Gap between Migrants and the Banking System." MPRA Paper 26476, University Library of Munich, Germany. http:// mpra.ub.unimuenchen.e/26476/1/Albareto_Mistrulli_Bridging_the_gap_between_ migrants_and_the_banking_system.pdf.

Bae-Hansard, Sungeun. 2015. "Korean Ethnic Churches' Benefits to Korean Immigrant Entrepreneurs and their Families." Master's thesis, Vanderbilt University.

Betancourt, Theresa S., Elizabeth A. Newnham, Dina Birnham, Robert Lee, B. Heidi Ellis, and Christopher M. Layne. 2017. "Comparing Trauma Exposure, Mental Health Needs, and Service Utilization Across Clinical Samples of Refugee, Immigrant, and U.S.-Origin Children." Journal of Traumatic Stress 30(3): 209-18. https://doi.org/10.1002/jts.22186. 
Blanchflower, David G., Phillip B. Levine, and David J. Zimmermann. 2003. "Discrimination in the Small-business Credit Market." Review of Economic and Statistics 85(4): 930-43. https:// doi.org/10.1162/003465303772815835.

Bruder, Jana, Doris Neuberger, and Solvig Räthke-Döppner. 2011. "Financial constraints of Ethnic entrepreneurship: Evidence from Germany." International Journal of Entrepreneurial Behaviour \& Research 17(3): 296 -313. https://doi.org/10.1108/13552551111130727.

Bustamante, Arturo, H. Fang, J. Garza, O. Carter-Pokras, Steven Wallace, John Rizzo, and Alexander Ortega. 2012. "Variations in Healthcare Access and Utilization Among Mexican Immigrants: The Role of Documentation Status." Journal of Immigrant and Minority Health 14(1): 14655. https://doi.org/10.1007/s10903-010-9406-9.

Catholic News Service. 2017. "Immigrants Aren't Getting Health Care, so Parish Brings it To Them. Catholic News Service, April 18. https://cruxnow.com/church-in-the-usa/2017/04/18/ immigrants-arent-getting-health-care-parish-brings/.

Coddou, Marion. 2017. "Sanctified Mobilization: How Political Activists Manage Institutional Boundaries in Faith-Based Organizing for Immigrant Rights." In On the Cross Road of Polity, Political Elites, and Mobilization, edited by Barbara Wejnert and Paolo Parigi. Bingley, UK: Emerald Group.

Constant, Amelie, Yochanan Shachmurove, and Klaus F. Zimmermann. 2007. "What Makes an Entrepreneur and does it Pay? Native Men, Turks, and other Migrants in Germany." International Migration 45(4): 71-100. https://doi.org/10.1111/j.14682435.2007.00420.x.

DeHaven, Mark, Irby B. Hunter, Laura Wilder, James W. Walton, and Jarett Berry. 2004. "Health Programs in Faith-Based Organizations: Are they Effective?" American Journal of Public Health 94(6): 1030-36. https://doi.org/10.2105/AJPH.94.6.1030.

Desiderio, Maria V. 2014. Policies to Support Immigrant Entrepreneurship. Washington, DC: Migration Policy Institute.

Drakopoulou Dodd, Sarah, and Paul Timothy Seaman. 1995. "Levels of religious practice amongst UK entrepreneurs." Paper presented at the Fifth Global Entrepreneurship Research Conference, Salzburg, March, 1995.

Ebaugh, Helen Rose, Paula F. Pipes, Janet Saltzman Chafetz, and Martha Daniels. 2003. "Where's the religion? Distinguishing faith-based from secular social service agencies." Journal for the Scientific Study of Religion 42(3): 411-26. https://doi.org/10.1111/1468-5906.00191.

Evans, David, and Boyan Jovanovic. 1989. "An Estimated Model of Entrepreneurial Choice under Liquidity Constraints." Journal of Political Economy 97(4): 808-27. https://doi. org/10.1086/261629.

Evans, David, and Linda S. Leighton. 1989. "Some Empirical Aspects of Entrepreneurship." American Economic Review 79(3): 519-35.

Eurofound (European Foundation for the Improvement of Working and Living Conditions). 2007. Employment and Working Conditions of Migrant Workers. Dublin: Eurofound. 
European Center for Disease Prevention and Control. 2016. Assessing the Burden of Key Infectious Diseases Affecting Migrant Populations in the E.U. / EEA. Stockholm: European Center for Disease Prevention and Control.

Georgetown University Child Development Center. 2001. Sharing a Legacy of Caring: Partnerships between Health Care and Faith-Based Organizations. Washington, DC: Georgetown University Child Development Center.

Hosler, Akiko Sugimoto. 1996. "Japanese Immigrant Entrepreneurs in New York City: The Role of Ethnic Collectivity in Business." PhD diss., State University of New York at Albany.

ICMC (International Catholic Migration Commission). 2016. Annual Report 2016. Geneva: ICMC.

IOM (International Organization for Migration). 2013. International Migration, Health, and Human Rights. Geneva: IOM.

Irastorza, Nahikari. 2010. Born Entrepreneurs? Immigrant Self-Employment in Spain. Amsterdam: Amsterdam University Press. https://doi.org/10.5117/9789089642431.

Jensen, Natasja K., Marie Norredam, Tania Draebel, Marija Bogic, Stefan Priebe, and Allan Krasnik. 2011. "Providing medical care for undocumented migrants in Denmark: what are the challenges for health professionals?" BMC Health Services Research 11: 154. https://doi. org/10.1186/1472-6963-11-154.

Kumar, Revathy, Nancy Seay, and Stuart A. Karabenick. 2015. "Immigrant Arab adolescents in ethnic enclaves: Physical and phenomenological contexts of identity negotiation." Cultural Diversity and Ethnic Minority Psychology 21(2): 201-12. https://doi.org/10.1037/ a0037748.

López-Cevallos Daniel F., J. Katherine Lee, and William Donlan. 2013. "Fear of deportation is not associated with medical or dental care use among Mexican-origin farmworkers served by a federally qualified health center-faith-based partnership: an exploratory study." Journal of Immigrant Minority Health 16(4): 706-11. https://doi.org/10.1007/s10903-013-98451.

Marchand, Katrin, and Melissa Siegel. 2015. Immigrant Entrepreneurship in Cities. Geneva: IOM.

Mora, Marie T., and Alberto Davila. 2007. "Ethnic Group Size, Linguistic Isolation, and Immigrant Entrepreneurship in the USA." Entrepreneurship and Regional Development 17(5): 389404. https://doi.org/10.1080/08985620500275612.

Nguyen, Mai Thi, and Hannah Gill. February 2016. "Interior Immigration Enforcement: The Impacts of Expanding Local Law Enforcement Authority." Urban Studies 53(2): 302-23. https://doi.org/10.1177/0042098014563029.

OECD (Organisation for Economic Co-operation and Development). 2001. International Migration Outlook. Paris: OECD.

Padovese, Valeska, Ada Maristella Egidi, Tanya Melillo Fenech, Marika Podda Connor, Daniele Didero, Gianfranco Costanzo, and Concetta Mirisola. 2014. "Migration and Determinants of Health: Clinical Epedemiological Characteristics of Migrants in Malta (2010-2011)." Journal of Public Health 36(3): 368-74. https://doi.org/10.1093/pubmed/fdt111. 
Priest, Dana, and Amy Goldstein. 2008. "As tighter immigration policies strain federal agencies, the detainees in their care often pay a heavy cost." Washington Post, May 11. http:// www.washingtonpost.com/wp-srv/nation/specials/immigration/cwc_d1p1.html.

Pumariega, Andres, Eugenio Rothe, and JoAnne B. Pumariega. 2005. "Mental health of immigrants and refugees." Community Mental Health Journal 41(5): 581-97. https://doi.org/10.1007/ s10597-005-6363-1.

Rath, Jan, and Robert Kloosterman. 2000. "Outsiders' business: A critical review of research in immigrant entrepreneurship." International Migration Review 34(3): 657-82.

Ronda Perez, Elena, Fernando G. Benavides, Katia Levecque, John G. Love, Emily Felt, and Ronan Van Rossem. 2012. "Differences in working ' conditions and employment arrangements among migrant and non-migrant workers in Europe." Ethnicity and Health 17(6): 563-77. https://doi.org/10.1080/13557858.2012.730606.

Ruiz-Casares, Monica, Cecile Rousseau, Ilse Derluyn, Charles Watters, and François Crépeau. 2010. "Right and access to healthcare for undocumented children: Addressing the gap between international conventions and disparate implementations in North America and Europe." Social Science \& Medicine 70(2): 329-36. https://doi.org/10.1016/j. socscimed.2009.10.013.

Salant, Tanya, and Diane S. Lauderdale. 2003. "Measuring culture: a critical review of acculturation and health in Asian immigrant populations." Social Science and Medicine 57(1): 71-90. https://doi.org/10.1016/S0277-9536(02)00300-3.

Seattle University School of Law International Human Rights Clinic and OneAmerica. 2008. Voices from Detention: A Report on Human Rights Violations at the Northwest Detention Center in Tacoma, Washington. Seattle, WA: Seattle University and OneAmerica. http:// www.landerholmimmigration.com/dhs-struggles-maintain-mental-health-providersimmigration-detention-facilities/.

Semenza, Jan C., Paloma Carrillo-Santisteve, Herve Zeller, Andreas Sandgren, Marieke J. van der Werf, Ettore Severi, Lucia Pastore Celentano, Emma Wiltshire, Jonathan E. Suk, Irina Dinca, Teymur Noori, and Piotr Kramarz. 2016. "Public health needs of migrants, refugees and asylum seekers in Europe, 2015: Infectious disease aspects." European Journal of Public Health 26(3): 273-73. https://doi.org/10.1093/eurpub/ckw023.

Sri Lanka Bureau of Foreign Employment. 2009. Annual Statistical Report of Foreign Employment. Colombo: Bureau of Foreign Employment.

UN DESA (UN Department of Economic and Social Affairs). 2017. The International Migration Report 2017. Geneva: UN DESA.

UNHCR (UN High Commissioner for Refugees). 2014. "Partnership Note: On Faith-Based Organizations, Faith Communities, and Leaders." Geneva: UNHCR.

Weathers, Andrea, Cynthia Minkovitz, Patricia O’Campo, and Marie Diener-West. 2004. “Access to care for children of migratory agricultural workers: factors associated with unmet need for medical care." Pediatrics 113(4). https://doi.org/10.1542/peds.113.4.e276. 
Yan, Wudan. 2016. "Only one country offers universal health care to all migrants." NPR, March 31. https://www.npr.org/sections/goatsandsoda/2016/03/31/469608931/only-onecountry-offers-universal-health-care-to-undocumented-migrants.

Yoo, Jin-Kyung. 1998. Korean immigrant entrepreneurs: Network and ethnic resources. New York: Routledge.

Yu, Elly. 2018. "Exclusive: an ICE detention center's struggle with 'chronic' staff shortages." WABE, May 31. https://www.wabe.org/exclusive-an-ice-detention-centers-struggle-withchronic-staff-shortages/.

Zhou, Min. 2004. "Revising Ethnic Entrepreneurship: Convergencies, Controversies, and Conceptual Advancements." International Migration Review 38(3): 1040-74. https://doi. org/10.1111/j.1747-7379.2004.tb00228.x.

Zhou, Min, and Myungduk Cho. 2010. "Noneconomic Effects of Ethnic Entrepreneurship". Thunderbird International Business Review 52(2): 83-96. https://doi.org/10.1002/ tie.20316. 


\section{Section 4: SIMN and CMS Policy Interventions During the Global Compact on Migration Process}




\section{Opening Remarks at the Side Event}

\section{"The Protection and Integration of Migrants in Vulnerable Situations: The Case of Faith- Based Organizations" 1}

\section{By Fr. Leonir Chiarello, Executive Director and Main Representative to the United Nations of the Scalabrini International Migration Network}

Your Eminences and Excellences, Esteemed Panelists, Dear Ladies and Gentlemen,

I am very pleased to welcome you to this afternoon's event on "The Protection and Integration of Migrants in Vulnerable Situations: The Case of Faith-Based Organizations" which the Scalabrini International Migration Network (SIMN) is sponsoring together with the Permanent Observer Mission of the Holy See and the Permanent Representation of Guatemala to the United Nations.

Before I introduce our distinguished panelists and respondents, I would like to frame our discussion. The Scalabrini International Migration Network (SIMN) is a nonprofit umbrella organization that oversees more than 250 programs for migrants and refugees around the world, including shelters, schools, clinics, and community centers. We see, first hand, the challenges that migrants, refugees and their families face in their attempts to find a better life and to live in safety. We also see how persons flee their situations for a wide range of reasons, and how their stories may not meet the exact criteria of the refugee definition but are just as gripping and their protection needs just as real.

We also see especially how they are vulnerable to harsh enforcement laws and to smugglers and human traffickers. We do our best to respond to their needs and to work with governments, international organizations and civil society organizations to provide them protection, where possible, but much more needs to be done, both legally and materially, to help all migrants, particularly those who fall through the international protection gaps, like women and children, families and migrants without health care.

The Global Compact on Safe, Orderly, and Regular Migration, as well as the Global Compact on Refugees, is a historic opportunity to fill those gaps and to formalize partnerships between faithbased organizations, member states, international organizations and civil society organizations in addressing the challenges of migration governance. We are pleased to see the addition of "faithbased organizations" as partners in the implementation section of the Global Compact on Migration and would like to see its addition in the preamble. As you know, faith-based organizations are not only relevant and crucial to welcome, protect, promote and integrate migrants and refugees, but also to work with States and international organizations in caring for them.

The issue of migrants in vulnerable situations - those fleeing generalized violence, climate change, and other crises, especially women, girls, and families - is one of the most critical

1 Talk delivered at UN side event sponsored by the Permanent Observer Mission of the Holy See to the United Nations, the Permanent Mission of Guatemala to the United Nations, and the Scalabrini International Migration Network, titled: "The Protection and Integration of Migrants in Vulnerable Situations: The Case of Faith-Based Organizations,” June 4, 2018. 
issues being considered by member states in their Compact deliberations. It is an issue on which the Global Compact on Migration can make a difference on the ground. We support the international human rights protection standard included in the current draft and encourage such language to be strengthened, where possible.

In addition, the Global Compact on Migration should more intentionally highlight the importance of regular pathways and other legal tools which can provide legal protection to migrants in vulnerable situations and access to social services, especially health care and education. We have concerns with language that could sanction the use of deterrence tactics and schemes to address mixed migration flows, policies that often lead to the weakening of due process protections.

While we will not dive into the wording of the Global Compact on Migration today, we hope to provide some context to the deliberations by detailing the realities we see every day on the ground. As the co-facilitators and others have said, the success of the Compact will be determined by how it improves the situation on the ground.

From this perspective, we will start with the testimony of Ana del Carmen Portillo, who was forced to flee her country with her family in search of international protection and is now assisting immigrant communities, especially young women and families, in Riverdale, Maryland.

The five speakers of the side event are the following: 1) His Excellency Ambassador SkinnerKlée, Permanent Representative of Guatemala to the United Nations; 2) His Excellency Archbishop Bernardito Auza, Permanent Representative of the Holy See to the United Nations;

3) Donald Kerwin, Executive Director of the Center for Migration Studies of New York (CMS);

4) Carol Girón, Policy Coordinator for Central America of the Scalabrinian Missionaries and the Scalabrini International Migration Network (SIMN); 5) Joseph Donnelly, Permanent Delegate to United Nations for CARITAS Internationalis.

The three respondents of the side event are the following: 1) His Excellency Ambassador Omar Hilale, Permanent Representative of Morocco to the United Nations; 2) His Excellency Ambassador Teodoro Lopez Locsin Jr., Permanent Representative of the Philippines to the United Nations; His Excellency Ambassador Geraldine Byrne Nason, Permanent Representative of Ireland to the United Nations.

I would like to express our gratitude to Ambassador Skinner-Klée and Archbishop Auza for cosponsoring this important side-event, to the expert panelists and respondent Ambassadors, and to all of you for joining this discussion on The Protection and Integration of Migrants in Vulnerable Situations: The Case of Faith-Based Organizations. I would like to express a special gratitude to the members of the SIMN Leadership Council of Ontario, Canada, and the Leadership Councils of Venezuela, Washington DC, Providence, Florida and New York for joining us in this important side event.

We hope the negotiations of the Global Compact on Safe, Orderly, and Regular Migration will be determined by how it improves the situation on the ground for migrants and their families. We hope global leaders take decisive action in support of migrants and refugees to save their lives and protect their rights, sharing this responsibility on a global level and lead to the approval of the two Global Compacts to work together with international organizations, faith-based organizations and civil society organizations. 


\title{
46. $\mathrm{CMS}$ sistorition
}

\section{The Importance of Families and Faith-Based Institutions to Migrants and the Migration Experience $^{1}$}

\author{
By Donald Kerwin, Executive Director, Center for Migration Studies
}

This talk will highlight the importance of families and faith-based institutions (FBOs) to migrants and to the migration experience. It will speak both to the challenges faced by migrant families and to what distinguishes the work of faith communities and FBOs with migrants. It will end with a few policy recommendations.

\section{Families and the Migration Experience}

Family unity should be a crosscutting migration policy priority. It implicates every category of migrant and every type of migration, but particularly the migration of vulnerable persons. Yet families are too often overlooked in state immigration laws and policies. Many states, for example, rely heavily on immigrant workers, but do not allow their families to join them: they want workers, but not the people that come with them (Kerwin 2013).

However, most migrants do not forget their families. Collectively, migrants sent $\$ 429$ billon to developing states in 2016, the great bulk of it to family members (World Bank 2017). In some cases, families lose touch with members who have migrated. In others, family members join migrants in the new country or see them in their home communities, but only during holidays or pauses in their work. More and more, migrant women care for the children and the elderly in other families, but rarely see their own children or parents.

Some nations have large family-based immigration programs, and award visas to those with a close family relationship to a citizen or lawful permanent resident. Many of these family members end up migrating to and working in destination states. Families contribute significantly to the integration and well-being of their members. In some countries, family unity is the de facto integration program.

Forced migrants often leave without their families, or become separated from family members in emergencies or transit. The Scalabrini International Migration Network (SIMN) and the Center for Migration Studies (CMS) just returned from a fact-finding trip to Chile and Peru, and met a few intact refugee families. But many more migrants fled with nothing and were desperate to find work, so that they could send monies to their destitute and starving family members at home. They hoped one day to be reunited with their families in a place where they could prosper and live in security. It didn't much matter where.

CMS and Cristosal co-authored a study one year ago that found that families hide members at risk of violence, decide when they should flee, sometimes accompany them in transit, and

\footnotetext{
1 Talk delivered at UN side event sponsored by the Permanent Observer Mission of the Holy See to the United Nations, the Permanent Mission of Guatemala to the United Nations, and the Scalabrini International Migration Network, titled: "The Protection and Integration of Migrants in Vulnerable Situations: The Case of Faith-Based Organizations,” June 4, 2018.
} 
provide them with the resources to migrate (CMS and Cristosal 2017). Family members also meet and receive migrants when they reach their destination. In other words, families protect and look after their members when states cannot or will not.

Sometimes the family unit is itself subject to persecution, and all of its members are at risk. In these circumstances, families seek protection wherever they can find it. However, they face many barriers - deterrence strategies, interception programs, detention, the criminal prosecution of asylum seekers, and the deliberate separation of parents from their children (Frelick, Kysel, and Podkul 2016; Kerwin 2018). These practices violate human rights and constitute a form of responsibility shunning, not sharing. They should be stopped.

Often immigration enforcement strategies - like deportation and detention — separate and impoverish families. In the United States, there are 6.6 million US citizen children with undocumented parents (Warren and Kerwin 2017). The deportation of a parent can gravely damage their children. In times of heightened immigration enforcement, the family members of irregular migrants often do not report crimes for fear their family members will be deported. In addition, many undocumented parents opt to forego public benefits for which their children qualify. And children may be bullied and teased in school regarding their parents' status or perceived status. Bans on entry or slow-downs in refugee admissions invariably affect families as well, by preventing or delaying family reunification.

Despite the immense importance of families to migrants and to the migration experience, UN agencies and states do not keep or, at least, produce sufficient data on family units seeking refugee status or asylum. States, in turn, should collect disaggregated data on migrant families, but they mostly do not. The UN and its member states should also collect better data on refugee children, who represent more than one-half of the world's refugees.

Overall, family unity should be prioritized in every migration situation — particularly those involving vulnerable persons. In addition, states should promote policies that strengthen immigrant families, if only for the indispensable role families play in immigrant integration. And there should be bottom line standards regarding the treatment of families. For example, children and families should not be detained, and children should not be removed from their parents, much less caged and drugged.

\section{The Work of Faith-Based Institutions}

We know that FBOs provide an abundance of services to migrants, but what is special about their work? First, FBOs cross borders and work in sending, transit, and receiving communities. This gives them a rich sense of the conditions that migrants encounter at every stage in this process. It also allows them to address the challenges of migrants in an integrated, holistic way.

Second, faith communities know migrants intimately and they take a person-centered approach to their work: their ideas and their programs are rooted in the lived experience of migrants.

Third, they also take a "whole-of-person" approach to their work: they do not just see migrants as people in need of work, but as persons with families, aspirations and gifts. Their work reflects this recognition. 
Fourth, at their best, FBOs do not do or speak for migrants, but they give voice and amplify the voice of migrants. More broadly, they treat migrants as agents in their own lives.

Fifth, at their best, FBOs advocate with, but do not condemn government officials or other policymakers. Their work is about building bridges and creating allies, not grandstanding. And, they can speak to the minds and hearts of government officials and native populations in ways that secular agencies often cannot. They can also facilitate "encounter" between diverse migrant groups and natives in order to promote mutual understanding and community building.

Faith communities see family unity as a fundamental right, but also as the glue that holds together the migration experience and those at its heart. They revere families at a time when they are increasingly under attack, but have never been more important.

Thank you.

\section{References}

CMS and Cristosal (Center for Migration Studies and Cristosal). 2017. Point of No Return: the Fear and Criminalization of Central American Refugees. Washington, DC: CMS. https://doi.org/10.14240/cmsrpt0617n2.

Frelick, Bill, Ian M. Kysel, and Jennifer Podkul. 2016. "The Impact of Externalization on the Rights of Asylum Seekers and Other Migrants." Journal on Migration and Human Security 4(4): 190-220. https://doi.org/10.14240/jmhs.v4i4.68.

Kerwin, Donald. 2013. "Does Respect for Migrant Rights Contribute to Economic Development?" Washington, DC: Migration Policy Institute.

https://www.migrationpolicy.org/research/does-respect-migrant-rights-contribute-economicdevelopment.

—. 2018. "The US Refugee Resettlement Program — A Return to First Principles: How Refugees Help to Define, Strengthen, and Revitalize the United States." Journal on Migration and Human Security 6(3): 204-24. https://doi.org/10.1177/2331502418787787.

Warren, Robert, and Donald Kerwin. 2017. "Mass Deportations Would Impoverish US Families and Create Immense Social Costs." Journal on Migration and Human Security 5(1): 1-8. https://doi.org/10.14240/jmhs.v5i1.71.

World Bank. 2017. "Migration and Remittances: Recent Developments to Developing Countries Decline for Second Consecutive Year." Migration and Development Brief 27. Washington, DC: KNOMAD (Global Knowledge Partnership on Migration and Development), World Bank. http://pubdocs.worldbank.org/en/992371492706371662/MigrationandDevelopmentBrief27.pdf. 


\section{The Current Context of Migration and Refuge in Central America: Vulnerability of Women and Girls ${ }^{1}$}

\section{By Carol Giron, Director of Policy for Central America, Scalabrini Missionaries and Scalabrini International Migration Network}

From the field work of the Scalabrinian Missionaries in the Central American region, we have been able to verify and accompany the experiences lived by migrants, asylum seekers and refugees. Briefly, I will share some findings of individuals on the move and migrants in the host countries, with special emphasis on girls, adolescents and women who are frequently exposed to highly risky and vulnerable situations in the context of human mobility.

This information is based on the work that we do every day in our shelters or "Casas del Migrante"; as well as in official spaces such as: air and ground reception; Government Reception Centers of unaccompanied children; reception spaces of migrant families; border areas; and, Guatemalan consulates in Mexico and in the United States. All our actions are part of an interinstitutional coordination with civil society, government and United Nations agencies, particularly UNICEF, UNHCR and IOM.

These findings are coincident with those faced in other Latin American countries or even in other regions of the world such as Europe, Africa and Asia.

\section{Countries of Origin}

Migration is the only choice for the majority of Central American women fleeing physical, sexual or economic violence in their homes. We also observe girls traveling with adults and smugglers seeking family reunification in the United States. These girls are highly vulnerable due to their age, gender, ethnic group and migratory status.

There are also other push factors related to women, girls, and families, related to contexts of political and social violence particularly from corruption, organized crime and extractive projects.

\section{In Transit}

Girls, adolescents and women who travel alone, or even in groups with other migrants, are much more vulnerable and are systematically exposed to being victims of sexual assault and violence, constant harassment and physical injuries. Sometimes gender is associated with an image of women as a sexual instrument and as caretakers (especially of unaccompanied minors).

Sexual aggression which is generally public or in the presence of other groups of migrants, brings stigma and shame; the fear; the lack of trust in public institutions; the lack of knowledge; and even the participation of authorities in human rights violations prevent or limit formal

1 Talk delivered at UN side event sponsored by the Permanent Observer Mission of the Holy See to the United Nations, the Permanent Mission of Guatemala to the United Nations, and the Scalabrini International Migration Network, titled: "The Protection and Integration of Migrants in Vulnerable Situations: The Case of Faith-Based Organizations," June 4, 2018. 
complaints. As a result, there is no psychosocial or medical approach to address the general health of the victims.

For adolescents and pregnant women, the risks and dangers are aggravated, particularly because they don't have access to necessary prenatal care and control. When women give birth on the move, the child's right to identity and to be registered by their parents could be complex and almost impossible to guarantee.

We are concerned that deportation continues to be the only alternative for dealing with mixed migration flows. This is one of the most important challenges regarding effective consular assistance and protection.

\section{In the Host Countries/Refuge}

Based on interviews conducted with girls, adolescents, and women in detention and processing centers, several causes have been identified for their migration. In the case of adolescents, some of them had to flee when the gangs intended to recruit them at an early age as brides and mates of the gangsters' leaders. In the North of Central America adolescents had to flee when the gangs persecute them to sell drugs or collect extortions. Some others had to flee since they were teenagers (14-year-old) because they were forced to have relationships and even marry older men. Several pregnant teenagers arrived in the United States with the promise that if they gave birth in the US would not be deported and their migratory status would be automatically regularized.

On the other hand, the testimonies show that some of them have used a contraceptive method before making the trip. For years we have seen that many girls are taking injection before starting the migratory route. Girls sadly assume that they will be raped. This is a fact and it is cruel.

The high presence and arrival of indigenous girls, adolescents and women require specific tools for the detection of vulnerabilities and protection needs.

\section{Return Countries/Reintegration}

Adolescents, women and mothers agree that they have been victims of discrimination; robbery; physical, verbal and emotional abuses; sexual assault; and victims of trafficking, especially in labor and sex. Most of them present anxiety and depression symptoms and feel guilty or responsible of the stigma of failure, the journey debt, including the return to the same community of violence they fled. We also are receiving people who applied for international protection, but they did not have access to legal advice, so they could not defend their cases or they gave up because of the long periods of detention.

As we have learned in our daily work, gender and health is still focusing on inequality and not on differentiated attention. Although both men and women are exposed to the same risks and dangers their treatment demands a special approach and perspective for women, for example for unwanted pregnancy, an unplanned abortion or abortion caused by the lack of medical attention and/or access to medicines. Women, unlike men, have other needs in terms of access to healthcare. 
On the other hand at the time of the reception of unaccompanied children, the institutions prioritize the fast delivery to the family resource as part of the cycle of deportation.

There are limited programs for the inclusion and integration of deported children and adolescents; they do not have access to a specialized and coordinated protection system.

Pregnant adolescents deported are not referred to the health system for follow-up and medical monitoring.

With high concern, we have registered and documented a significant number of cases of families that have been separated at the time of detention and deportation.

It is very common for women to experience skin and gastrointestinal diseases that can lead to dehydration as well as, respiratory diseases associated with weather or the temperature in the detention and processing centers. In addition, we find cases of women suffering Diseases of Sexual Transmission DST, unwanted pregnancies, abortions, among others.

\section{Recommendations in the Framework of the Global Compact}

From the countries of origin and return, the Global Compact is expected to be a complementary instrument that sustains and strengthens the principles and rights of migrants and their families, especially those groups in situations of high vulnerability, such as girls, adolescents, women, indigenous peoples and LGBTI people.

We insist on the non-criminalization of irregular migration and/or persecution based on physical appearance, ethnic group, and gender. There should be promoted the right and access to Consular Notification, as well as the review case by case, access to International Protection measures and the right to be informed about their process.

We are concerned that some political contexts are severely criminalizing other forms of protection such as people with Temporary Protected Status (TPS), refugees, asylum seekers, victims of trafficking, witnesses of crimes, among others.

We insist on the access of women and families to the health system as a basic right that can define the future of a person and their children. We have seen how the lack of medical care can affect the mental health of people. The right to health care must consider aspects related to their recent migratory history, their gender, age and even ethnic group.

From our experience, we recommend that the discussions of the Global Compact consider the good practices used in countries of the region, for example, the adoption and application of protection mechanisms or protocols. Here we would like to acknowledge the progress made by countries such as Guatemala and their experience in the design and implementation of the Protocol for the Reception of Unaccompanied Children ${ }^{2}$; the Consular Assistance Protocol ${ }^{3}$;

\footnotetext{
2 Protocolo de Recepción de niñez y adolescencia migrante no acompañada. Basado en enfoque de derecho y enfoque psicosocial. (2015) Actualización del Protocolo (2017) Secretaría de Bienestar Social de la República de Guatemala, Fondo de Naciones Unidas para la Infancia UNICEF y Misioneros de San Carlos Scalabrinianos. Guatemala.

3 Protocolo Psicosocial para la Atención y Protección Consular a la Niñez y Adolescencia Migrante con Enfoque de Derechos (2015) Ministerio de Relaciones Exteriores, Fondo de Naciones Unidas para la Infancia UNICEF y Misioneros de San Carlos Scalabrinianos. Guatemala.
} 
and, its recent Protocol for the Care of Returned Families ${ }^{4}$. These instruments have been built as a joint effort between public institutions such as Ministry of Foreign Affairs, the Secretariat of Social Welfare and Secretariat of First Lady, UNICEF and Scalabrinian Missionaries.

Recently, Guatemala approved the Migration Code as one of the most innovative initiatives in the region, since it promotes a change in the migration concept, leaving the security approach and adopting a renewed focus of human rights.

We hope that the Global Compacts will make an ample emphasis on guaranteeing unrestricted access to rights such as health, education, work, migratory regularization and justice system.

Due to the different situations that Central American migrants face, we insist on the right to international protection and respect and monitoring of the principle of "non-refoulement."

We promote the non-detention due to immigration status. This is a principle that should be effective in all cases of children and adolescents in their best interests.

From the countries of origin and return, it is observed that the separation of families during transit and at the time of detention and deportation are operating as mechanisms that stop migration; this causes serious consequences in people, especially in the health and development of children.

We urge the interest and responsibility of the States -especially of the Central American regionto take a leading role in the final discussion and especially in the content of the Global Compacts as a sign of their high commitment and political will towards migrants and their states.

Finally, considering that we, faith-based organizations, are first respondents to migrants vulnerabilities and we collaborate with governments and international organizations to protect and promote migrant's rights, we strongly suggest considering explicitly faith-based organizations in the list of stakeholders of the Global Compacts, including in the implementation process of the Compacts.

As a Central American and Guatemalan woman I'm here to represent the voices of thousands of migrants that need our States to respond and commit to addressing all these challenges. I want to express our support and reiterate our commitment to migrants and refugees.

So I would like to remember the words of Pope Francis to welcome, protect, promote and integrate them into the host and returning countries with dignity and respect.

4 Protocolo para la Atención Integral a Familias Migrantes con Enfoque de Derechos y Enfoque Psicosocial. Secretaría de Obras Sociales de la Esposa del Presidente SOSEP Ministerio de Relaciones Exteriores, Fondo de Naciones Unidas para la Infancia UNICEF y Misioneros de San Carlos Scalabrinianos, Guatemala. 


\section{4. $\mathrm{CMS}$ sistorison}

\section{Global Compact on Migration: Issues at Play \\ By Kevin Appleby \\ May 8, 2018}

One of the most significant outcomes of the New York Declaration on Large Movements of Refugees and Migrants, a non-binding international agreement adopted by the United Nations General Assembly in September, 2016, was the launching of a two-year process to develop a Global Compact for Safe, Orderly, and Regular Migration, or as it is better known, the Global Compact on Migration.

The goal of the Compact is to identify specific policy goals and best practices to which UN member states can commit in promoting safe and legal alternatives to irregular migration (Costa and Martin 2017). While the document will reaffirm important principles outlined in the New York Declaration, its success will be defined by the actions member states agree to take to address large-scale movements of migrants (UN 2017a), ideally in a manner which upholds human rights while preserving national sovereignty. ${ }^{1}$

UN member states gathered in Puerto Vallarta, Mexico from December 4 to 6, 2017 to engage in a "stocktaking" meeting to assess the information gathered from a series of thematic and regional hearings held on various migration issues during 2017 (UN 2017b). The negotiating stage of the process, in which member states will negotiate language of the Compact, will begin in February 2018, when the "zero draft," or the initial draft, of the Compact is released by the co-facilitators of the process, Mexico and Switzerland (Genina 2017).

From the thematic sessions and the deliberations in Puerto Vallarta, the major issues involved in the Compact have emerged more clearly, both points of consensus and points of contention. The US withdrawal from the Compact process the weekend before the Puerto Vallarta meeting, while regrettable, has not discouraged 192 other member states from moving forward with their deliberations or from their commitment to develop a progressive and forward-looking agreement (Gladstone 2017).

Civil society organizations, important contributors to the process, have released a blueprint for the Compact, titled, "Now and How: Ten Acts for the Global Compact,"2 which offers recommendations for the Compact from a human rights-based perspective. The Holy See Mission has offered its own blueprint, titled, "Responding to Refugees and Migrants: Twenty Action Points" (Permanent Mission of the Holy See to the United Nations 2017).

There are several flashpoints which member states will have to navigate to ensure the adoption of a Compact which makes a difference on the ground. During the negotiating phase of the process, member states will have to resolve the following issues:

\footnotetext{
${ }^{1}$ See "Joint statement of UN and regional experts on migration in light of stocktaking meeting in Puerto Vallarta towards a human rightsbased Global Compact for Safe, Orderly and Regular Migration," December 6, 2017, https://reliefweb.int/report/world/joint-statement-unand-regional-experts-migration-light-stocktaking-meeting- puerto.

${ }_{2}^{2}$ https://www.icmc.net/sites/default/files/documents/ten-acts-global-compact-migration.pdf.
} 
Increasing legal avenues for migration. Almost uniformly, the notion of providing legal channels for migration was reaffirmed, but how nations will accommodate this goal was left illdefined (Catholic News Service 2017). The Scalabrini International Migration Network (SIMN) has stated that family immigration offers extensive benefits to nations, including economic entrepreneurship, social cohesion, and efficient immigrant integration (SIMN 2017c). Family immigration should not be sacrificed for labor migration — immigration is not a zero-sum game (Boehm 2017).

A point of contention emerging over the Global Compact on Migration is the use of temporary labor programs, which can take various forms, including "seasonal' or exploitative "temporary" programs in which foreign laborers come and work for a short time and then leave after the harvesting season is over (Costa and Martin 2017).

Civil society advocates have long characterized these programs as inherently abusive, as workers are tied to one employer and wages and working conditions are substandard, with little oversight from authorities (Global Unions 2017). They argue that foreign laborers should have full labor rights and the ability to work for more than one employer, so as to be able to better assert those rights.

Governments and some in the private sector generally find these programs useful in meeting their agricultural and low-skilled industry labor needs (GFMD 2017). Governments find that these programs are more easily sold to their citizens, as, theoretically, foreign workers do not remain in the country and compete with the populace for other jobs. Whether member states can agree to a labor migration model in the Compact that protects labor and human rights while also meeting state labor needs remains an open question.

Another area of possible contention is the balance between labor migration and family-based immigration visas (Fragomen 2017). While the Global Compact would likely not specifically devalue family-based immigration, an over-emphasis on labor migration without a reinforcement of the importance of family-based visas could give a green light to member states to cut family immigration slots.

Another area of debate will be over the demand for high-skilled workers in developed nations. Several questions have emerged from the initial discussions. First, will high-skilled worker visas supplant, or even eliminate, visas for low-skilled workers and family members? Some nations, including the United States, have proposed a merit-based or "point"-based system, in which skills, education, and wealth take precedence over family-based immigration and lower-level skills (Cortes 2017). Such programs, opponents argue, would allow high-skilled applicants to become permanent residents while low-skilled workers would be relegated to temporary worker programs, making them an underclass of persons.

The second potential conflict is the age-old "brain drain" debate, in which developed nations recruit the best and brightest from developing countries. Nations of the global south have consistently expressed concern about losing their most educated and skilled workers to developed countries, thus stilting their own development (Kigotho 2013). How high-skilled labor programs are presented in the Compact, if at all, should include the concept of return, whereby 
workers receive training in developed nations and are able to return to their countries of origin to contribute to their development (Soergel 2016).

A final challenge, which also represents an opportunity, is the chance to set targets for increasing legal avenues for migration, perhaps tied to the 2030 Sustainable Development Goals. In a statement before the Puerto Vallarta stocktaking meeting, SIMN proposed that member states increase their legal avenues for migration by 25 percent by 2030, in line with the International Organization for Migration's (IOM) 2007 estimate of the percentage of undocumented migrants in the world (SIMN 2017b).

The issue of sovereignty and enforcement. In their statement announcing their withdrawal from the Global Compact process, the United States suggested that the Compact would infringe upon "national sovereignty" and that the United States would instead create and conduct its own immigration policies (Karimi 2017). This argument is disingenuous, given that the Compact will be a non-binding document. Nevertheless, some member states may see the Compact as an avenue to tighten borders by encouraging international cooperation on enforcement.

Indeed, several member states have prioritized "border cooperation," which is seen as a code word for regional deterrence arrangements. Such arrangements have materialized in Asia through the interdiction and offshore processing program initiated by the Australian government; in the Americas through US-Mexico cooperation in stemming the flow of refugees from the northern triangle of Central America; and in Europe, where the European Union forged an agreement with Turkey to halt the migration of Syrian refugees. These policies are characterized by interdiction and return, the liberal use of detention, and the closing of borders (Frelick, Kysel, and Podkul 2016).

The New York Declaration on the Large Movements of Refugees and Migrants contains language in paragraph 24 that encourages "international management and border cooperation" and the sharing of "best practices," interpreted as enforcement practices (Voltaire Network 2016). Such language could be used as a springboard to enhance enforcement coordination in regional settings or, at a minimum, to legitimize policies such as detention, interdiction and expedited return, and the closing of borders.

SIMN, in a statement to an IOM-hosted meeting in April 2017, suggested that the success of the Global Compact would be measured by how these deterrence arrangements are mitigated, not augmented. SIMN has argued that the "externalization of borders" should be replaced with an "externalization of protection" (SIMN 2017a). In other words, nations must cooperate on sharing the responsibility in protecting large movements of migrants, not in pushing them back to their countries of origin, often into dangerous situations.

An enforcement-related issue surfacing is the issue of the return of migrants to their countries of origin, which could include language encouraging sending nations to more readily accept their deported nationals. Member states are anxious to develop a system that facilitates returns, while advocates have expressed that due process protections and reintegration efforts must be incorporated into any program of return (EBL News 2017; PICUM 2017). CMS has argued that 
returnees should receive retirement benefits they have accrued from their work in destination countries (Kerwin 2017a).

The issue of unaccompanied children and detention should again surface as a point of contention, as it was during the New York Declaration process (Global Campaign to End Child Detention 2017). Some nations, including the United States, have maintained that governments should have an option to detain minors as a "last resort." Other member states, as well as civil society, argue that detaining children, regardless of their age, should be ended (Global Coalition on Migration 2016). How these two positions are reconciled could become a flashpoint during the negotiations, just as it was during the New York Declaration process. The rights of child migrants extend beyond the issue of detention, as well (Initiative for Child Rights in the Global Compacts 2017).

Of the many complex issues involved in the Compact, the balance between enforcement and protection is among the most challenging. How member states resolve this balance could define its legacy.

Filling gaps in protection for vulnerable migrants. An issue that could be important to both the Migration Compact and the Global Compact on Refugees concerns migrant populations that do not meet the refugee definition set forth in the 1951 Convention relating to the Status of Refugees, but that nevertheless have protection needs. For example, migrants who flee natural disasters, climate change, or generalized violence often do not meet the five grounds for refugee protection, but can be in life-threatening danger if returned to their home country.

One solution is to adopt principles from the Nansen Initiative, which encourages nations to take steps to assist at-risk populations fleeing natural disaster, and the Migrants in Countries of Crisis (MICIC) initiative, which covers migrants caught in conflict or natural disaster in the nation in which they are residing (Martin 2016). A more global commitment to these principles by UN member states would encourage a more coordinated response to these situations. The adoption and use of temporary protection laws, similar to the Temporary Protected Status (TPS) law in the United States, is another way to offer protection to these populations, at least until it is safe to return home (Kerwin 2017b).

Immigrant integration/regularization. A strong theme among participants in the Puerto Vallarta stocktaking meeting was immigrant integration, or policies that facilitate the contributions of immigrants and their participation in their new society. Although member states acknowledged immigrant integration as a worthy goal, there were divergent views as how to best achieve it. Many pointed to the role of local governments and civil society in assisting in this task, while others emphasized that it was part of a national government's role to provide services needed to help the integration of immigrants. The Compact will likely recommend a "whole-ofsociety" model to integration, leaving it up to member states to define how such a model is constructed (Permanent Mission of Canada to the United Nations 2017).

The integration issue also has relevance in a nation's immigration policies. Migrants who enter as permanent residents by definition have more leverage and possibilities for integration than those on temporary visas. Civil society has recommended that regularization programs be 
adopted to permit long-term undocumented residents with equities to integrate more easily into society (Women in Migration Network 2017). Member states generally have not embraced the idea of regularization as an effective tool in this regard, with some arguing that it incentivizes unauthorized immigration.

Complementarity of the Global Compacts. One area that has received insufficient attention, at least publicly, are overlapping issues between the Global Compact on Migration and the Global Compact on Refugees (ICVA, ICMC, and the NGO Committee on Migration-New York 2017). There are many potential areas of overlap, as large movements of persons include those who are migrating for different reasons and individuals with mixed motives - some have valid refugee claims while others may not. The treatment of asylum seekers, migrants in vulnerable situations, and victims of human trafficking, for example, must be coordinated between the two Compacts, so that they are consistent.

To date, there remains no clear line of demarcation between the two Compacts, not to mention no formal mechanism for ensuring they do not conflict with each other (UNHCR 2017). It is vital, however, that none of the overlapping issues fall through the cracks and are left unaddressed.

Implementation/targets. Perhaps the most significant issue to determine the long-lasting impact of the Global Compact on Migration is how it will be implemented. At the Puerto Vallarta meeting, there were suggestions that follow-up mechanisms be established to monitor implementation, and that a UN agency, such as IOM, be charged with assisting member states in meeting the Compact's goals. A "financing facility" to help member states achieve certain goals was also recommended, as well as a periodic progress report (Global Compact for Migration 2017a). It was made clear, however, that member states would themselves determine if they were meeting their goals (Global Compact for Migration 2017b).

The question is what goals, or targets, member states would agree to meet. The term "actionable commitments" has been used frequently, but without specific targets included in the Compact to measure progress toward specific goals, any judgment would be subjective (IRIN News 2017). To their credit, the co-facilitators of the process, Mexico and Switzerland, have emphasized the need for actionable commitments, but specific suggestions tied to indicators and goals have yet to materialize in the public sessions.

What should an actionable commitment look like? There are several examples:

An increase in legal avenues for migration should be adopted.

An increase in the use of community-based alternatives to detention should be considered.

- Reductions in transfer fees for remittances should be assessed and achieved.

- The detention of children should be ended.

- Firewalls between immigration benefit programs and enforcement should be established.

- Regularization programs should be implemented.

- National and local immigrant integration plans should be developed and measured. 
- An increase in development assistance to and job creation in developing countries should be quantified and provided.

- The Nansen Principles and MICIC Initiative recommendations should be included and followed.

- Regional protection mechanisms should be strengthened and monitored, and deterrence tactics eliminated.

Such concrete commitments would give the Compact some teeth, and, importantly, make a difference on the ground. Specific and quantifiable targets should be added to the commitments and could be tied to the UN 2030 Sustainable Development Goals (SDGs), giving member states sufficient time to achieve them.

The question of implementation goes to the purpose of the Global Compact, which, as its formal title suggests, is to increase safe, regular, and orderly migration. With quantifiable and achievable targets to achieve its purpose, the Global Compact would become a vital, and relevant, international instrument in the years ahead.

Moving forward. With the information-gathering stage of the process nearing its conclusion, and the negotiation phase about to begin, the real work on the Compact still lies ahead. The negotiation phase of the process will commence with the release of the "zero draft" document by the co-facilitators sometime in February. It is during this phase that the issues of contention, but also moments of opportunity, will be joined. Hopefully, member states will take risks and push for a progressive document which will make a real difference in the lives of migrants around the world.

\section{References}

Boehm, Deborah. 2017. "Separated Families: Barriers to Family Reunification After Deportation." Journal on Migration and Human Security 5(2): 401-16.

https://doi.org/10.14240/jmhs.v5i2.90.

Catholic News Service. 2017. "Vatican: Lack of legal, safe channels for migration helps traffickers." Catholic News Service, September 5. https://www.thecompassnews.org/2017/09/vatican-lack-legal-safe-channels-migration-helpstraffickers/.

Cortes, Steve. 2017. "End chain migration, as Trump wants, and switch to merit-based immigration." http://www.foxnews.com/opinion/2017/12/20/end-chain-migration-as-trumpwants-and-switch-to-merit-based-immigration.html.

Costa, Daniel, and Philip Martin. 2017. "Why the UN Global Compact on Migration Matters." Working Economics Blog, Economics Policy Institute. https://www.epi.org/blog/why-the-unglobal-compact-on-migration-matters/.

EBL News. 2017. "EU calls on member states to step up migrant returns.” EBL News, March 2. 
https://eblnews.com/news/europe/eu-calls-member-states-step-migrant-returns-59994.

Foley, Elise, and Arthur Delaney. 2017. “The Real Goal Of Trump's 'Merit-Based' Immigration Plan May Just Be Fewer Immigrants.” Huffington Post, March 9. https://www.huffingtonpost.com/entry/trump-merit-based-legalimmigration_us_58c0813fe4b0ed718269ade8.

Fragomen, Austin. 2017. "Implementing the Global Compact on Migration: Existing and Envisaged Cooperation and Follow-up Mechanisms." Statement at the International Dialogue on Migration 2017, New York, April 19. https://www.iom.int/sites/default/files/our_work/ICP/IDM/Panel\%206\%20$\% 20$ Austin\%20Fragomen.pdf.

Frelick, Bill, Ian M. Kysel, and Jennifer Podkul. 2016. "The Impact of Externalization of Migration Controls on the Rights of Asylum Seekers and Other Migrants." Journal on Migration and Human Security 4(4): 190-220. http://dx.doi.org/10.14240/jmhs.v4i4.68.

Genina, Victor. 2017. "Proposals for the Negotiation Process on the United Nations Global Compact for Migration.” Journal on Migration and Human Security 5(3): 682-93. https://doi.org/10.14240/jmhs.v5i3.104.

GFMD (Global Forum on Migration and Development). 2017. Toward a Global Compact on Migration: Perspectives on Labour Migration from the GFMD Business Mechanism. Geneva: GFMD. http://gfmdbusinessmechanism.org/wp-content/uploads/2017/07/Business-MechanismReport-to-10-GFMD-Summit-2017-06-19-final.pdf.

Gladstone, Rick. 2017. “U.S. Quits Migration Pact, Saying It Infringes on Sovereignty.” New York Times, December 3. https://www.nytimes.com/2017/12/03/world/americas/united-nationsmigration-pact.html.

Global Campaign to End Child Detention. 2017. "A Step Backwards from Leaders at the UN High Level Summit." https://endchilddetention.org/news/a-step-backwards-from-leaders-at-theun-high-level-summit/.

Global Coalition on Migration. 2016. “Don’t Lower the Bar on Children's Rights: End the Detention of Migrant Children!" http://gcmigration.org/2016/08/statement-end-child-detention/.

Global Compact for Migration. 2017a. "Preparatory (stocktaking) meeting 4-6 December 2017, Puerto Vallarta, Mexico."

https://refugeesmigrants.un.org/sites/default/files/171222_final_pv_summary_0.pdf.

—. 2017b. "Canadian Statement, Puerto Vallarta, December 6, 2017."

https://refugeesmigrants.un.org/sites/default/files/pv_day3_canada.pdf.

Global Unions. 2017. "Labour's Demands for the Global Compact on Migration." https://www.ituc-csi.org/IMG/pdf/labour_demands_5-final_2_.pdf. 
ICVA (International Council of Voluntary Agencies), ICMC (International Catholic Migration Commission), and the NGO Committee on Migration-New York. 2016. "The imperative for complementarity, coherence and consistency in the follow-up to the New York Declaration: A civil society proposal." https://www.icmc.net/sites/default/files/documents/icmc-joint-statementglobal-compact-nov-2016.pdf.

Initiative for Child Rights in the Global Compacts. 2017. The Global Compact for Migration: Actionable Commitments for Children on the Move. http://www.childrenonthemove.org/wpcontent/uploads/2017/12/Actionable-Commitments_01122017.pdf.

IRIN News. 2017. "UN global compact for migration must be made fit for purpose." IRIN News, December 18. http://www.irinnews.org/opinion/2017/12/18/un-global-compact-migration-mustbe-made-fit-purpose.

Karimi, Faith. 2017. "US quits UN global compact on migration, says it'll set its own policy." CNN, December 17. https://www.cnn.com/2017/12/03/politics/us-global-compactmigration/index.html.

Kerwin, Donald. 2017a. "The Global Compact on Migration Should Support Portable Social Security Benefits, Including for Irregular Migrants and Deportees.” Huffington Post, October 4. https://www.huffingtonpost.com/entry/the-global-compact-on-migration-should-supportportable_us_5979265de4b06b305561cde4.

—. 2017b. "The Besieged US Refugee Protection System: Why Temporary Protected Status Matters." Huffington Post, December 27. https://www.huffingtonpost.com/entry/the-besieged-usrefugee-protection-system-why-temporary_us_5a3aa281e4b0d86c803c6e19.

Kigotho, Wachira. 2013. "Migration and brain drain from Africa acute - Report." University World News, October 11. http://www.universityworldnews.com/article.php?story=20131011121316706.

Martin, Susan. 2016. "New Models of International Agreement for Refugee Protection.” Journal on Migration and Human Security 4(3): 60-75. http://dx.doi.org/10.14240/jmhs.v4i3.62.

Permanent Mission of Canada to the United Nations. 2017. "Global Compact on Migration: Thematic Consultation on Human Rights, Inclusion and Integration." https://refugeesmigrants.un.org/sites/default/files/canada-ts1-p2.pdf.

Permanent Mission of the Holy See to the United Nations. 2017. "Responding To Refugees And Migrants: Twenty Action Points." https://holyseemission.org/contents/statements/5a2716362f88c.php.

PICUM. 2017. "New EU Commission Plans on Returns and Detention Will Create More Harm and Suffering." http://picum.org/new-eu-commission-plans-returns-detention-will-create-harmsuffering/. 
SIMN (Scalabrini International Migration Network). 2017a. "Statement of the Scalabrini International Migration Network International Dialogue on Migration April 19, 2017." New York: SIMN. http://www.simn-global.org/news_post.php?category=press\&news_id=346.

. 2017b. "SIMN Policy Director Calls Upon UN Member States to Increase Legal Channels for Migration in Global Compact.” New York: SIMN. http://www.simnglobal.org/news_post.php?category=press\&news_id=444.

_. 2017c. "The Scalabrini International Migration Network Presence at the Tenth Global Forum on Migration and Development (GFMD).” New York: SIMN. http://simnglobal.org/news_post.php?category=press\&news_id=380.

Soergel, Andrew. 2016. "Sub-Saharan Africa Bleeds Skilled Labor as 'Brain Drain' Continues." U.S. News, October 7. https://www.usnews.com/news/best-countries/articles/2016-10-07/subsaharan-africa-bleeds-skilled-labor-as-brain-drain-continues.

UN. 2017a. "Global cooperation vital to maximize benefits of migration, says UN envoy." http://www.un.org/apps/news/story.asp?NewsID=58238\#.WjwniTgo6Uk.

_. 2017b. "Conference Launches Stocktaking Phase to Shape Global Compact for Migration.” https://www.un.org/press/en/2017/dev3301.doc.htm.

UNHCR (UN High Commissioner for Refugees). 2017. "Strong compacts for refugees and migrants more urgent than ever." http://www.unhcr.org/news/press/2017/9/59c274f64/strongcompacts-refugees-migrants-urgent.html.

Voltaire Network. 2016. "New York Declaration for Refugees and Migrants." New York: Voltaire Network. http://www.voltairenet.org/article193286.html.

Women in Migration Network. 2017. Regularisation as a Core Policy for Safe Migration Pathways. http://womeninmigration.org/wp-content/uploads/2017/06/Berlin-2017_5Regularisation.pdf. 


\title{
$96 \mathrm{CMS}$
}

\section{The Global Compact on Migration Should Support Expanded Social Security Coverage and Portability of Benefits, Including for Irregular Migrants and Deportees ${ }^{1}$}

\section{Statement at the Fourth Informal Thematic Session on Facilitating Safe, Orderly, and Regular Migration: Remittances and Portability of Earned Benefits, July 25, 2017}

\author{
By Donald Kerwin, the Center for Migration Studies
}

How can international migration be managed to maximize the contributions of migrants and diaspora communities to sustainable development? Over the last few days, the President of the United Nations (UN) General Assembly hosted a thematic session that addressed this challenge, one in a series of gatherings in preparation for the adoption in 2018 of a "global compact for safe, orderly and regular migration."

The session devoted significant attention to migrant remittances and the portability of social security benefits - retirement, disability, health, and others. In 2016, international migrants sent $\$ 575$ billion to their home countries, including $\$ 429$ billion to developing states, roughly three times the amount of overseas development assistance (World Bank 2017). Like remittances, portable social security benefits have immense potential to alleviate poverty and contribute to development. It stands to reason that increased economic integration and international migration should be accompanied by a substantial increase in benefit coverage and portability. Yet only 23 percent of international migrants - mostly those moving between developed states - benefit from bilateral social security agreements (Holzmann, Wels, and Dale 2016). There is a large need for more bilateral and for multilateral agreements that provide for portable benefits.

Portable benefits should also be available for irregular migrants and deportees. Portability is a matter of equity. It speaks to allowing a migrant - whose work has benefitted a state - to keep what he or she has earned. Economic development can obviate the need to migrate, but migration can also contribute to development. Migration can lead to the transfer of skills, ideas, monies, training, education, and (often positive) social norms. Yet the literature also suggests that the lack of portability of benefits can impede development by preventing the return of migrants to their communities of origin. For some migrants, the decision is stark: return home and lose benefits, or stay in a foreign country and retain them.

If economic integration is on the rise, so too are mass deportation and involuntary return policies, which begs the question: What happens to the social security benefits earned in developed states by irregular migrants and deportees? By 2012, the US Social Security Administration's (SSA's) Earnings Suspense File counted \$1.4 trillion in uncredited wages (OIG 2015). This figure refers to unrecorded earnings, not to the Social Security and Medicare taxes paid on them. In 95 percent of these cases between 2008 and 2012, the names and social security numbers on the federal W-2 (wage and salary) forms did not match official SSA records. This is because an extremely high percentage of uncredited earnings come from outof-status workers, who cannot receive these benefits unless they can obtain legal status. Moreover, legal immigrants who are deported lose status and, as a result, lose eligibility for old-age and disability benefits. Like irregular migrants, they cannot receive the fruits of their labor unless and until they obtain legal status and are lawfully readmitted, which is a very unlikely prospect in most cases.

\footnotetext{
${ }^{1}$ This intervention was previously published as a Huffington Post blog at https://www.huffingtonpost.com/entry/theglobal-compact-on-migration-should-support-portable_us_5979265de4b06b305561cde4.
} 
Combined, these practices deny migrants the benefits they have earned, diminish development in migrant sending communities, and risk impoverishing hard-working persons and their dependents. The Global Compact for Safe, Orderly, and Regular Migration should support the eligibility of workers (regardless of status) for these benefits and should support the portability of benefits, including for deportees. As a matter of equity and a potential development tool that could obviate the need to migrate, developed states should also consider channeling social security earnings that cannot be credited to individual workers to development initiatives in migrant-sending states.

Even more important than the ability of social security benefits to move with migrants is the ability of families to move and stay together. It is impossible to think of an immigration system that promotes safe, orderly, and regular migration but does not prioritize family unity, or to think of development in the sense of enlarging people's freedoms and capacities without recognizing the central importance of intact family. Families contribute immensely to immigrant integration, social cohesion, the protection of members who are at risk, and to the labor markets of receiving states (CMS and Cristosal 2017; Gubernskaya and Dreby 2017). For these reasons, the global compact should also underscore the need for family unity.

\section{References}

CMS (Center for Migration Studies) and Cristosal. 2017. Point of No Return: The Fear and Criminalization of Central American Refugees. New York and San Salvador: CMS and Cristosal. https://doi.org/10.14240/cmsrpt0617n2.

Gubernskaya, Zoya, and Joanna Dreby. 2017. "US Immigration Policy and the Case for Family Unity." Journal on Migration and Human Security 5(2): 417-30. https://doi.org/10.14240/jmhs.v5i2.91.

Holzman, Robert, Jacques Wels, and Pamela Dale. 2016. “Assessing Benefit Portability for International Migrant Workers: A Review of the Belgium-Morocco Bilateral Social Security Agreement." Social Protection and Labor Discussion Paper 1603. Washington, DC: World Bank.

OIG (US Office of the Inspector General). 2015. "Status of the Social Security Administration's Earnings Suspense File.” Baltimore, MA: OIG, Social Security Administration.

World Bank. 2017. "Migration and Remittances: Recent Developments and Outlook Special Topic: Global Compact on Migration." Migration and Development Brief 27. Washington, DC: KNOMAD (Global Knowledge Partnership on Migration and Development), World Bank. http://pubdocs.worldbank.org/en/992371492706371662/MigrationandDevelopmentBrief27.pdf. 


\section{SIMN Policy Director Testifies at Interactive Multi-Stakeholder Meeting on UN Global Compact on Migration}

New York, New York, July 26, 2017-The Scalabrini International Migration Network (SIMN) gave testimony to the first Interactive Multi-Stakeholder meeting on the United Nation's Global Compact on Safe, Orderly, and Regular Migration, held at UN headquarters July 26, 2017.

In his statement, Kevin Appleby, Senior Director for International Migration Policy for SIMN, stated that the contributions of migrants to both origin and destination countries are maximized when they are allowed to migrate and work in a safe and legal manner.

"Providing legal pathways for migration ensures that migrants are able to contribute fully to their new communities and also help their families and communities in their countries of origin," Appleby said. "It increases their earnings, allows them to develop their own businesses, and gives them the freedom to fully unleash their talents and expertise," he added.

Appleby testified on the panel focusing on the contributions of migrants and their production of remittances. Member states, UN organizations, and civil society attended the hearing, which occurred a day after the two-day thematic session on the same subjects, part of the process of producing the Global Compact on Migration.

"The Global Compact on Migration is an opportunity to correct the excesses and shore up the weaknesses of the global migration system, in which all stakeholders - governments, civil society, and, yes, migrants - benefit and in which labor and other human rights are upheld," Appleby concluded. "It is vital that the Compact has measureable goals and outcomes, as well as accountability mechanisms to attain those goals."

About SIMN - SIMN is supporting more than 250 Scalabrinian centers, shelters and programs that are providing lodging, food, training and employment programs; psychological and religious services; protection to victims of human trafficking and support in the integration process to migrants, refugees and seafarers in five continents. In 2016, for example, Scalabrinian Centers has supported 120,738 migrants and refugees and 172,790 seafarers around the world. SIMN is also supporting a network of schools providing education, school supplies, and food, (possibly their only meal of the day) to thousands of needy children. In addition, SIMN is an accredited Non-Governmental Organization at the United Nations, the International Organization for Migration (IOM) and the Organization of American States (OAS) and from this perspective is providing research and support for regional and global policies to protect and promote the dignity and the rights of migrants and their families. 


\section{Statement of Scalabrini International Migration Network (SIMN) and \\ Center for Migration Studies of New York (CMS) on \\ Zero Draft of Global Compact on Migration}

February 22, 2018

We would like to thank the co-facilitators for the substantive and comprehensive zero draft.

We offer the following general comments and edits:

We would like to see "faith-based organizations" specifically mentioned in the draft, as they are present in sending, transit, and destination countries, accompanying migrants on their journey and filling in service gaps to migrants that member states are unwilling or unable to do. Member states should welcome partnerships with faith-based groups.

We are disappointed that the Compact does not include specific targets tied to the 2030 SDGs. Progress on the important goals in the Compact cannot be properly measured without targets - otherwise such progress is subjective and illusory. With an ill-defined implementation process and a lack of specific funding to build capacity, we are afraid the goals of the Compact may not be realized.

\section{Preamble:}

Suggested change: Insert "faith-based organizations," after "civil society organizations," in the paragraph on the whole of society approach.

\section{Objective 1}

We support the objective of gathering data on migration trends, but feel that a firewall should exist to ensure that information provided by migrants in an irregular status is not used for enforcement purposes.

Suggested change: In paragraph 15, at end of first sentence insert, “,to be used for nonenforcement purposes."

\section{Objective 2}

We support the goals of Objective 2 on adverse drivers of migration but would add language in paragraph $\mathrm{g}$ that states that funding assistance for sustainable development should not be conditioned based on a developing state's migration policies, i.e. the prevention of migration.

Suggested change: At the end of paragraph g, add: "Such support should not be conditioned on steps to prevent migration by developing states."

In paragraph e, we would insert, "build local capacity," after emergency operations 


\section{Objective 3}

Suggested change: In paragraph e, add "on a voluntary basis" after "migrants abroad" to ensure migrants are not required to provide personal and sensitive information against their will.

\section{Objective 5}

We support language in Objective 5, paragraph $\mathrm{J}$ regarding family reunification in migration laws and policies, but believe that family unity should be added to the labor mobility model recommended in 19 a and d. We also would support language encouraging an increase in legal immigration channels, as the purpose of the Compact is to create safe, regular, and orderly migration.

Suggested changes: In paragraphs a and d, insert "family-based" after "rights-based." In paragraph c, delete "and" after "Review" and add "expand" after revise. Add "family unity" after "imbalances." In paragraph g, add "narrow definitions of family membership" after "length of stay."

\section{Objective 6}

We support maintaining the current language in paragraph $\mathrm{h}$. Migrant workers tied to single employers are more susceptible to exploitation.

\section{Objective 7}

In Objective 7, paragraph $\mathrm{f}$, we would add language that specifies that migrants in detention should have access to legal assistance, because often those in detention do not have access to counsel because of hard to reach or hard to access locations.

Suggested change: After "affect them," insert "particularly those in custody,"

\section{Objective 8}

Objective 8, paragraph $\mathrm{b}$, we would add language that would review how migration policies raise the risk of driving migrants to take dangerous crossing routes and methods. Border enforcement often has the effect of driving migrants into remote areas and possible death, or in taking perilous sea journeys.

Suggested change: After "missing" add "or driving migrants to take dangerous crossing routes and methods."

\section{Objective 10}

We would add language that encourages member states to screen children apprehended at borders as possible victims of human trafficking.

Suggested change: Add a new paragraph g which reads: "Establish screening mechanisms at borders with child welfare professionals to identify and protect children who have been victims of are at risk of human trafficking." 


\section{Objective 11:}

We strongly support Objective 11, particularly protection language in paragraph B encouraging regional cooperation on the protection of vulnerable migrants, but would welcome more specific language discouraging the use of deterrence tactics in response to large movements, such as interdiction and return without due process, detention, family separation, and offshore processing. We would also discourage, in paragraph $\mathrm{f}$, technical assistance designed to increase interdiction and return capabilities.

Suggested changes: In paragraph $\mathrm{f}$, add after "border management," insert "consistent with international law,"

Create a new paragraph h: "Ensure that the use of policies which deny due process, including push backs, interdiction and return, detention, offshore processing, and family separation are minimized."

\section{Objective 13}

We support Objective 13 on detention, but would place "community-based" before alternatives to detention at the appropriate places, to ensure that comprehensive support is given to released detainees, including legal representation, and would discourage the use of alternative forms of detention, such as ankle bracelets and other electric monitoring systems.

In paragraph E, we would add "access to legal representation" along with food, healthcare and accommodation provided to detainees.

Finally, we would add language to paragraph g that would reduce the use of family detention and creates sufficient alternatives for family units so that no child is ever detained. This is an increasing practice which should be minimized, if not ended, in the best interests of the child.

Suggested changes: Add "community-based" before "alternatives to detention" in paragraph a. Insert "legal orientation and representation," after "healthcare" in paragraph e. Add "community-based" before "alternatives to detention" and "parents," before "family members" in paragraph $\mathrm{g}$.

\section{Objective 15}

We support firewall language in paragraph $\mathrm{c}$ and ask that it be retained

\section{Objective 16}

We support language in paragraph $\mathrm{g}$ and ask that it be retained

Suggested change: Add "ethnicity, ancestry" after "religion" in paragraph 31

\section{Objective 21}

Suggested change: At the end of paragraph e, insert "and the principle of nonrefoulement." In paragraph i, add "family reunification," after "social protection and services." 


\section{Objective 22}

Suggested change: In paragraph 36, insert "in their destination countries" after "social protection."

\section{Implementation}

Suggested change: In paragraph 40, add "faith-based organizations" after "civil society" 


\section{Statement of Scalabrini International Migration Network}

\section{Second Round of Negotiations of the Global Compact on Migration}

With over 270 programs worldwide serving migrants, including shelters, SIMN is well-versed in the reality of large migration movements. In our experience, we find that stark distinctions between regular and irregular migrants and migrants and refugees do not reflect what is happening on the ground, which is what the GCM is trying to impact. A person can meet the definition of a migrant or refugee, or can be seen as an irregular migrant or regular migrant, all at the same time.

For example, an individual or family can be seeking family reunification at the same time they have a valid protection need. We see this in our experience in working with Central American migrants, who can be fleeing organized criminal networks at the same time they are trying to reach a parent or other family member in the United States. Because in some cases they are fleeing generalized violence, these persons or families may not receive asylum protection in the United States, even though their return may result in harm or even death.

A bright distinction between regular/irregular and migrants/refugees also impacts families, as some in the family unit may qualify for protection under a nation's laws, but not other members of a family unit. More families are migrating globally, especially women with children. Children are particularly at risk in these situations, as they may face separation from a parent in some cases, or may be forced to go back to a dangerous situation with their parent.

Moreover, a lot depends on the type of screening mechanisms nations employ and whether they meet due process standards. Persons who cross an international border seeking protection are not breaking the law-they are not irregular and deportable---until they receive appropriate asylum review.

However, they often are treated as such, as they are detained for extended periods of time, unable to access legal representation, and at times are dissuaded from applying for asylum, despite having a valid claim. Often how they are viewed is how they may answer the first questions from an enforcement officer, not how they are viewed by an adjudicator or judge. We also witness situations in which mixed movements are responded to with deterrence policies which deprives all people access to protection-interdiction and return schemes, family separation at borders, push backs, and the closing of borders, to name a few. These tactics should be discouraged in the Global Compact.

What should member states do to fill the protection gaps? Other than assuring fair and transparent due process, they should add tools to their tool box of legal remedies, so that persons with protection needs who do not meet the refugee definition can receive some form of protection. This could include humanitarian visas and parole, temporary protected status, or visas for special classes of persons - abandoned and separated unaccompanied children, victims of domestic violence, and victims of human trafficking. We support Objective 5, paragraph $\mathrm{F}$ in the compact and ask that these classes be added to that paragraph. 
In general, we urge language be added to say that a goal of the Compact is to increase regular and legal pathways as a means to reducing irregular migration and in protecting vulnerable migrants. This language should be added to the guiding principles.

We are in agreement with the Holy See and other member states that migrants have certain rights, regardless of status, and should be afforded access to necessary basic needs assistance. We agree with Objective 22 regarding the right of migrant workers to receive social security and earned benefits, regardless of legal status. Member states should not accept their sweat equity and then deprive them of retirement benefits they have earned. Additionally, personal information of migrants for these purposes or other immigration benefits should not be used for enforcement purposes.

We concur with the recommendations of the Civil Society statement regarding implementation and review, with a timeline for implementation, capacity building mechanisms and financing, and a robust role for civil society, including faith-based organizations, in implementation. We continue to call upon member states to add specific goals, targets, and indicators to the Compact. 


\section{Statement of Scalabrini International Migration Network Third Round of Negotiations of the Global Compact on Migration}

New York, April 6, 2018 - We have submitted our edits to the Revision 1 of the GCM. I would like to make some overall points.

Consistent with statements made by several member states, we support adding language that makes it clear that member states should increase or expand regular pathways for migration. This should be a central goal of the Compact, which has the goal of promoting safe, orderly, and regular migration. If origin countries have an obligation to accept their nationals, then destination nations have an obligation to increase legal avenues for migration, as they benefit from the labor of migrants. Regularization programs should be part of this effort, as they can be tailored to longstayers and other migrants in vulnerable situations in destination countries and provide these countries economic growth, social integration, and national security.

We oppose a section by section delineation of regular and irregular migrants. Many of the objectives, such as Objective 5 on regular pathways, by definition apply to irregular migrants. Finally, we disagree with Paragraph 3 in the preamble that says that migrants are not inherently vulnerable, as that is not the reality on the ground. This term can also be used by immigration opponents to deny all human rights to irregular migrants and to fan the flames of xenophobia. The sentence should be changed to "migrants may not have a protection claim under the 1951 Refugee Convention and its 1967 protocols.

Second, we support the language of human rights protection added to the draft, especially in terms of migrants in vulnerable situations, but there needs to be clarification as to what human rights protections means, especially as it applies to access to services, as it could be interpreted in different ways. Language tying it to such instruments as the Universal Declaration on Human Rights would be appropriate.

Third, we understand the dilemma between the need to collect adequate data about migrants and how this information is used. We strongly support firewall language, as it is needed to ensure that irregular migrants participate and have access to necessary benefits. We would suggest adding language that states that demographic data should not be used to target enforcement efforts or to direct federal funding to local jurisdictions. We support removing the question of "country of citizenship." We also would suggest adding to Objective 15, 30 c language which clarifies which places of service delivery where migrants should not be apprehended. These should include charitable organizations, places of worship, schools, and courts, where they receive necessary material, pastoral, educational, and access to justice services.

Fourth, we support language in Objective 5 on family reunification and oppose removal of language listing barriers imposed by member states to prevent family unity. Income requirements, for example, discriminates against vulnerable families. We also support the addition of a new paragraph at the end of Objective 11 which eliminate the separation of family members at international borders. 
Fifth, we oppose language offered by Austria and European Union states that would add deterrence language to the chapeau and paragraph $26 \mathrm{f}$ of Objective 11 . This would approve the use of tactics which deprive migrant of due process rights, such as interdiction and return, pushbacks, offshore processing, detention, family separation, conditional aid, and other bi-lateral or multi-lateral formal and informal enforcement cooperation agreements, such as between Australia and other Asian countries. We urge the co-facilitators to reject such language.

Sixth, we oppose the removal of language in Objective 12 which relieves member states of the obligation to screen migrants for protection needs and informing them of their right to apply for asylum. This language does not confer a benefit but ensures due process for them.

Finally, we support the recommendation of the Holy See that faith-based organizations be added to the stakeholder list in both the preamble and implementation sections. Faith-based organizations are unique, as they have greater reach than governments - they are universal — and fill gaps in providing services to migrants, regardless of governmental action, but ideally to complement governmental action. Migrants also trust their own faith-based organizations in receiving support.

Mr. Co-facilitator, we will submit further comments for the remaining objectives after Member States review them in negotiations.

Thank you. 


\section{Statement of the Scalabrini International Migration Network \\ Global Compact on Safe, Orderly, and Regular Migration \\ United Nations}

\section{May 18, 2018}

Thank you, Mr. Co-Facilitator.

SIMN would like to make several comments on Revision 1 of the zero draft:

With regard to regular pathways and regularization, we agree with the Swiss delegation that these policies have their own legitimacy, as they lead to increased economic output in the host country, an increase in remittances in the source country, and upward mobility and stability for migrants - a win-win-win proposition. They also encourage integration into the host society and are pro-security, as governments know who is in the country and who is coming, and for what purpose.

With regard to regularization programs-- the so-called "pull" factor--we are not recommending that these programs, or increases in regular pathways, be conducted in a vacuum, but are part of a mix of policies to manage migration. This would necessarily include humane enforcement efforts which ensure due process protections. The goal is to incentivize regular migration by ensuring all stakeholders play by the rules, including employers.

Indeed, member states should not accept the "sweat equity," taxes, retirement payments, and consumer spending of irregular migrants without providing them the legal protection that their human rights and dignity demand. As a moral matter, the global community cannot have it both ways.

As such, we propose that the promotion of legal pathways and regularization programs be added as a principle in the preamble to the Compact and that language in Objective 5 and Objective 16 be strengthened to make clear that member states should increase legal pathways and regularization programs as a tool for fighting irregular migration.

We agree with Bahrain that these legal avenues and regularization policies should promote family reunification, as this would increase social cohesion and gender balance in host countries. Therefore, we oppose the removal of language in Objective 5, Paragraph G, which prevents member states from discriminating against families based on income, language or type of regular status.

With regard to border management, we would oppose the addition of any language to Objective 11 or any other Objective which would sanction the use of deterrence schemes to address large movements of migrants, as they encourage tactics which deny due process protections. Adding such language would undermine the purpose of the Compact to foster safe, orderly, and regular migration, as it forces migrants into situations which are not "safe." 
In this regard, we support the amendment of the Holy See to add a paragraph to Objective 11 prohibiting the use of family separation-normally children from their mothers-- as an enforcement tool at international borders. This is a cruel policy which should be ended.

We support the inclusion of "firewalls" throughout the draft, so that irregular migrants have access to basic services, consistent with their human rights, and can be part of data collection efforts. How you construct this language, co-facilitators, is vital, as it must not be left to interpretation.

The reason is simple: migrants will not access services or cooperate with census takers if they know they could be targeted for removal. Without firewalls, you are essentially denying them access to services and are effectively denying them their human rights. Studies show that the best way to reduce crime is to establish trust between local police and immigrant communities---the best way to identify the bad apples.

In this spirit, we would suggest adding to Objective 15, 30C language which clarifies places of service delivery where migrants should not be apprehended. These should include charitable organizations, places of worship, schools, and courts, where they receive necessary material, pastoral, educational, and access to justice services.

We agree with the majority of member states that the principle of non-refoulement should be included in the text, particularly in Objective 21. If source nations have an obligation to receive their nationals, then transit and destination nations have an obligation to abide by due process protections and international law during the return process.

Additionally, there is voluntary and forced return, but there is a third category - forced "voluntary" return, in which migrants are coerced by enforcement officials to voluntarily return. The use of coercive tactics, including the unnecessary detention of asylum seekers, to force "voluntary" return, should be discouraged in the Compact.

With regard to re-integration, providing returned migrants "equal" access to re-integration services means they will not get assistance, as they are usually inadequate in sending nations, one reason they left in the first place. Programs tailored specifically to their needs-employment, job training, physical security — must be provided. Destination nations should help in financing such programs, as these are more effective and cost-efficient investments in preventing irregular migration than spending billions on enforcement.

Finally, with regard to implementation, we will leave it to your wisdom about the role IOM may have in the implementation of the Compact. Regardless of their role, but particularly if they have a leading role, you must ensure that their new leadership is unequivocally committed to the implementation of the Compact. Otherwise, the goals of the GCM - and the good efforts of 192 Member States - may not be fully realized.

We will submit our additional suggestions in writing.

Thank you. 


\section{Statement of the Scalabrini International Migration Network \\ Fifth Round of Negotiations \\ Global Compact on Safe, Orderly, and Regular Migration}

\section{June 5, 2018}

Thank you co-facilitators.

We would like to thank you for improvements in Revision 2, including reaffirming the principle of non-refoulement, improved family unity language, a listing of the services available to irregular migrants, and the recognition of faith-based organizations as stakeholders in the implementation process.

We have several suggestions on how the Compact can be improved and strengthened. We have submitted these suggestions for your consideration, a few of which I would like to highlight:

First, we still believe that language encouraging an increase in regular pathways should be strengthened, as this should be a central means for promoting safe, orderly, and regular migration.

In Objectives 5 and 7, respectfully, we recommend adding language that member states "create new pathways" re regular pathways, and "create new policies, when practicable," re regularization. On regularization, the current language calls for individualized assessments based on current efforts but it should be clear that member states should consider regularization for specific groups, defined by particular criteria, as an option for reducing irregular status in their countries.

With regard to family unity, we recommend adding in Objective 5, paragraph 20i "legal status' to the list of areas member states should consider in promoting family unity and in Objective 9, paragraph $24 \mathrm{e}$ "the principle of family unity," to situations in which border crossers are prosecuted, to prevent the separation of mothers from their children.

With regard to children, we oppose replacing the best interest of the child principle as "the' primary consideration to a primary consideration in the preamble, which gives member states the option to minimize this principle. We also would add "as soon as possible" to child detention language in Objective 13 so it reads, "working to end, as soon as possible, the practice of child detention in the context of international migration." There must be urgency on this issue; it should not be open-ended.

In Objective 11, chapeau, we would delete "preventing' irregular migration and replace it with "reducing the incidence of irregular migration, consistent with due process protections and international law." This is basic language used elsewhere in the text that helps ensure that the human rights of migrants are upheld and respected in enforcement situations. 
In Objective 15, Paragraph 30c, we would add "places of worship" and "charitable organizations" to places where migrants should not be apprehended. Pastoral services and material services are necessary services to which migrants should not be deprived, based on their human rights

In Objective 21, chapeau, we would add "voluntary" so it reads, "human right to voluntarily return to his or her country." Forced return is not a human right.

In Objective 23, paragraph 38e the term "unconditional" should be added as a qualification of partnerships between member states.

Finally, Mr. Co-Facilitator, we agree with the Swiss delegation's construction of paragraph 15, replacing policy options with policy instruments, so as to not send a signal that member states can pick and choose the policies it adopts. In this vein, we recommend that more accountability be put in the implementation and review process, including more stringent reporting requirements by member states, such as national implementation plans. Without such accountability, the goals of the GCM may not be realized.

Thank you. 


\section{Statement of Scalabrini International Migration Network Sixth Round of Negotiations \\ Global Compact on Safe, Orderly, and Regular Migration \\ New York, NY}

July 10, 2018

Co-facilitators, we thank you for your leadership in getting the Compact to this point. We offer these comments in the spirit of making the final product even more effective in creating a sustainable framework for migration governance.

First, we encourage you to add "and family unity" to the "right to family life," as this principle is part of the Convention on the Rights of the Child and, by definition, children are part of families.

Second, we believe you should restore the term "nonrefoulement" at some place in the text. We are concerned that if the word is not there, regardless of it is rephrased elsewhere in the text, some will point to its absence as a justification to return migrants in vulnerable situations without due process, thus eroding, over time, international human rights protection. If you are unable to re-insert this principle, then a savings clause should be added to the text which states nothing in the Compact should be interpreted as falling below international human rights law. The legacy of the Compact should be to strengthen international human rights protection, not to weaken it.

Third, we urge you to restore paragraph 25e in Objective 9. By approving of the criminalization of migrants who cross international borders, the Compact could defacto encourage the violation of human rights, such as family separation, the detention of children and families, and the weakening of due process for asylum-seekers, all things we are seeing now on the US-Mexico border.

Fourth, we ask that you maintain the word "expand" in the chapeau of Objective 5. Expanding legal avenues for migration represents the best practice for creating safe, orderly, and regular migration.

In the chapeau of Objective 11, we urge you to replace "preventing' irregular migration with "reducing" irregular migration. The word "preventing" could be interpreted as sanctioning enforcement tactics, some of which undermine due process. The goal of the Compact should be to reduce irregular migration by offering legal means to migrate and to foster sustainable development in sending countries, not to externalize enforcement actions against large movements of migrants and refugees.

In Objective 15, chapeau, we urge you to restore the list of services as a baseline to which migrants, regardless of their legal status, have access. Without a floor, you risk a race to the bottom re the provision of basic, life-sustaining services, in violation of human rights.

Finally, Mr. Co-facilitator, we strongly support Paragraph 53 in the follow-up and review section. National responses to the Compact as crucial to ensuring that its principles are realized 
and that it becomes a living document which makes a difference on the ground. We, as a faithbased organization present on the ground in many countries, stand ready to work with Member States to realize this goal.

The Thai soccer team and their coach are safe due to international cooperation. This is a small sign of hope in a world often in disarray and at odds. We hope this spirit of cooperation lives as you finish the Compact in the days ahead and in its implementation in the years ahead.

Thank you. 


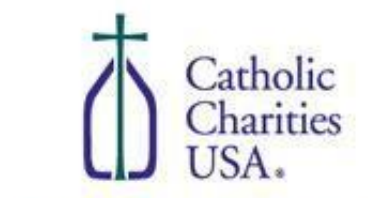

Working to Reduce Poverty in America.

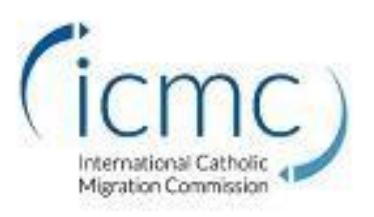

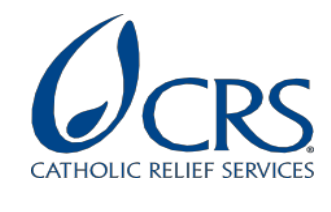
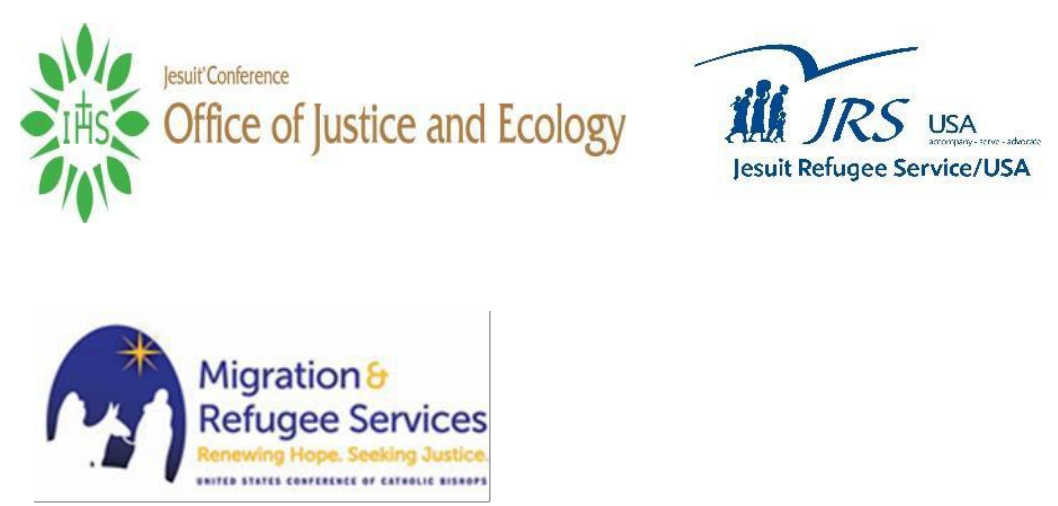

Introduction. Members of the U.S. Catholic Working Group on the Global Compacts on Refugees and Migration ${ }^{1}$ are deeply involved in the care and accompaniment of migrants and forcibly displaced persons at every stage of their journeys. We often work in partnership with the U.S. government, international organizations, and local organizations. Through advocacy and service our work includes fighting against the root causes of migration, providing humanitarian support to forced migrants, especially those in vulnerable situations, and advocating for just reform of national immigration laws in the United States. While we bring a distinct American Catholic experience to our statement, we also echo and build upon the Twenty Points document issued by the Holy See Mission to the United Nations in New York. ${ }^{2}$ We thank the co-facilitators of Mexico and Switzerland for their able leadership in developing the latest draft of the Global Compact on Safe, Orderly, and Regular Migration ("Global Compact on Migration").We offer the following principles which we believe should be reflected in the final draft of the Global Compact on Migration.

\section{The Global Compact on Migration should foster the catalytic role of faith-based organizations that} provide service to migrants at every stage of their journey. We strongly believe that the Global

\footnotetext{
${ }^{1}$ The working group includes Catholic Charities-USA, Catholic Relief Services (CRS), U.S. Liaison Office of the International Catholic Migration Commission (ICMC), Jesuit Conference of Canada and the United States, Jesuit Refugee Services/USA (JRS-USA), Scalabrini International Migration Network (SIMN), and the U.S. Conference of Catholic Bishops' Migration and Refugee Services (USCCB/MRS).

2 "Responding to Refugees and Migrants: Twenty Action Points," Migrants \& Refugee Section, Dicastery on Integral Human Development, Vatican, 2017. A summary of the document is also in a video featuring Pope Francis. See "Let's welcome, protect, promote and integrate refugees as Pope Francis is asking us," Migration \& Refugee Section, Dicastery of Integral Human Development, Vatican, January 18, 2018, video available at https://www.youtube.com/watch?v=dDIxrlY96ak
} 
Compact on Migration should specifically include faith-based organizations as important stakeholders and partners in both the Preamble and the Implementation sections of the document. As has been stated by the Holy See during the negotiations, faith-based organizations are unique because of their presence in sending, transit, and destination countries--at every point of the migration process. Faithbased organizations are universal in nature and thus have a reach beyond that of a single government.

Moreover, faith-based organizations fill gaps in services to migrants which governments are unable or unwilling to fill and work closely with many member states to protect migrants in vulnerable situations. They often build bridges between migrants and the local people. In addition, migrants often are attracted to faith-based groups because they are members of the faith or otherwise trust them to look after their best welfare, including warning them about the potential dangers of the migration journey.

The Global Compact on Migration should highlight increased legal avenues and regularization programs as the primary tools for reducing irregular migration and encourage member states to adopt these tools more aggressively. Consistent with its goal to promote safe, orderly, and regular migration, the Global Compact on Migration should include specific language, in both the preamble and Objective 5 , which calls for a significant increase in legal avenues for migrants and regularization programs for migrants residing in their countries.

In most cases, migrants travel in an irregular status because there are insufficient visas available for them to migrate in a legal manner. Once they have navigated an arduous and dangerous journey, they fill low-skilled jobs in many economies, yet remain susceptible to exploitation and abuse in the workplace. Legal avenues, which should include the option for permanent residency, should be increased to protect their lives, their human rights and the integrity of their family.

Migrants who reside in a country often live in fear of deportation, despite equities they may have builtfamilies, businesses, homes-over time. Family separation, in which parents are deported away from their citizen children, is a real threat. Regularization programs bring immigrants and their families into society, thus increasing their economic contributions, preserving family unity, and aiding national security, as governments would know who they are and more effectively integrate them into society.

In our view, the Global Compact on Migration should increase legal immigration as a method for reducing irregular migration, as opposed to using enforcement and methods of deterrence to accomplish this goal. Not only is it the most humanitarian way to respond to the challenge of irregular migration, it also is the most effective and sustainable.

\section{Border management should ensure that migrants receive due process protections and should not} deploy deterrence schemes to halt large movements of migrants and refugees. More and more, destination nations, sometimes in conjunction with transit nations, are using deterrence tactics to prevent large mixed movements of persons from reaching their borders, including the use of interdiction and return, detention, family separation, push backs, criminal prosecution of irregular migration, the closing of borders, and conditional aid agreements, among other tactics. These formal and informal arrangements among nations can prevent migrants in vulnerable situations and even refugees from receiving protection and in some cases entail returning vulnerable individuals to harm.

Objective 11 of the Global Compact on Migration should prohibit the use of these tactics and encourage responsibility-sharing among member states that ensures that migrants and refugees are screened by a 
competent and independent authority, and, if necessary, offered protection, by either a transit nation or other nations in a region. In addition, language should be restored in the draft that encourages member states to promote screening of asylum-seekers, including informing migrants of their rights to apply for asylum protection.

Migrants, regardless of their legal status, should be guaranteed certain services, consistent with their human rights and international law. Human persons, regardless of legal status, possess God-given human rights that should not be violated, including the right to life, and thus should be provided services necessary to protect those rights, including health-care, social services, access to justice, education, and pastoral services. Such services should be specified in the Global Compact on Migration, so that member states have a common understanding of this requirement. In providing these services to undocumented persons or to persons in a temporary legal status, firewalls should exist to prevent personal information from being used for enforcement purposes.

Migrants in vulnerable situations should receive protection. Perhaps the most difficult issue to address between the Global Compact on Migration and the Global Compact on Refugees is the issue of migrants in vulnerable situations. This group may include persons fleeing natural disaster or the effect of climate change; migrants in countries in crisis; migrants who may not achieve refugee protection or asylum but nevertheless have legitimate protection claims and could face harm upon their return; victims of human trafficking or forms of domestic violence; and inherently vulnerable migrants, such as unaccompanied children, the elderly, or the disabled.

These groups may not meet the refugee definition laid out in international refugee law, but nevertheless face danger and possible harm in their home countries. Member states should increase the legal tools available to them to address these populations, including humanitarian visas, temporary protected status, and visas targeted toward specific groups, such as victims of human trafficking, victims of domestic violence, and unaccompanied alien children. Protection consistent with international human rights law should be afforded them.

\section{Return of migrants to their countries of origin should uphold the principle of non-refoulement and} when return is proper should include re-integration programs which offer them comprehensive reintegration services. Just as countries of origin have an obligation to their nationals to receive them, destination countries should follow international law in assessing their status, informing them of their rights in the process, and, as the law requires, either allowing them to remain or returning them to their homes. We oppose policies which deny due process to migrants seeking protection, as well as tactics that pressure them to acquiesce to deportation without due process. Non-refoulement should govern the return policies of all nations.

Safeguarding the integrity of the family is crucial when people are subjected to detention and deportation processes. Humane alternatives to detention and defenses to removal based on family unity should be available in lieu of detention and deportation. In cases where family members are detained and/or returned, systems should be established to track their locations and to inform family members.

Moreover, re-integration programs should be created in countries of origin that assist returnees with job training and placement, access to social services, and physical security, so they are able to remain and 
live in safety and dignity. Destination countries should provide assistance to source countries in creating these programs.

The root causes of migration should be comprehensively addressed, so that migration is a choice, not a necessity. Migration and development are intrinsically linked, as remittances are a primary resource for development efforts. The Global Compact on Migration should facilitate remittances by lessening fees and fostering financial inclusion. Remittances should not be a substitute for global support for sustainable economic development in developing nations.

Finally, we urge the creation of a well-financed capacity-building framework that facilitates the actionable commitments of the Global Compact on Migration, as well as a monitoring system that holds member states accountable in implementing them. While the Global Compact on Migration may be legally non-binding, it should be politically binding, so that good faith efforts are made by all member states in reaching its goals and achieving a positive impact on migrants around the world. 


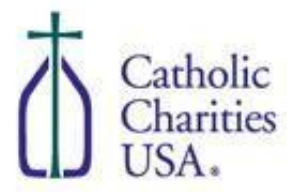

Working to Reduce Poverty in America.

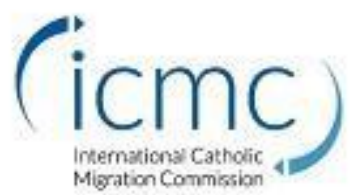

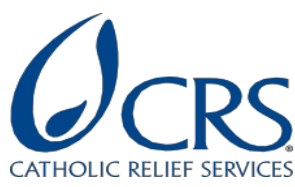
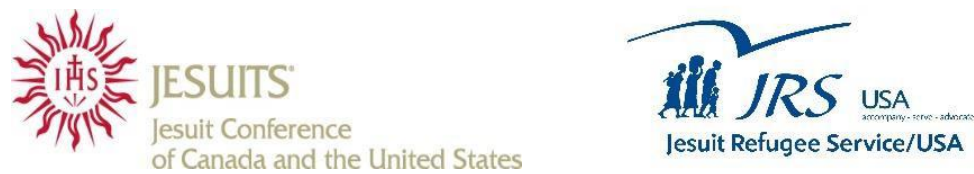

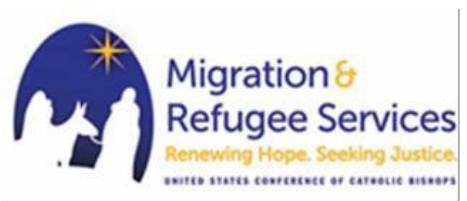

U.S. Catholic Working Group on Global Compacts on Refugees and Migration Statement on Second Formal Consultations towards a Global Compact on Refugees

Introduction. Members of the U.S. Catholic Working Group on Global Compacts on Refugees and Migration $^{1}$ are deeply involved in the care and accompaniment of forcibly displaced people at every stage of their journey, often in partnership with the U.S. government and United Nations agencies. We thank the United Nations High Commissioner for Refugees (UNHCR) for his able leadership in developing the latest draft for the Global Compact on Refugees. Through advocacy and service our work includes fighting against the root causes of forced migration, providing humanitarian support for internally displaced people (IDP) and refugees, seeking durable solutions with all stakeholders, and engaging local communities to provide protection and durable solutions through local integration, voluntary repatriation, and resettlement. While bringing a distinct American Catholic experience to our statement, we also echo and build upon the March 20, 2018 intervention by the delegation of the Holy See to the United Nations and Other International Organizations in Geneva. ${ }^{2}$

\section{Foster the catalytic role of faith-based groups that accompany refugees at every stage of their} journeys. We strongly believe that the Global Compact on Refugees should continue to emphasize an all-of-society approach to improve the situation of refugees, with a crucial role for faith-based organizations. Pope Francis reminds us all to defend the inalienable rights of people forced to migrate "as duties from which no one can be exempted." As noted by the Holy See, faith-based groups play a crucial role in assisting refugees, with "an enduring presence" and a response "driven by solidarity, compassion,

\footnotetext{
1 The working group includes Catholic Charities-USA, Catholic Relief Service (CRS), U.S. Liaison Office of the International Catholic Migration Commission (ICMC), Jesuit Conference of Canada and the United States, Jesuit Refugee Services/USA (JRS-USA), Scalibrini International Migration Network, and the U.S. Conference of Catholic Bishops' Migration and Refugee Services.

2 "

Refugees," March 20, 2018. Our statement also seeks to add unique U.S. and Catholic perspectives to the "NGO Reaction to the First Draft of the Global Compact on Refugees," March 2018, that included ICMC and JRS as signatories. Another important Catholic statement is the following: "CRS, U.S. Liaison Office of ICMC, JRS-USA Statement for the Second Formal Consultation of the Global Compact on Refugees, " March 21, 2018.

3 Pope Francis, Address to the International Forum on "Migration and Peace," February 21, 2017.
} 
and a deep understanding of the local context." For the next draft of the Global Compact on Refugees, the Holy See has urged that the strong links between UNHCR and faith-based groups be highlighted. We would add that the importance of the unifying role of faith-based groups needs to be further described and affirmed, as well.

Catholic organizations actively collaborate to weave together networks of service and advocacy organizations, galvanize local people to join in improving refugees' situations, and work with civil society partners, the U.S. government and UNHCR to create policies and programs that improve refugees' lives. We, along with our local Catholic partners, work in partnership with UNHCR and the U.S. government to provide services and protections to those fleeing, with special reach to those most at risk.

2. Welcome, protect, promote and integrate all refugees. As Catholic organizations of faith, we urge that the next draft underscore the necessity for and ability of the international community to successfully address the current global refugee crisis. We join the Holy See in urging that the next draft of the Global Compact on Refugees continue to promote a theme of hope, illustrating the courage and fortitude of refugees, while commending regions, nations, and communities that call us all to our better selves with generous and admirable responses. We urge the United States and all nations to be exemplary host nations and to model through action what it means to share responsibility with those nations that already host large numbers of migrating people.

Through the Vatican's Migration \& Refugee Section of the Dicastery on Integral Human Development, the Church has gleaned through the best practices of our Catholic organizations and those throughout the world and developed Twenty Action Points. ${ }^{4}$ These points help to guide us in fulfilling the duty we all share regarding refugees, whether as a host nation or as a supporter of host nations, or as a nation of third country resettlement. These action points are organized under four action verbs which Pope Francis himself is promoting: to welcome, to protect, to promote and to integrate migrants and refugees. ${ }^{5}$

\section{Focus on solutions for those most at risk: separated and unaccompanied children, women at} risk, victims of human trafficking, and those unsafe in refugee host countries. Every day, Catholic organizations from this working group support and seek durable solutions in the best interest of children alone in the world whose parents have died or from whom they have been separated through war and flight. We build community-based protections for widows and single women targeted by gender- based violence. We provide alternatives to dangerous migration for youth, and shelters and rehabilitation for trafficking victims. We support those integrating into the host community and help make voluntary repatriation safer. And we help process and resettle the most at-risk refugees for resettlement. Motivated and encouraged by this firsthand experience and the Twenty Points, we call upon nations to enhance safe and legal channels for migrants and refugees, encouraging them and all actors involved to expand the number and range of alternative legal pathways for safe and voluntary migration and resettlement.

As Catholic organizations, we urge the United States and other nations to focus particularly on protecting and securing durable solutions for unaccompanied children and those at risk of becoming unaccompanied. Lack of sufficient food and shelter puts families at risk of illness and death that can leave children on their own to seek refuge. Sometimes family separation is caused by violence against the family. Other times families are broken apart and children left alone when the status of some family members is taken away or when family members are detained and deported. In some instances, parents are separated from their

\footnotetext{
4 "Responding to Refugees and Migrants: Twenty Action Points," Migrants \& Refugee Section, Dicastery on Integral Human Development, Vatican, 2017.

5"Let's welcome, protect, promote and integrate refugees as Pope Francis is asking us," Migration \& Refugee Section, Dicastery of Integral Human Development, Vatican, January 18, 2018, video available at https://www.youtube.com/watch?v=dDlxrIY96ak
} 
children at international borders as a method to deter the family's search for protection. We must seek solutions to all these situations. Solutions must include access to a quality education, life-sustaining employment, family unity, and safety and well-being for all children and families.

We are deeply concerned about the use of detention for refugees and for migrants in general. It is especially problematic when used to deter migration of asylum seekers, children, and families who are forcibly displaced. The Global Compact on Refugees should urge countries to halt detention of children and asylum seekers, and offer community-based alternatives to detention.

In addition, refugees and other vulnerable migrants are increasingly under the "double risk" of being not only persecuted in their home countries but also subsequently trafficked when fleeing internationally. From our experience working with the U.S. government, members of the U.S. Catholic Working Group on Global Compacts on Refugees and Migration know that anti-trafficking collaborations work. Collaboration between government and civil society must be further prioritized to stop human trafficking, rehabilitate victims, and provide durable solutions through integration or resettlement, so that those seeking a new life do not become victims of modern slavery.

Finally, we speak from our deep experience as Catholic organizations partnering with the U.S. government to screen refugees overseas for resettlement. The experience also includes collaboration with the U.S. government and local communities to welcome refugees to the United States for over 35 years, as the largest domestic resettlement network in the world. Many at risk refugees are neither able to safely return home, nor are they able to safely remain in a host country. The only safe course for them is resettlement to a third country. It is vital that the Global Compact on Refugees clearly identifies the important, distinct, and urgent protection role of resettlement among the durable solutions. Resettlement is one of the strongest tools in the protection toolbox. The Global Compact on Refugees should also identify resettlement as a strategic and diplomatic action the international community can take to protect refugees, support allies, and stabilize sensitive regions of the world.

4. Address root causes of forced migration. Working with the U.S. government, UN agencies, and the local Catholic (arch)dioceses and their civil society partners around the world, our Catholic agencies provide humanitarian assistance and help to seek durable solutions for the displaced. While necessary and life-saving, this humanitarian work will never be a permanent solution to the refugee crises around the world. As Catholics, we believe in the right to migrate when necessary, but we also believe in the right to remain, the right not to have to migrate, and the right to thrive in your home country. ${ }^{6}$ This proposition requires peace and stability at its core, and we therefore must elevate the need to seek political solutions and development outcomes in origin countries. We join the Holy See to urge that the Global Compact on Refugees includes a strong commitment to address the root causes of forced migration, including situations of conflict and violence, climate change, and persecution.

Conclusion. We respectfully submit these recommendations to further strengthen the Global Compact on Refugees. We urge all nations to commit to multilateral cooperation in addressing and protecting large movements of migrants and refugees in a humane manner, while at the same time working to end conflict, persecution, and other drivers of forced migration where they exist.

\footnotetext{
${ }^{6}$ The Catholic Bishops of Mexico and the United States, Strangers No Longer: Together on a Journey of Hope (Washington, DC: The United States Conference of Catholic Bishops, 2003), nos. 34-36.
} 


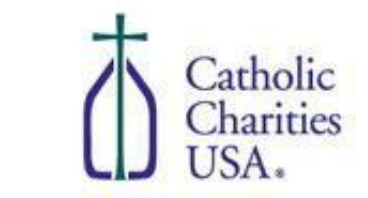

Working to Reduce Poverty in America.

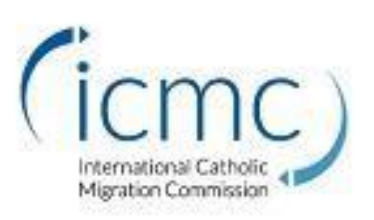

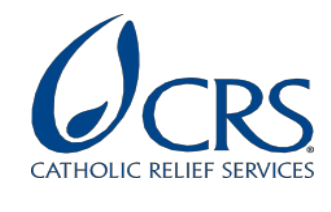

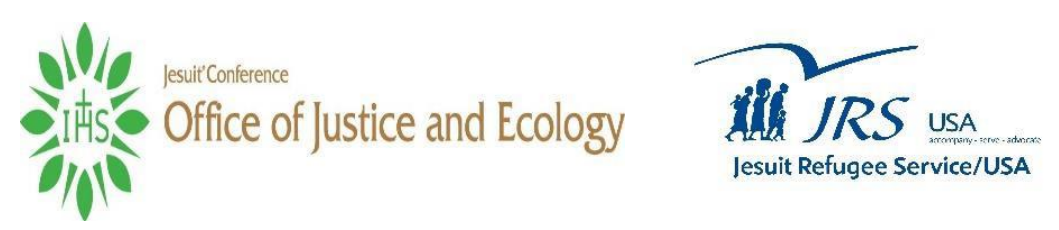

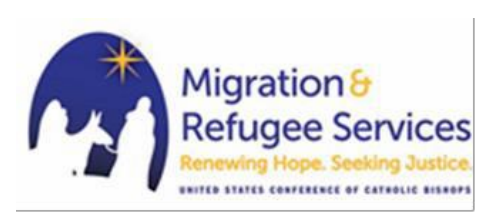

\section{Statement on the Global Compact on Migration Leading into the Sixth and Final Round By the U.S. Catholic Working Group on Global Compacts on Refugees and Migration June 25, 2018}

We, the members of the U.S. Catholic Working Group on the Global Compacts on Refugees and Migration ${ }^{1}$, write to provide our position on several issues debated during the fifth round of negotiations on the Global Compact on Safe, Orderly, and Regular Migration. We consider the positive resolution of these issues vital to the success and integrity of the Compact and to its contribution in improving the situation of the world's migrants.

First, we urge you to not make distinction between irregular and regular migrants in each objective of the document. All human beings, whether migrating in a regular or irregular manner, possess fundamental human rights that entitle them to certain benefits, including life-sustaining services such as health-care, shelter, food, and education. Also, individuals often go between the two categories, for example, when they are granted a regular migration status through domestic laws, consistent with each nation's security, such as those promoting family unity, child protection, or refugee protection.

Second, we ask you to maintain and reinforce the principle of non-refoulment in the Compact to assure that this principle provides its fullest, life-saving protection on the ground. Removing this term would represent a step back in international protection of migrants in vulnerable situations, many of whom may face harm or death if forcibly returned to their countries.

\footnotetext{
${ }^{1}$ The working group includes Catholic Charities-USA, Catholic Relief Services (CRS), U.S. Liaison Office of the International Catholic Migration Commission (ICMC), Jesuit Conference of Canada and the United States, Jesuit Refugee Services/USA (JRS-USA), Scalabrini International Migration Network (SIMN), and the U.S. Conference of Catholic Bishops' Migration and Refugee Services (USCCB/MRS).
} 
Third, we urge you to resist calls to remove language that discourages the criminalization of migrants crossing international borders. In our view and many others', migrants in search of work or safety are not criminals, as they do not intend to cause harm, but merely to reach safety or seek a better life.

Moreover, the criminalization of migrants adds to the spread of xenophobic attitudes, which is contrary to the goals of the Compact.

Fourth, we support the maintenance of language protecting the privacy of migrant's personal information as they seek vital humanitarian services, so it cannot be used for enforcement purposes. The removal of this protective language would keep migrants from coming forward and accessing needed services or from participating in data collection efforts.

Fifth, we would support the inclusion of a paragraph that states that nothing in the Compact relieves Member States from honoring the human rights of migrants, as contained in UN-approved human rights instruments.

Finally, we support a robust implementation, follow-up, and review mechanism which includes objective criteria for measuring progress and national implementation plans. Civil society, including faith-based organizations, should be partners in implementation efforts and be allowed to participate in the monitoring and evaluation, review, and follow-up processes of the Compact.

While these recommendations do not represent the totality of our concerns, we believe they are essential to fashion a Global Compact which upholds the human rights of all migrants.

We thank the co-facilitators for their consideration and for their leadership in this important effort. 


\title{
Joint Civil Society Statement at the Conclusion of Negotiations on the Global Compact for Safe, Orderly, and Regular Migration
}

\author{
New York, July 13, 2018
}

Co-facilitators, we are grateful for you and your staff's guidance and work over the past two years in producing the Global Compact for Safe, Orderly, and Regular Migration. We appreciate your efforts to promote the voice and space for participation of civil society and migrant networks in a formal and diligent process.

We also acknowledge all participating Member States who have worked to create this agreement, particularly in a xenophobic political environment often hostile to understanding the realities of migrants and refugees. We express our strong hope that when properly implemented and with concerted efforts to address remaining gaps, the Compact provides Member States with a sound framework for governing migration in a manner which respects human rights and the rule of law.

We would like to highlight some of the significant achievements of the Compact:

○ Working to end child detention;

- Expanding regular avenues for migration and measures for regularization as a way to increase safe, orderly, and regular migration and reduce vulnerabilities;

- Emphasizing community-based alternatives to detention, and not promoting detention as a deterrent to irregular migration;

- Protecting migrants in situations of vulnerability, including those fleeing slow and sudden onset natural disasters, the adverse effects of climate change, and environmental degradation;

- Safeguarding the rights of children by adhering to the principle of the best interest of the child at all times and ensuring their protection and access to sustainable solutions;

$\circ$ Ensuring decent work and labour rights

- Promoting concrete gender responsive policies and the empowerment of women as agents rather than from the lens of victims;

- Guaranteeing due process, individual assessment and effective remedy in return procedures, by upholding the prohibition on collective expulsion and the principle of non-refoulement;

- Strengthening the collection of data on migration in order to better inform humane policy responses, in a manner which respects the right to privacy;

- Investing in sustainable development at national and local levels in order to honour the right of migrants to live and support their families in their countries of origin;

- Cooperating to provide international protection to migrants in situations of vulnerability at borders. 
Unfortunately, the Compact falls short in several important areas and in some aspects steps away from current international standards and regional practice. For example: we regret that no stronger language could be achieved on the non-criminalisation of migrants and of those who provide support to them, on firewalls, access to basic services and on full labour rights and freedom of association for irregular migrant workers.

Nonetheless, we will interpret such formulations in a way that fully adheres to international law. Indeed, we aim to strengthen them in their implementation and seek to hold governments and stakeholders accountable in the follow-up and review process. This is the beginning, not the end.

In this regard, we look forward to participating in the concrete next steps. We will continue to work on behalf of migrants and their communities around the world, with the goal of ensuring their human rights and upholding human dignity.

Signatories:

- ACT Alliance

- Africa-Europe Diaspora Development Platform (ADEPT)

- African Foundation for Development (AFFORD)

- Alianza Americas

- Asia Pacific Refugee Rights Network (APRRN)

- Caritas Internationalis

- Centro de Estudios Legales y Sociales (CELS)

- Comisión Argentina para los Refugiados y Migrantes (CAREF)

- Company of the Daughters of Charity of St.Vincent de Paul

- Congregation of Our Lady of Charity of the Good Shepherd

- Dianova International

- Global Coalition on Migration

- Greek Orthodox Archdiocesan Council

- Institute of Studies and Outreach about Migration

- Institute of the Blessed Virgin Mary-Loreto Generalate

- Instituto para las Mujeres en la Migracion, Mexico

- International Catholic Migration Commission
- Loretto Community - Sisters of Loretto

- Maryknoll Office for Global Concerns

- Migrant Forum in Asia

- Mixed Migration Centre

- National Network for Immigrant and Refugee Rights

- NGO Committee on Migration

- OXFAM International

- Pacific Islands Association of Nongovernmental Organizations (PIANGO)

- Pan African Network in the Defense of Migrants' Rights (PANiDMR)

- Partnership for Global Justice

- PICUM - Platform for International Cooperation on Undocumented Migrants

- Religious of the Sacred Heart of Mary

- Scalabrini International Migration Network

- Servicio Jesuita de Chile

- Sisters of Charity Foundation

- Society of Catholic Medical Missionaries

- Terre des Hommes International Federation 
- International Council of Psychologists

- International Council of Voluntary Agencies

- International Presentation Association

- Jesuit Refugee Service Australia
- The World Organization for Early Childhood Education (OMEP)

- Trade d'Union Mediteranean Subsaharan Migration Network (RSMMS)

- VIVAT International 
CENTERS 